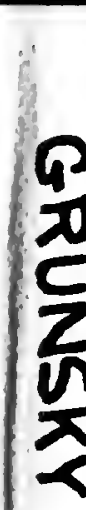




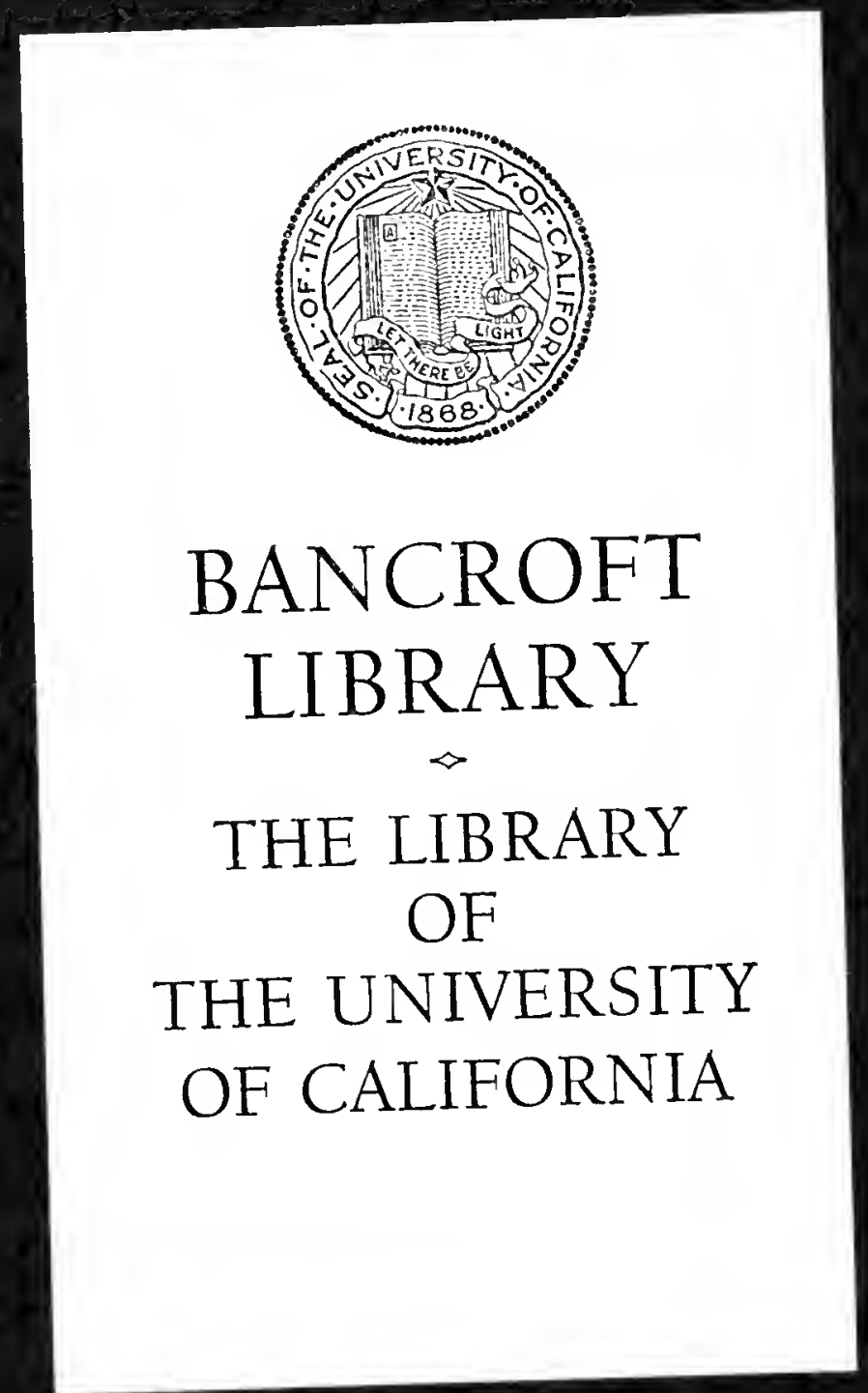



Digitized by the Internet Archive in 2007 with funding from Microsoft Corporation 


\title{
AMERICAN SOCIETY
}

OF

\section{CIVIL ENGINEERS}

\author{
THE APPRAISAL OF \\ PUBLIC SERVICE PROPERTIES \\ AS A BASIS FOR THE REGULATION OF RATES.
}

BY .

C. E. Grunsky, M. Am. Soc. C. E.

WITH DISCUSSION BY

MrssRs. WILLIAM BROKAW BAMFORD, JAMES V. OXTOBY, CHARLES H. HIGGINS, HENRY FLOY,

J. MARTIN SCHREIBER, WILLIAM J. BOUCHER, R. D. COOMBS, A. H. VAN ClEVE, W. KIERSTED, AND C. E: GRUNSKY. 

Compliments of

AMERICAN ENGINEERING CORPORATION

Mechanics Institute Building

57 Post Street, San Francisco 


\title{
AMERICAN SOCIETY OF CIVIL ENGINEERS
}

I N S T T U T E D 1852

\section{TRANSACTIONS}

\author{
Paper No. 1232
}

THE APPRAISAL OF

PUBLIC SERVICE PROPERTIES

AS A BASIS FOR THE REGULATION OF RATES."

By C. E. Grunsky, M. Am. Soc. C. E.

With Discussion by Messrs. William Brokaw Bamford, James 'V. Oxtoby, Charles H. Higgins, Henry Floy, J. Martin

Schreiber, William J. Boucher, R. D. Coombs, A. H.

Van Cleve, W. Kiersted, and C. E. Grunsixy.

\section{IntronuCtion.}

It is the purpose of this paper to make clear the fact that appraisals of public service properties for rate-fixing purposes can be made, with advantage to all parties concerned, without deducting anything from the properly invested capital for depreciation. Incidentally, it will be pointed out that depreciation must, and how it should, be taken into account in estimating net earnings; that appreciation should be regarded as a reinvestment of earnings; and that there is and can be no definite basis for such elements of value as "going concern" and the like, unless operations are conducted under a restrictive franchise, that is, unless the franchise frees the public service corporation from outside control of its rates. No apology need be made for the elementary treatment of parts of the subject.

The appraisal of public service property for various purposes, such as taxation, regulation of rates, purchase, and limitation of indebtedness is receiving attention by many engineers and financial experts at the present time. 
Ideas in the matter of valuation, both in relation to what should be included in the valuation and to the valuation itself, are so diverse that a few words about the fundamental principles which should control when the appraisal of a public service property is to serve as a basis for fixing the rates to be charged for the service, are now offered in the hope that what is presented may aid in unifying methods of computing the desired earnings and in overcoming some of the difficulties into which the Courts are leading the experts.

The definite programme herein indicated for dealing with depreciation and amortization is the outcome of the writer's professional employment in California on appraisals, representing, at various times, the rate-payers, and, at other times, the owners of public service properties.

No attempt will be made to apply the conclusions reached to valuation for other purposes than the regulation of rates, nor to valuations in those cases in which special privileges have been granted, in which, therefore, the franchises are in the nature of an agreement or contract. Neither is it proposed to deal with any cases out of the ordinary, such as those in which the owner of a property was aided by bond issues, land grants, and the like. The main purpose will be kept in view of presenting a clear analysis of the fundamental problem, so that an understanding may be had of the principles which should prevail whenever an appraisal is made for rate-regulation purposes.

\section{The Law in California.}

The following is from the Constitution of the State of California (in effect January 1st, 1880) :

"The use of all water now appropriated, or that may hereafter be appropriated, for sale, rental or distribution, is hereby declared to be a public use and subject to the regulation and control of the State, in the manner to be prescribed by law; provided, that the rates or compensation to be collected by any person, company or corporation in this State for the use of water supplied to any city and county, or city or town, or the inhabitants thereof, shall be fixed annually by the Board of Supervisors, or city and county, or city or Town Council, or other governing body of such city and county, or city or town, by ordinance or otherwise, in the manner that other ordinances or legislative acts or resolutions are passed by such body, and shall continue in force for one year and no longer. Such ordinances or resolutions shall be passed in the month of February of each year, and take effect on the first day of July thereafter. 
"The right to collect rates or compensation for the use of water supplied to any county, city and county, or town, or the inhabitants thereof, is a franchise, and cannot be exercised except by authority of and in the manner prescribed by law.

"In any city where there are no public works owned and controlled by the municipality, for supplying the same with water or artificial light, any individual, or any company duly incorporated for such purpose under and by authority of the laws of this State, shall, under the direction of the Superintendent of Streets, or other officer in control thereof, and under such general regulations as the municipality may prescribe for damages and indemnity for damages, have the privilege of using the public streets and thoroughfares thereof, and of laying down pipes and conduits therein, and connection therewith, so far as may be necessary for introducing into and supplying such city and its inhabitants either with gas light, or other illuminating light, or with fresh water for domestic and all other purposes, upon the condition that the municipal government shall have the right to regulate the charge thereof."

The charter of the City and County of San Francisco (in effect January 8th, 1900) mentions, among the powers of the Supervisors:

"To fix and determine by ordinance in the month of February of each year, to take effect on the first day of July thereafter, the rates of compensation to be collected by any person, company or corporation in the City and County, for the use of water, heat, light or power, supplied to the City and County or to the inhabitants thereof, and to prescribe the quality of the service."

\section{General Remarks.}

The value of a revenue-producing property is determined ordinarily by its earning capacity; but this earning capacity, when it is to be used as a basis for valuation, must itself be determined with proper consideration of all attendant circumstances. It is not enough to compare receipts with current expenditures when estimating net returns. Account must be taken of the useful life of the property, because, in order that the property may be kept at a standard serviceability, parts, or all of it, must be replaced from time to time, unless indeed it happens to be of a character similar to real estate, having for all practical purposes a perpetual life. Such circumstances as appreciation in value which may arise from an advance of real estate values, or from other causes, must also be taken into account.

Knowing the earning capacity and the ordinary interest return 
expected from an investment, it becomes an easy problem in mathematics to capitalize earnings, it being understood that no necessary expenditure, present or. prospective, has been overlooked, and that, in estimating, useful life and the requirements of an amortization or a replacement fund, every factor, such as ordinary deterioration, inadequacy, and obsolescence due to advance in the arts, shall have been given due weight and consideration.

In the case of properties, however, the earnings of which are subject to regulation, an element of uncertainty concerning the amount of earnings may be introduced, rendering it impossible to use earnings as a basis for computing value.

Cases do occur in which franchises are exclusive, and in which rates for services rendered remain operative for long periods of time, in which, therefore, even under a system of rate regulation, it is possible to estimate earnings for long future pericds and in which the earnings are determinable with sufficient precision to be used, in some measure at least, in determining value; but this is not so in California. There the system of annual rate fixing prevails, and the maximum rates allowed are presumed to be fixed so that under them there may be a fair return to the corporations on the value of the properties actually in use in rendering the service. Perhaps the use of the term, "value," in this connection is unfortunate, because it is not clear why "value," as ordinarily defined (which is not always synonymous with capital reasonably and properly invested), should be made the criterion of allowable earnings. It is reasonable to assume that the term, "value," in connection with the fixing of rates, has been used without prejudice to the rights of the owner of a public service property, and, therefore, some note will be taken, in what is here presented, of value as it may appear from different standpoints.

It is not necessary to state that, in a critical analysis of earnings, which go in part to an amortization fund and are in part distributable as a return on the investment, the rate of interest taken into account should be the same throughout. When it shall have been determined in any particular case what the earnings must be to yield the same rate of return as could be obtained from ordinary safe investments, then any desired addition as compensation for having undertaken the operation of the public service property, or for unusual risk, may be added. 
Useful Life, Value, Depreciation, and the Amortization Fund.

The general presentation of the problem will be simplified by assuming that the actual useful life or service of a plant, or part of a plant, conforms in every case exactly to its expectancy. That this is not in reality the case, and how it affects the conclusions which otherwise would be reached, will be referred to later.

In the presentation of the subject, this assumption has been strictly adhered to, and the rate of interest uniformly applied is $4 \%$ per annum.

Take the case of a plant, every part of which has a life of 20 years, all constructed at one time and owned by a prudent owner who sets apart, as an amortization fund, each year $\$ 0.03358$ for every dollar invested therein at an interest of $4 \%$ per annum. If the plant is one which will actually net $4 \%$, then the apparent excess of the earnings, including amortization, over expenses, should be $4+3.36=7.36 \%$, and the owner, in estimating the price at which he can sell without loss at the end of any period, as, for example, at the end of 10 years, would figure as follows (for each $\$ 100$ of original investment):

Investment ...................... $\$ 100.00$

In the amortization fund: being the amount of a 10-year annuity of $3.358 \%$ at $4 \%$ interest. . $\quad 40.30$

Remaining value.................. \$59.70

A prospective purchaser would figure that the plant should be worth at least as much as the annuity of $3.358 \%$ would amount to in the remaining years of the plant's life.

The amount of a 10-year annuity of $\$ 3.358$ is $\$ 40.30$, and to this amount he would add a sum determined from the excess earnings of the plant over a net earning of $4 \%$ during its remaining life on the part of the value which he has estimated, as explained, on the amortization or retirement fund basis.

The earnings being based on $4 \%$ of the originally invested capital, the increment of value covered by the amortization fund being $\$ 40.30$, on which $4 \%$ is $\$ 1.609$, for 10 years there will be earned an additional $\$ 2.391$ per annum, of which the present value is $\$ 19.40$. The purchaser, therefore, will conclude that he can invest with assurance of a $4 \%$ net return, $\$ 40.30+\$ 19.40=\$ 59.70$. 
Of course, the same conclusion could have been reached by determining the present value of the earnings treated as an annuity of $\$ 7.358$ for the remaining 10 years, which, at $4 \%$ per annum, is $\$ 59.70$.

At the end of 10 years, the original owner, keeping for his own use the money in the replacement fund, will be satisfied to sell at $\$ 59.70$. The purchaser, content in this case with the assumed rate of interest of $4 \%$, will be willing to pay this $\$ 59.70$, because, at the end of the plant's useful life, he will have recovered his investment with $4 \%$ interest compounded annually. He will then be under the necessity of replacing the plant, making a new investment of $\$ 100$, as the original owner would have been if he had remained in possession.

During the entire 20 years of usefulness the plant has been rendering adequate service. The sufficiency of the service is independent of, and bears no relation to, the useful life of the plant, nor to the fact that it was gradually deteriorating. During all periods of the plant's life, the depreciation of its physical elements was offset by the accumulation in the amortization fund.

Of course, it cannot be known just how, nor at what rate, the actual deterioration of a plant takes place. This may be rapid at some period of its life, and slow at another, but, as it is supposed, at all times during its life, to be adequately performing the service expected of it, this rate of decay is entirely immaterial.

In other words, the amortization may be determined without regard to the physical condition of a plant at any period of its life, provided, of course, that the plant fulfills the requirements of adequate service at all times of its life. For this reason it has become convenient to consider the actual, or the theoretical, accumulation in an amortization fund as the measure of plant depreciation with a consequent interchange of terms, which has led to a quite general use of the term, "depreciation," when designating the retirement of invested capital.

There is a clear distinction between amortization and replacement. The amortization deals with the repayment of the original investment. This may be in installments in uniform or unequal annual amounts, or in a lump sum at the end of useful life. The replacement may mean the substitution of a new identical plant, but at a cost dependent on new conditions, new prices of labor and material, or it may mean the substitution of new devices rendering equivalent service. In 
either event the replacement may be at a greater or less cost than the original cost, with, therefore, a corresponding increase or decrease of capital invested. The expenditure for replacement is amortization only to the extent that it retires capital already invested.

Perhaps, in referring to the worn-out part, the term "retirement" would be more applicable. In the sense in which "replacement" is used throughout this paper, except when otherwise explained, it is that part of the new investment in permanent construction which is equal to the capital theretofore invested in the parts which are discarded and replaced. Expenditures for new parts of a plant, which take the place of old parts which are retired for any cause, should be charged to replacement only to the extent of capital thus retired. Any excess of the expenditure for replacement over the cost of the discarded part of a plant should be treated as an addition to, and any less cost as a deduction from, the invested capital. The term, "replacement," used in the sense of retirement of invested capital, deals with the cost of the replaced part and not with that of the new equivalent installation. Theoretically, the amount which should go into an amortization fund should be estimated on the basis of invested capital or cost, and actual replacement should be made up out of this fund as far as the same may prove adequate.

Returning again to the case of the supposed valuation by a seller and by a.purchaser of a plant with a 20-year useful life, at the end of a 10-year period; there is no need of assuming that an amortization fund has actually been created. In the case of both the original owner and a purchaser, the amortization annuity, instead of being actually placed in funds, may be otherwise invested.

When the owner of a plant which is yielding $4 \%$ per annum and nothing for amortization, sets apart, out of the $4 \%$, an annual amount, also bearing interest at $4 \%$, to meet its replacement at the end of the plant's useful life, he has invested not only the original cost of the plant, no part of which comes back to him in the annual $4 \%$ return, but also a gradually increasing sum which in the life of the plant will become adequate to replace it. At the end of the plant's usefulness, after replacing it with a new one, the total investment will be doubled without any increase of earning capacity, and the owner will have in effect lost his original investment.

It follows from this that a return of $4 \%$ per annum, without any- 
thing for amortization, on an investment in a perishable plant, when money is worth $4 \%$, is inadequate. The excess of earnings over expenditures must be at least equal to the current interest rate on safe money investments plus an increment depending on the useful life of the plant. This increment must be such that, within the life of the plant, it will return to the owner his original investment.

Had the owner borrowed money for the construction of the plant, and were he paying interest on the borrowed money at $4 \%$, this fact would be self-evident. The $4 \%$ earnings would then be required to meet interest payments, and, at the time when his plant has reached the end of its life and must be replaced with a new one, he would find himself, not only in debt for the original plant, but would have to duplicate the indebtedness for the replacement.

The amortization increment is ordinarily expected to appear in the earnings as that sum which, at compound interest during the life of the plant, will be adequate to retire the original investment.

To illustrate these points further, let it be supposed that ownership is represented by capital stock of a corporation. If the plant owned by the corporation earns just enough to net $4 \%$ without any allowance for amortization, the stock which at the outset was worth $100 \%$ will gradually decrease in value until, at the end of the plant's usefulness, it will be worth nothing.

The situation is quite different when the earnings net $4 \%$ plus an annual amortization increment. In this case, the stockholder receives $4 \%$ each year, and the amortization fund grows as the plant depreciates in value. The stock remains at par from the beginning to the end of the plant's usefulness, and the money in the fund at the end of the period is available either for distribution to the stockholders, being a return of the money advanced by them, or for reinvestment in a new plant to replace the original one.

Should a sale be made at any time while the plant is in service, the valuation of the plant would be made, as already explained, with due allowance for its depreciation, and, this value being recognized by a purchaser and the price paid, there would again be $100 \%$ available for distribution to the stockholders, the deficiency of the selling price being made up by the accumulation in the amortization fund.

In the case of inadequate earnings, the valuation of the plant by a purchaser would be at all times less than the value determined by 
deducting depreciation; in the case of adequate earnings the valuation would be, as already explained, capital invested (or the replacement cost) less depreciation. Yet, in either case, amortization being computed in the ordinary way for the full expectancy of the plant, the only fair valuation for rate-fixing purposes, in a spirit of fairness to both owner and rate-payer, would be a valuation at par without any deduction for depreciation.

Theoretically, then, a part of the earnings each year should 'be placed in an amortization fund as a repayment of capital invested, and this may be used for the replacement of the plant when it has reached the end of its life.

The accumulation of an amortization fund to be thus used, however, while theoretically sound policy, is a measure not always adopted in actual practice, particularly when the properties owned are of a complex character-when they are made up of numerous parts of various periods of probable usefulness. Municipalities, State, and National Governments, do not set apart funds for the replacement of worn-out or antiquated buildings, parts of water-works, street pavements, sewers, and the like, until occasion arises. They do not maintain funds at interest out of which to reconstruct their public works. The sinking fund required to retire bonds which may have been issued to construct these works originally must not be confounded with a replacement fund. The one may be necessary to pay for the works in the first instance, the other to maintain them for all time. The annual contribution to the sinking fund is a partial payment for the original work. The contribution to a replacement fund, in the case of a plant free from debt which is to serve without time limit, is for the purpose of perpetuating the work, because in that case the replacement fund, as far as it will go, or as far as it is required, will be used for making. replacements.

Though it may be difficult to make satisfactory forecasts with reference to necessary reinvestments to replace discarded parts of a plant, the requirements for amortization, being based on cost, are usually readily determinable with some degree of precision.

Thus far, the plant considered is assumed to have been constructed and put into use all at once, and is of such a character that all its parts have the same life. The same principles will apply when a plant 
is made up of many elements or parts having various periods of usefulness.

It is again possible to determine for each part the amortization fund or the replacement fund annuity, and from the annuities thus determined to estimate what the minimum earnings should be to prevent loss.

The following problem presents itself: In the case of a plant of gradual development, but of full growth and mature age, the useful life of all the parts of which is $n$ years, it is desired to know what amount is in the amortization fund at any time, that fund being assumed to receive such an increment at the end of each year that, during the life of the several parts of the plant, this annuity, with interest, will amount to the original cost of these parts.

Being composed of a large number of elements-each year having added new ones-the addition to it per year will be taken at one- $n$th of the total plant as it stands at the end of the $n$th year.

For each dollar invested in the first year, there will be $\$ 1$ invested in each succeeding year, and for each dollar thus invested there will be $n$ dollars of total investment.

Let $i$ represent the rate of interest per year, and $a$ represent the annual contribution to the amortization fund for each dollar invested.

Assume this to be available at the end of each year.

Then $n a$ will be, after $n$ years, the annual contribution to the amortization fund for each dollar invested.

Let $m$ represent any number of years greater than $n$.

During the first $n$ years, after beginning the construction of the plant, there will be no replacements, and the amortization fund continues to grow. At the end of the $n$th year the replacement requirement, assuming permanency in character and cost, will be $\$ 1$ for each dollar of annual investment, and this replacement requirement will continue at this rate thereafter.

At the end of the $n$th year the amortization fund will contain:

For each dollar invested the first year:

$\mathrm{Or}$

$$
a\left(\frac{100+i}{100}\right)^{n-1}+a\left(\frac{100+i}{100}\right)^{n-2}+\ldots+a \text { dollars }
$$$$
\frac{100 a}{i}\left[\left(\frac{100+i}{100}\right)^{n}-1\right] \text { dollars }
$$ 
For each dollar invested the second year:

Or,

$$
\begin{aligned}
& a\left(\frac{100+i}{100}\right)^{n 2}+a\left(\frac{100+i}{100}\right)^{n-3}+\ldots+a \text { dollars } \\
& \frac{100 a}{i}\left[\left(\frac{100+i}{100}\right)^{n-1}-1\right] \text { dollars }
\end{aligned}
$$

For each dollar invested the $n$th year: $a$ dollars

Less the $\$ 1$ replacement requirement at the end of the $n$th year.

Therefore, the total amount in the sinking fund at the end of the $n$th year, after deducting the $\$ 1$ replacement requirement of that year:

$$
\begin{gathered}
S_{n}=\frac{100 a}{i}\left[\left(\frac{100+i}{100}\right)^{n}-1+\left(\frac{100+i}{100}\right)^{n-1}-1+\ldots\right. \\
\left.\quad+\frac{100+i}{100}-1\right]-1 \\
S_{n}=\frac{100 a}{i}\left\{\frac{100}{i}\left[\left(\frac{100+i}{100}\right)^{n+1}-\frac{100+i}{100}\right]-n\right\}-1 \\
S_{n}=\frac{10000 a}{\cdots i^{2}}\left[\left(\frac{100+i}{100}\right)^{n+1}-\frac{100+i}{100}-\frac{n i}{100}\right]-1
\end{gathered}
$$

There will be in the sinking fund for each dollar invested:" At the end of the $(n+1)$ st year :

$$
S_{n+1}=S_{n}\left(\frac{100+i}{100}\right)+n a-1 .
$$

At the end of $(n+2)$ d year :

$$
S_{n+2}=S_{n}\left(\frac{100+i}{100}\right)^{2}+(n a-1)\left(\frac{100+i}{100}\right)+n a-1 .
$$

At the end of the $(n+3)$ d year :

$$
\begin{aligned}
S_{n+3}= & S_{n}\left(\frac{100+i}{100}\right)^{3}+(n a-1)\left(\frac{100+i}{100}\right)^{2} \\
& +(n a-1)\left(\frac{100+i}{100}\right)+n a-1 .
\end{aligned}
$$

And so on, and at the end of the $m$ th year :

$$
\begin{aligned}
& S_{m}=S_{n}\left(\frac{100+i}{100}\right)^{m-n}+(n a-1)\left(\frac{100+i}{100}\right)^{m-n-1} \\
& +(n a-1)\left(\frac{100+i}{100}\right)^{m-n-2}+\ldots \ldots+n a-1 .
\end{aligned}
$$

Substituting the value of $S_{n}$ and summarizing the series: 


$$
\begin{aligned}
S_{m}=\frac{10000 a}{i^{2}} & {\left[\left(\frac{100+i}{100}\right)^{m+1}-\left(\frac{100+i}{100}\right)^{m-n+1}\right.} \\
& \left.-\frac{n i}{100}\left(\frac{100+i}{100}\right)^{m-n}\right]-\left(\frac{100+i}{100}\right)^{m-n} \\
& +\frac{100}{i}\left[\frac{(100+i)^{m-n}-100^{m-n}}{100^{m-n}}\right](n(c-1) .
\end{aligned}
$$

In this form the formula is convenient for use, being applicable to any value of $n$ and any rate of interest.

For the interest rate of $4 \%$ per annum, that is, for $i=4$, the formula becomes:

$$
\left.\begin{array}{c}
S_{m}=\frac{a}{0.0016}\left[1.04^{m+1}-1.04^{m-n+1}-0.04 n(1.04)^{m-n}\right]-1.04^{m-n} \\
+\frac{1.04^{m-n}-1}{0.04}(n a-1) .
\end{array}\right\}
$$

For $m=n$, this formula becomes :

$$
S_{n}=\frac{a}{0.0016}\left(1.04^{n+\mathrm{i}}-1.04-0.04 n\right)-1 .
$$

Applying the foregoing formulas to various periods of life, but adhering to an interest rate of $4 \%$, the following amounts in amortization funds at various times are to be noted:

For a plant of full growth, all parts of which have a useful life of 5 years: $n=5, a=0.1846$, and the total invested capital is equal

\begin{tabular}{|c|c|c|}
\hline Years. & $\begin{array}{c}\text { Amount in amortization } \\
\text { fund for each } \$ 1 \\
\text { of annual investment. }\end{array}$ & $\begin{array}{l}\text { Amount in amortization } \\
\text { fund in percentage } \\
\text { of total investment. }\end{array}$ \\
\hline 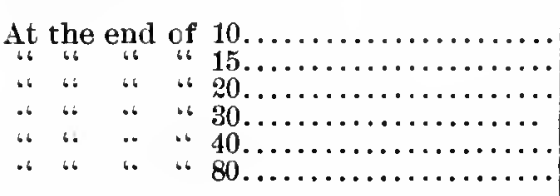 & $\begin{array}{r}\$ 4.17 \\
4.18 \\
4.18 \\
4.18 \\
\cdots\end{array}$ & $\begin{array}{r}41.7 \\
41.8 \\
41.8 \\
\quad \quad \because 1 . \dot{8} \\
\quad \cdots .\end{array}$ \\
\hline
\end{tabular}
to five times the annual investment:

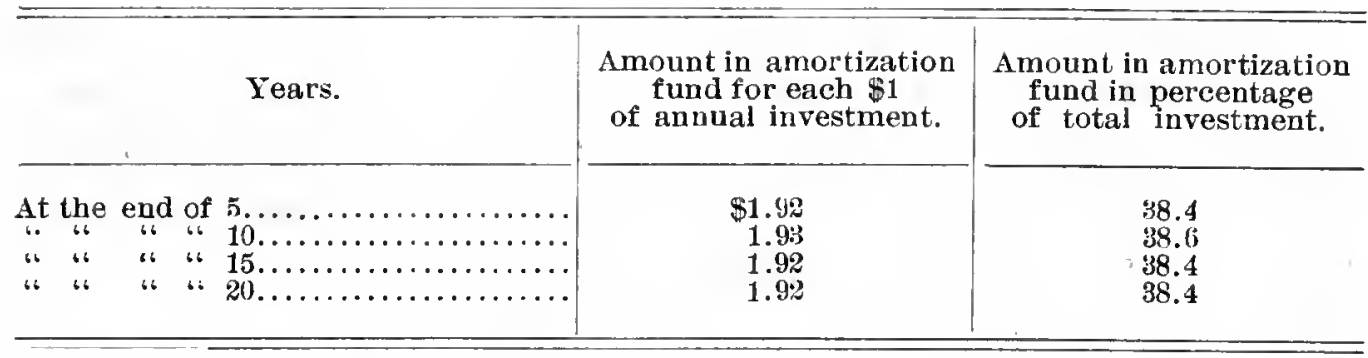

For a plant of full growth, all parts of which have a useful life of 10 years: $n=10, a=0.08329$, and the total invested capital is equal to ten times the annual investment: 
For a plant, all parts of which have a useful life of 20 years: $n=20, a=0.3358$, and the total invested capital is equal to twenty times the annual investment:

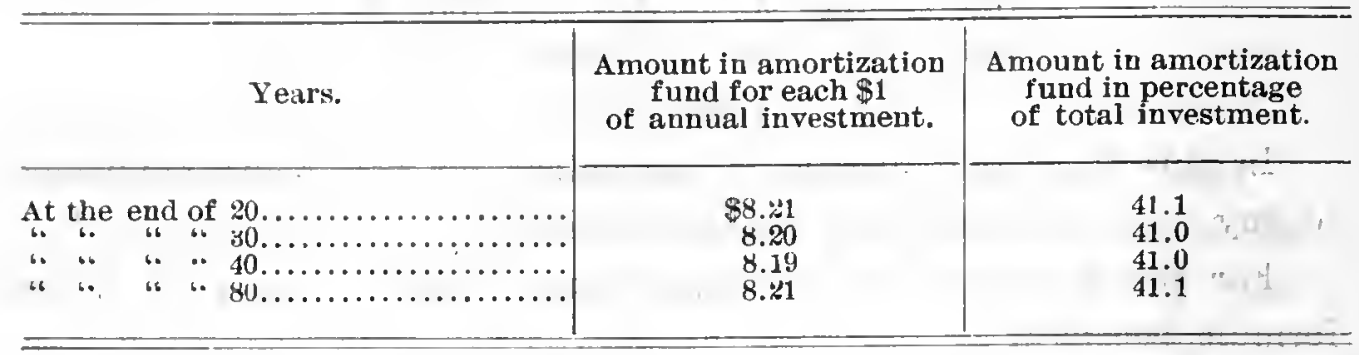

For a plant of full growth, all parts of which have a useful life of 40 years: $n=40, a=0.01052$, and the total invested capital is equal to forty times the annual investment:

\begin{tabular}{|c|c|c|}
\hline Years. & $\begin{array}{l}\text { Amount in amortization } \\
\text { fund for each } \$ 1 \\
\text { of annual investment. }\end{array}$ & $\begin{array}{l}\text { Amount in amortization } \\
\text { fund in percentage } \\
\text { of total investment. }\end{array}$ \\
\hline 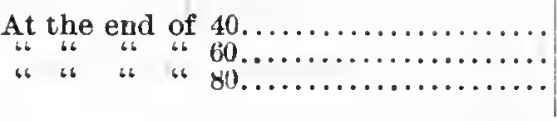 & $\begin{array}{r}\$ 14.4 \pi \\
14.40 \\
14.43\end{array}$ & $\begin{array}{l}36.1 \\
36.0 \\
36.1\end{array}$ \\
\hline
\end{tabular}

In the foregoing mathematical analysis, a plant has been assumed which has already reached an age exceeding the useful life of its parts, and has reached its full growth.

The same formulas will apply in the case of any plant of mature age and gradual growth, even when the growth is still being extended, because in this special case the plant may be regarded as made up of two groups of parts, one embracing all those having an age of $n$ years or less, and the other those parts which are more than $n$ years of age, and for both these groups the formulas apply.

It is noteworthy, in the assumed case of a plant of full growth made up of numerous parts, that the amortization fund should bear a nearly uniform relation to capital invested, whatever the life of the plant may be. For such a plant constructed progressively, all parts of which have a useful life of 5 years, the amortization fund will, at any time after 5 years, contain an amount equal to about $38 \%$ of the cost; for a similar plant with a 20 -year life, $41 \%$; and for a similar plant with a 40-year life, 36 per cent.

The accumulation, therefore, in amortization funds, under certain hypothetical conditions, when plants are of progressive growth and 
mature age and are composed of numerous parts, at. $4 \%$ interest, amounts to about $40 \%$ of the invested capital. In reality, however, there is never absolute agreement between the actual useful life of every part of the plant and its expectancy. The formulas are never strictly applicable. The requirements for replacement may begin long before the expectancy is attained, and if met from the amortization fund will check its growth.

The non-existence of a fund in the full amount indicated by mathematical and theoretical considerations, therefore, does not always show that it has been distributed as profit, nor yet that there has been an intentional waiver of the right to have the earnings cover a fair amortization allowance.

Furthermore, if the annual amortization increment is immediately applied in repayment of invested capital, the same no longer bears interest. Treated as an annuity, interest may be compounded only as long as the fund remains practically in escrow for its intended purpose, that is, for complete retirement at the end of the useful life of the plant. Interest ceases to accumulate the moment the fund is applied to retire the investment in whole or in part. Consequently, if the amortization be determined from amortization tables based on expectancy, and be covered by the earnings from year to year, even though the amortization increment as earned be reinvested in the property, it cannot rightfully be classed as a repayment of invested capital until the end of the period of expectancy. If so applied at any earlier date, a new amortization annuity, based on the remaining life, must be computed.

If, nevertheless, the amortization annuity as originally determined be deducted from the investment from year to year, the result will be incomplete amortization. In the case of a 40-year life, the amortization of the invested capital would be only $\$ 42.08$ of each $\$ 100$, and there would still remain $\$ 57.92$ to be made good.

These facts make clear the point which is to be emphasized, that, whenever amortization is based on annuities bearing: compound interest, the appraisal for rate-fixing purposes must be of the entire investment without reduction for depreciation.

The foregoing mathematical demonstration that the accumulation in an amortization fund for a plant of mature age should amount to 
a considerable sum, confirms a conclusion which can be reached in a more direct way.

In the assumed case of a plant which has a life of $n$ years, and of which one-nth has been constructed each year, after $n$ years there will have to be replaced one-nth thereof each year. Because the annual investment in the installation has been uniform, there will be, for each dollar invested per year, a total investment of $n$ dollars.

The amnual replacement after $n$ years, for each dollar annually invested, will be $\$ 1$. If now the anmuity to replace the several parts of the plant in $n$ years is a for each dollar of the annual investment, then after $n$ years, the annual amount received as annuity will be $a n$, and this will fall short of meeting the actual expenditure by an amount expressed by $(1-a n)$ which, at $4 \%$ per annum, is the interest on $\frac{100(1-a n)}{4}$ dollars; or, expressed in percentage of the cost, is $\frac{100^{2}(1-a n)}{4 n}$ per cent. of the total investment in the plant.

For a plant not subject to further growth, with a uniform useful life of all its parts, and constructed progressirely, there will be needed, at $4 \%$ interest, to supplement the deficient amortization annuity:

When the useful life is 5 years:

$$
\frac{100^{2}(1-0.923)}{20}=38.5 \% \text { of the total replacement cost. }
$$

When the useful life is 10 years:

$$
\frac{100^{2}(1-0.8329)}{40}=41.3 \% \text { of the total replacement cost. }
$$

When the useful life is 20 years:

$$
\frac{100^{\circ}(1-0.6716)}{80}=42.3 \% \text { of the total replacement cost. }
$$

When the useful life is 40 years:

$$
\frac{100^{2}(1-0.4208)}{160}=36.2 \% \text { of the total replacement cost. }
$$

These figures are in substantial agreement with those resulting from the first analysis. They show that, in order to make an annual allowance, estimated by the annuity amortization fund method, adequate to keep a plant, of the kind assumed, in good condition, there must be allorred to accumulate and be kept alrars on hand a fund at 
$4 \%$ interest which, for expectancies of from $\tilde{5}$ to 40 years, is somewhere near $40 \%$ of the replacement cost of the plant.

Some such amount, depending on the expectancy, represents the accurnulation of the annuities during that period of the plant's life during which no replacements were necessary. If the annual allowance for maintenance has been in the past based on the requirements of operation and-repair without surplus to meet future replacemente, then the current allowance for amortization or replacement should not be determined by the amortization fund annuity method, but should be otherwise determined, as shown subsequently.

When, in other words, opportunity has not been given to accumulate the $40 \%$ (approximately), for ordinary periods of useful life of perishable properties, of the invested capital, then any amount estimated from amortization tables on the original full period of useful life will fall short of the real replacement requirement. To illustrate this point, let it be assumed that a conduit, such as a cast-iron pipe, used for any purpose, has a length of 40 miles. Let it be also assumed that the pipe is not being further extended, that the expectancy of this pipe is 40 years, and that it was constructed progressively, 1 mile each year. It took 40 years to install the pipe, and at the end of this time the first mile of pipe laid was ready for replacement-it had served its tiree. Each year thereafter, 1 mile of pipe has to be replaced, and the replacement at this rate will continue indefinitely. The annual replacement expenditure during the first 40 years is nothing, but, thereafter, it is the cost of installing 1 mile of pipe. If prices of labor and material have remained constant, and if conditions have otherwise remained as they were when the first mile of pipe was laid, then the annual replacement expenditure will be onefortieth of the total amount invested in the pipe line.

Provision for this replacement must be made if the pipe is to continue in service. If, now, the extension of the pipe progresses beyond the 40-year period at the same rate, before assumed, of 1 mile per year, there will be no changes in the annual replacement requirement during a second period of 40 years, but at the end of this second period-at the end of 80 years-there will be 80 miles of pipe in service, and thereafter during the third 40-5ear period there will have to be replaced annually 2 miles of pipe, or one-fortieth of 80 miles, or trice the amount of pipe extension per annum. 
It is possible, by such analysis, when a plant is of progressive growth and has attained an age exceeding the life of its perishable parts, to prescribe a rule for determining the replacement requirement; but it must be remembered that a rule thus determined can be strictly correct only for the hypothetical case of service in exact conformity with the assumed probable life, and that a rule thus determined may require some modification, as hereinafter explained.

For each group of parts having the same length of life, there is to be determined: first, the average annual capital invested, using, however, replacement cost instead of the actual investment; and second, the full number of times that the age of the plant is greater than the useful life of the particular group of parts under consideration. The replacement requirement (for the hypothetical case, in which actual service conforms throughout with the assumed probable life) is then ascertained by multiplication.

A pipe line may again serve as an illustration: Suppose it is desired to know the replacement requirement for a pipe line 300 miles long, which has been extended 2 miles each year, the age of the oldest portion of which, therefore, is 150 years.

The life of the pipe being taken at 40 years, the full number of times this is contained in 150 years is three. The annual replacement requirement will be three times two, or 6 miles of pipe.

The 6 miles of pipe requiring replacement were constructed 40 years ago, and the conditions under which this was done may have been materially at variance with those prevailing at the time of their replacement. Consequently, in the determination of the replacement requirement, expressed in dollars instead of in miles of pipe, the replacement cost of the system and not the original cost of capital invested should be taken into account. Expressed as a percentage of the total length of pipe in service, or of the total cost of replacing the entire pipe line, this would be 2 per cent.

By the annuity method of computation, in the selected illustration, the allowance for replacement would be $1.052 \%$ of the cost of the system, which is barely:more than one-half of the actual requirement, and this allowance, as already explained, would only then be justified if amortization had covered the entire period in the life of each part of the pipe during which there was no expenditure for replacements, 
so that the inadequate annual allowance could be supplemented by the earnings of an accumulated amortization fund.

In a plant which is made up of a multiplicity of parts of various periods of usefulness, those which have the same expectancy should, as before stated, be grouped together. For each group, the replacement requirement can then be estimated separately, and from the several amounts thus ascertained the total requirement is determined.

The rule previously laid down for a hypothetical case is not strictly applicable under the conditions as they actually present themselves. There can be no absolute conformity between the assumed period of usefulness of any part of a plant and the time during which it actually proves useful.

The probable useful life or expectancy is merely the average life, which is often not reached and is just as often exceeded. Thus, again referring to the pipe line, it is to be assumed that while some of it may serve beyond the average period of usefulness of such pipe, other parts thereof, from one cause or another, will require replacement early in its life. Consequently, any rule such as that previously laid down, which indicates a uniform replacement requirement in successive periods, with a sudden rise in the requirement at the beginning of each new period, if the plant be one that is steadily growing, will require some modification.

The simplest modification of the foregoing rule is to assume gradual changes in the annual replacement requirement as the age of the plant increases, instead of the sudden changes, and then to call this requirement at all times inversely proportional to the useful life of any group of parts. This is sometimes referred to as the "straightline" method. It might with equal propriety be called the direct percentage method, as the inverse ratio is usually expressed in percentage.

Under this direct percentage method, there would be allowed $2.5 \%$ per annum of the replacement cost of all parts of a plant having a 40-year life; $3.33 \%$ per annum of the replacement cost of all parts having a 30 -year life; $5 \%$ per annum of the replacement cost of all parts having a 20-year life, and so on.

This method, applied to the hypothetical case of a pipe line, con'structed' and extended 1 mile per year, and each mile thereof having a useful life of exactly 40 years, would, at the end of the fortieth 
year, make the replacement requirement $2.5 \%$ per annum, or 1 mile of pipe. At the end of the sixtieth year, the requirement thus determined would be $2.5 \%$ of the 60 miles of pipe then in service, or 1.5 miles of pipe. This would be $50 \%$ in excess of the amount actually replaced, which at that time would be only 1 mile. This would also apply for any time before the pipe first laid has reached the limit of its usefulness, as at 20 years. In the assumed case there is no replacement requirement at 20 years; yet the straight percentage method indicates $2.5 \%$ of 20 miles of pipe, or 0.5 miles of pipe: It follows from this illustration that the straight-line, or direct percentage, method, applied to an estimated total cost of replacement, would give results somewhat too high.

By further analysis of this problem, the following formulas have resulted, which are free from this objection and fulfill every ordinary requirement. In devising these formulas, the fact was taken into account that there may be some replacement requirement in the early years of a plant's life, and that this requirement gradually increases. These formulas apply strictly only to plants which have been developed gradually and are being extended at a uniform annual rate.

Using the notation already introduced, and designating with $R$ the total cost of replacing the group of items, the probable useful life of which, when new, was $n$ years, and with $e=$ the average annual cost of extensions, the formulas are:

For $m$ less than $n: r=\frac{m e}{2 n}$, or $=\frac{R}{2 n}$.

For $m$ greater than $n: r=\frac{R}{n}-\frac{e}{2}$.

For very large values of $m$ in relation to $n$ ( $n$ being the years of probable usefulness), the value of this expression approaches $\frac{R}{n}$, which is the mathematical equivalent of the straight-line, or direct percentage, method.

However desirable, it might otherwise appear to introduce a method of computing the replacement requirement by recourse to amortization tables, to do this equitably, in the case of a complex plant, is usually difficult, if past earnings have been inadequate to supply the proper amortization increment. In such cases the use of some formula, as 
above noted, for probable replacement requirement is to be recommended.

This method is strictly equitable from the standpoints of both the owner and the ratepayer. That this must be so will be seen on reflection.

The annuity or ordinary method of retirement may be regarded as an. installment method. Under the replacement method an exactly equivalent lump sum, "the amount of the annuity," takes the place of: the installments. If the installments are forthcoming as they are due, then the annuity method is adequate. If they are not paid, then recourse must be had to the lump sum or replacement method as above described.

It is perfectly reasonable, moreover, to assume, unless there is evidence to the contrary, that the method of estimating amortization requirements, which prevails in any case, has been introduced deliberately. The owner of the public service property may be perfectly willing to waive the annuity payments if he knows that what they will amount to, that is, the actual annual replacement, will be covered by the gross earnings when the time comes for discarding parts of his plant. In other words, he may be willing to accept the amount of an annuity in lieu of the annuity itself; and the rate-payer may desire such an arrangement, because, in the early days of the plant's life, he may not be able to pay a sufficient amount for the service to cover the amortization annuity. It must be remembered, however, that such an arrangement burdens the future rate-payer to some extent for the benefit of the rate-payer in the early days of a plant's. life. This is the same idea as the one which prompts some engineers to add early losses to the valuation as a part of that intangible value which is usually called "going concern."

It follows directly from the foregoing that there may be cases in which, even though it be found proper to allow the full actual average annual replacement, the appraisal for rate-fixing purposes should still be the entire investment without any reduction for depreciation. This will be the case whenever it can be shown that past earnings were inadequate to provide an amortization fund.

\section{The Expectancy.}

Whether the plan of making the annual replacement allowance conform to the annual actual replacement requirement, as determined 
by formula, be followed, or whether either of the other two methods be adopted (the direct percentage method or the annuity method), due regard should be had, in fixing the expectancy, to the circumstances under which the plant is being operated and has been operated in the past.

Such disasters as the fire and earthquake of 1906, which suddenly put out of service large portions of the public service plants of San Francisco, which would otherwise have remained useful, may properly be taken into account, as noted hereafter, in estimating the probable useful life of any part of a plant.

It must not be expected, however, that the replacement increment, by whatever method determined, will in any year exactly meet the actual replacement requirement of that year. When some unusually costly part of the plant goes out of use and must be replaced, a single item of the replacement expense may greatly exceed the annual replacement allowance, while, on the other hand, whole series of years are to be expected in which the actual expenditure for replacement will fall below the allowance for replacement.

In the long run, if all assumptions have been properly made, there should be neither gain nor loss resulting from the allowance for replacement.

Before leaving this subject, it may, be well to iliustrate the fact that, when the age of a growing plant is many times greater than the useful life of a class of parts, the error made in applying the direct percentage method of computing replacement requirement will be small, and may ordinarily be disregarded.

In a plant which is 63 years old, for example, and has been extended at a uniform rate, those parts which have a useful life of 5 years should, according to the correct formula, be $19.2 \%$ per annum. while, on the assumption that all the parts having a 5-year life have been replaced, or have been put in new at a uniform rate during the preceding 5 years, the replacement requirement would be figured at 20 per cent.

Absolute accuracy cannot be hoped for, whatever the method of calculation, because the premises assumed as the basis for formulas are never exactly realized. Generally, however, under consideration of all circumstances, a reasonable approximation, either by the direct percentage method or by some formula similar to those previously laid 
down for a special case, can be made of the actual, average annual replacement requirements, whenever the amortization annuity method of retirement does not prevail.

While the process of determining the annual requirement for replacement appears to be simple, it is, as previously intimated, made somewhat difficult and uncertain of application owing to the incomplete information available, from which to estimate the useful life of a plant or of the many parts which make up the whole. Many circumstances are to be taken into account in determining useful life, for this depends not only on deterioration by natural processes of decay, or wearing away by use, but also on inadequacy resulting from growing demand upon the plant; also on inadequacy or obsolescence resulting from changes in processes of manufacture, or from the use of new and better types of machines and appliances, and the like; and also destruction by unforeseen agencies, such as fires and earthquakes, landslides, floods, and the like. In these matters, past experience is the best guide, and, as already stated, should be given weight in some measure in assigning probable life to the parts of a plant.

In the case of gas-works, for example, the life of generators is shortened by the advance made in the art of gas manufacture. Within the last few decades, because of the high price of coal, the moderate price of oil, the local abundance of oil, and the introduction of new processes, the art of gas manufacture in California has been revolutionized. Old processes, are, for the time being, classed as obsolete, and generators and other parts of gas-works have gone out of use, in some cases, almost before their installation was completed.

\section{Amortization and Annuity Tables.}

The following tables have been prepared to illustrate certain principles, and no attempt has been made to give the figures therein presented that degrec of accuracy which is usually looked for in amortization tables.

Table 7 is derived from the values noted in Tables 2,4 , and 6 . It is the result of a multiplication of 100 times the figures in the column, "Remaining Value," with the figures in the next to the last column of each of these three tables.

The information contained in the tables is also presented in the curves in Figs. 1 and 2. Attention is directed to the fact, appearing 
in Table $\tau$ and in Fig. 2, that the amortization increment required to retire the remaining value in the remaining life increases from year to year.

TABLE 1.-AMortization and Annuities. 5-Year Expectancy.

Interest at 4 per cent. Annuities applied at the end of each year.

\begin{tabular}{|c|c|c|c|c|c|}
\hline \multirow{2}{*}{$\begin{array}{l}\text { At the end } \\
\text { of year. }\end{array}$} & \multicolumn{3}{|c|}{$\begin{array}{l}\text { ANNOAL AMORTIZATION INCREMENT FOR } \\
\text { EACH DOLLAR INVESTED }=\$ 0.1816 .\end{array}$} & \multirow{2}{*}{$\begin{array}{c}\text { Annuity } \\
\text { which will } \\
\text { amount to } \$ 1 \\
\text { in the } \\
\text { remaining } \\
\text { life. }\end{array}$} & \multirow{2}{*}{$\begin{array}{l}\text { * Amount of } \\
\text { an annuity of } \\
\$ 0: 20 \text { in re. } \\
\text { maining life. }\end{array}$} \\
\hline & $\begin{array}{l}\text { Amount in } \\
\text { amortization } \\
\text { fund. }\end{array}$ & $\begin{array}{c}\text { Value } \\
\text { remaining in } \\
\text { the physical } \\
\text { properties. }\end{array}$ & $\begin{array}{l}\text { Amount of } \\
\text { the annuity in } \\
\text { the remain- } \\
\text { ing life. }\end{array}$ & & \\
\hline 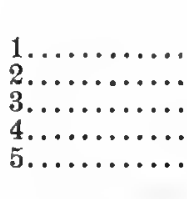 & $\begin{array}{l}\$ 0.000 \\
0.185 \\
0.377 \\
0.576 \\
0.784 \\
1.000\end{array}$ & $\begin{array}{r}\$ 1.000 \\
0.815 \\
0.623 \\
0.424 \\
0.214 \\
0.000\end{array}$ & $\begin{array}{l}\$ 1.000 \\
0.785 \\
0.577 \\
0.376 \\
0.184 \\
0.000\end{array}$ & $\begin{array}{c}\$ 0.1846 \\
0.2355 \\
0.3204 \\
0.4901 \\
1.000 \\
\cdots \cdots\end{array}$ & $\begin{array}{r}\$ 1.083 \\
0.849 \\
\mathbf{0 . 6 2 4} \\
0.408 \\
0.200 \\
\ldots \ldots\end{array}$ \\
\hline
\end{tabular}

* The annuity here noted is $\$ 1$ divided by the expectancy.

\section{Appraisals Without Deduction for Depreciation.}

In determining the part of the investment on which the investor in public service properties should be allowed a reasonable income, all attendant circumstances must be duly considered. It may be stated, however, that, apart from the determination of the rate of interest which should result from the investment, it will be strictly equitable and fair to consider the public service corporation as the agent of the State or municipality, as the case may be, and to determine in what situation the State or municipality would have found itself had there been no intermediate owner or public service corporation.

Let it be assumed that the owner of a public service plant has made his investment under good expert advice, and that the plant is in every respect the same as, or equal to, what the people could have constructed for themselves. Let it be further assumed that the plant is free from debt, and that it and all its parts have a probable useful life of $n$ years. The owner will then be entitled:

First.-To a reasonable interest on his investment;

Second.-To operating expenses;

Third.-To maintenance and repair expenditures;

Fourth.-To an annuity which, in $n$ years, at the ordinary rate of interest, will amount to his investment. 


\section{TablE 2.-Amortization and Annuities. 10-Year Expectancy.}

\begin{tabular}{|c|c|c|c|c|c|}
\hline \multirow{2}{*}{$\begin{array}{l}\text { At the end } \\
\text { of year. }\end{array}$} & \multicolumn{3}{|c|}{$\begin{array}{l}\text { ANNUAL AMORTIZATION INCREyENT FOR } \\
\text { EACH DOLLAR INVESTED }=\$ 0.833 .\end{array}$} & \multirow{2}{*}{$\begin{array}{l}\text { Annuity } \\
\text { which will } \\
\text { amount to } \$ 1 \\
\text { in the } \\
\text { remaining } \\
\text { life. }\end{array}$} & \multirow{2}{*}{$\begin{array}{l}\text { * Amount of } \\
\text { an annuity of } \\
\$ 0.10 \text { in re- } \\
\text { maining life. }\end{array}$} \\
\hline & $\begin{array}{l}\text { Amount in } \\
\text { amortization } \\
\text { fund. }\end{array}$ & $\begin{array}{l}\text { Value } \\
\text { remaining in } \\
\text { the physical } \\
\text { properties. }\end{array}$ & $\begin{array}{l}\text { Amount of } \\
\text { the annuity in } \\
\text { the remain- } \\
\text { ing life. }\end{array}$ & & \\
\hline 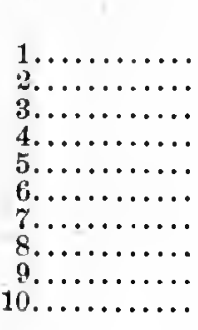 & $\begin{array}{l}\$ 0.000 \\
0.083 \\
0.170 \\
0.260 \\
0.354 \\
0.451 \\
0.552 \\
0.658 \\
0.767 \\
0.881 \\
1.000\end{array}$ & $\begin{array}{r}\$ 1.000 \\
0.917 \\
0.830 \\
0.740 \\
0.646 \\
0.549 \\
0.448 \\
0.342 \\
0.233 \\
0.119 \\
0.000\end{array}$ & $\begin{array}{l}\$ 1.000 \\
0.881 \\
0.766 \\
0.658 \\
0.552 \\
0.451 \\
0.354 \\
0.260 \\
0.170 \\
0.083 \\
0.000\end{array}$ & $\begin{array}{c}\$ 0.08329 \\
0.09449 \\
0.10853 \\
0.12661 \\
0.15079 \\
0.18463 \\
0.23550 \\
0.32036 \\
0.49020 \\
1.000 \\
\ldots \ldots \ldots\end{array}$ & $\begin{array}{l}\$ 1.201 \\
1.058 \\
0.921 \\
0.790 \\
0.663 \\
0.542 \\
0.425 \\
0.212 \\
0.204 \\
0.100 \\
\ldots \ldots\end{array}$ \\
\hline
\end{tabular}

* The annuity here moted is \$1 divided by the expectancy.

TABLE 3.-AMortization and Anvuities. 15-Year Expectanct.

\begin{tabular}{|c|c|c|c|c|c|}
\hline \multirow{2}{*}{$\begin{array}{l}\text { At the end } \\
\text { of year. }\end{array}$} & \multicolumn{3}{|c|}{$\begin{array}{c}\text { ANNUAL AMORTIZATION INCREMENT FOR } \\
\text { EACH DOLLAR INVESTED }=\$ 0.0499 .\end{array}$} & \multirow{2}{*}{$\begin{array}{l}\text { Annuity } \\
\text { which will } \\
\text { amount to } \$ 1 \\
\text { in the } \\
\text { remaining } \\
\text { lite. }\end{array}$} & \multirow{2}{*}{$\begin{array}{l}\text { * Amount of } \\
\text { an annuity of } \\
\$ 0.066=2 \text { in } \\
\text { remaining } \\
\text { life. }\end{array}$} \\
\hline & $\begin{array}{l}\text { Amount in } \\
\text { amortization } \\
\text { fund. }\end{array}$ & $\begin{array}{l}\text { Value } \\
\text { remaining in } \\
\text { the physical } \\
\text { properties. }\end{array}$ & $\begin{array}{l}\text { Amount of } \\
\text { the annuity in } \\
\text { the remain- } \\
\text { ing life. }\end{array}$ & & \\
\hline 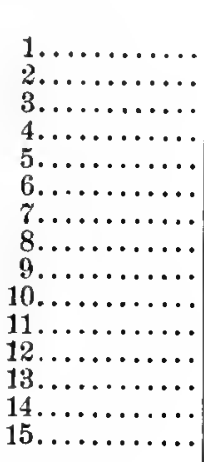 & $\begin{array}{r}\$ 0.000 \\
0.050 \\
0.102 \\
0.156 \\
0.212 \\
0.270 \\
0.331 \\
0.394 \\
0.460 \\
0.529 \\
0.600 \\
0.673 \\
0.750 \\
0.830 \\
0.913 \\
1.000\end{array}$ & $\begin{array}{r}\$ 1.000 \\
0.950 \\
0.898 \\
0.844 \\
0.788 \\
0.730 \\
0.670 \\
0.606 \\
0.540 \\
0.471 \\
0.400 \\
0.327 \\
0.250 \\
0.170 \\
0.087 \\
0.000\end{array}$ & $\begin{array}{r}\$ 1.000 \\
0.913 \\
0.830 \\
0.750 \\
0.673 \\
0.600 \\
0.529 \\
0.460 \\
0.394 \\
0.331 \\
0.270 \\
0.212 \\
0.156 \\
0.102 \\
0.050 \\
0.000\end{array}$ & $\begin{array}{c}\$ 0.04991 \\
0.05467 \\
0.06014 \\
0.06655 \\
0.07415 \\
0.08329 \\
0.09449 \\
0.10853 \\
0.12661 \\
0.15079 \\
0.18463 \\
0.23550 \\
0.32036 \\
0.49020 \\
1.000 \\
\ldots . . .\end{array}$ & $\begin{array}{r}\$ 1.335 \\
1.219 \\
1.008 \\
1.002 \\
.0 .899 \\
0.800 \\
0.706 \\
0.614 \\
0.527 \\
0.442 \\
0.361 \\
0.283 \\
10.208 \\
0.136 \\
0.067 \\
\ldots . . .\end{array}$ \\
\hline
\end{tabular}

* The annuity here noted is $\$ 1$ divided by the expectancy.

If it be now supposed that the owner actually received these amounts, estimated on a proper basis, and that he allows the annuity to accumulate so that amortization will be an accomplished fact at the end of $n$ years, then, as he has command of the amortization fund, he will have a decreasing amount of capital actually tied up in the plant. This decreasing capital or remaining value of the plant is the complement of the growing amortization fund. This fund is supposed to be held 


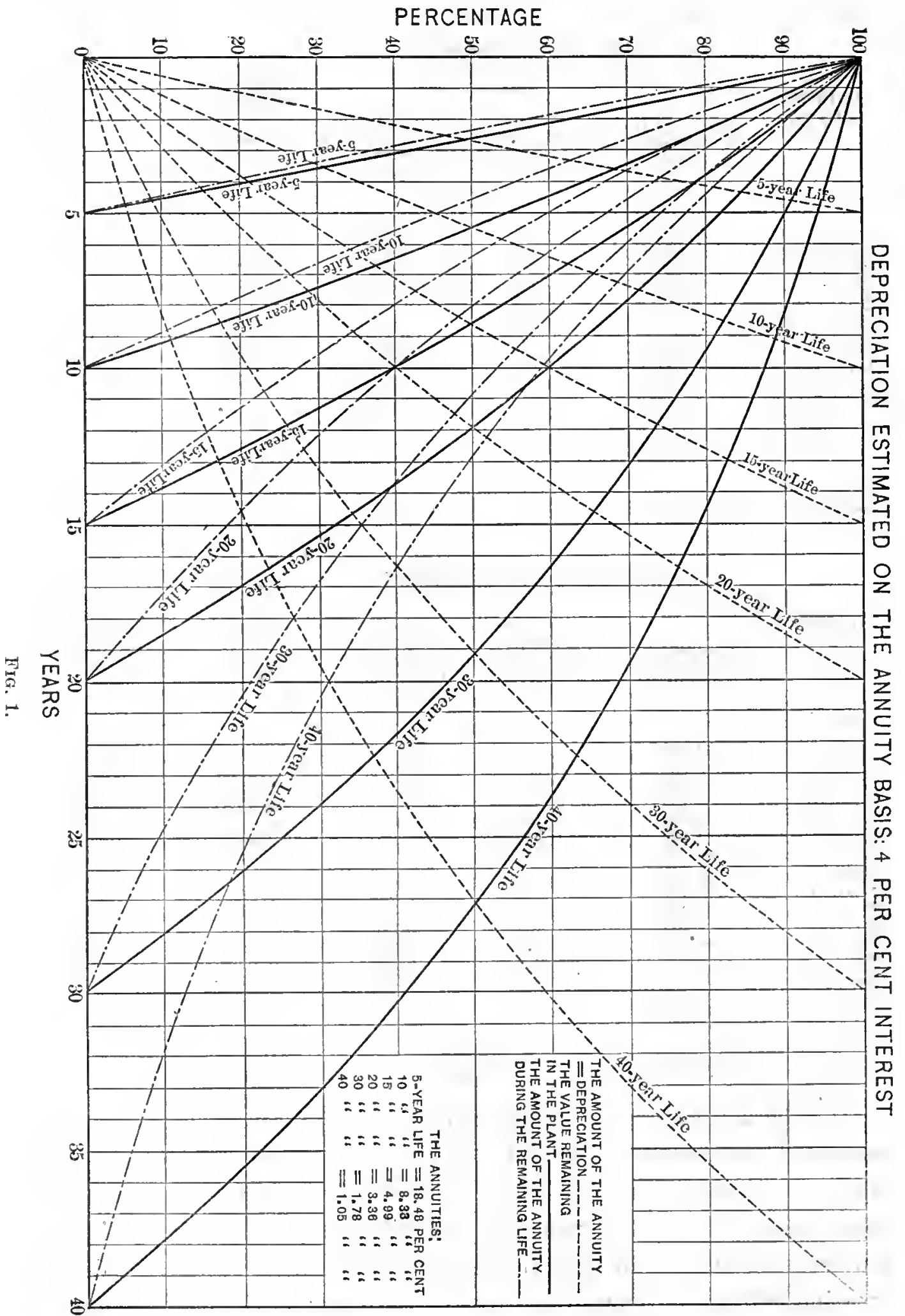




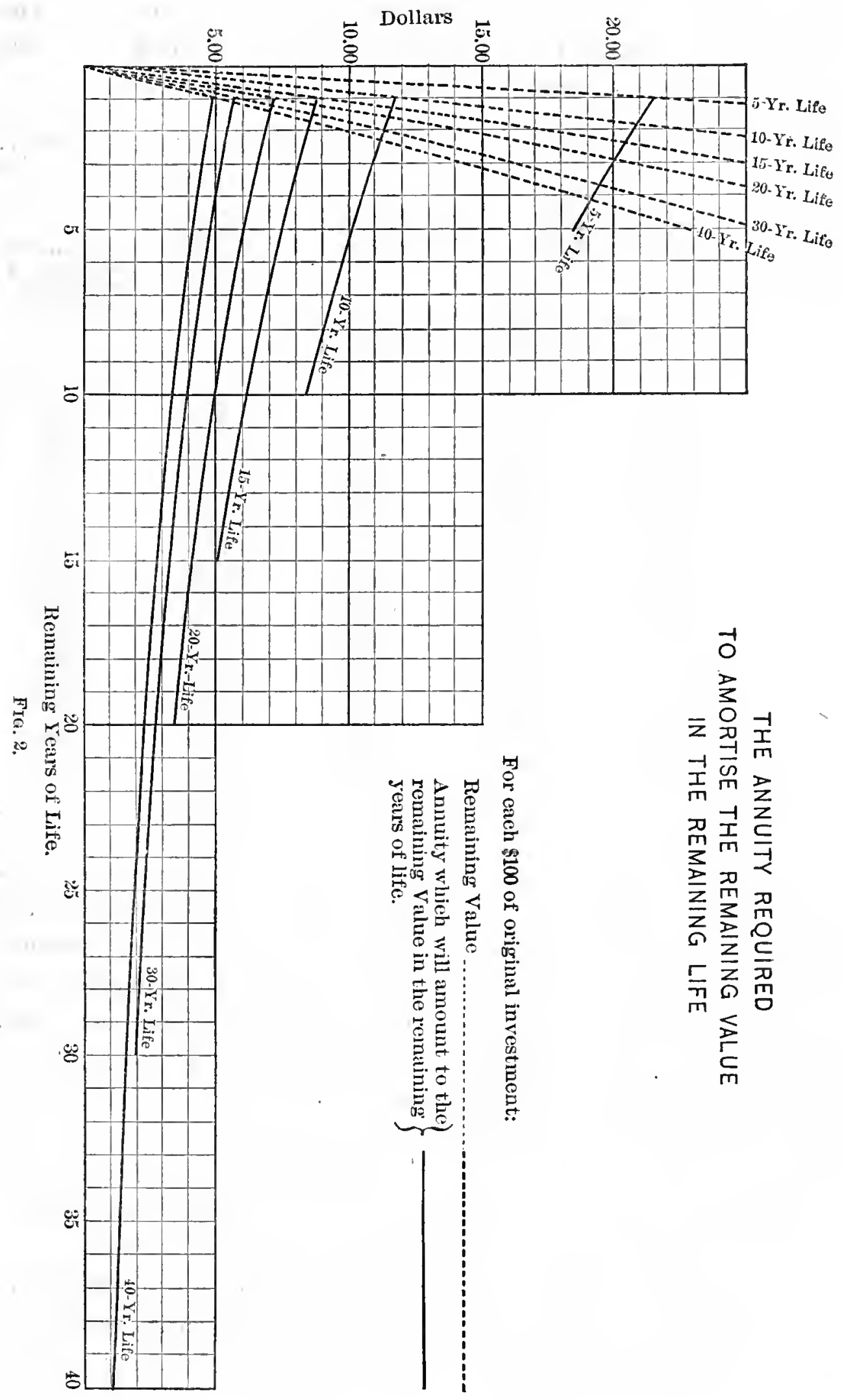


inviolable for the replacement of the plant at the end of its life. The owner reaps no benefit from it whatever, beyond holding it as the means for replacing. a worn-out plant.

TABLE 4.-Ayortization and Annuities. 20-Year Expectancy.

\begin{tabular}{|c|c|c|c|c|c|}
\hline \multirow{2}{*}{$\begin{array}{l}\text { At the end } \\
\text { of year. }\end{array}$} & \multicolumn{3}{|c|}{$\begin{array}{l}\text { ANNUAL AMORTIZATION INCREMENT FOR } \\
\text { EACH DOLLAR INVESTED }=\$ 0.0336 .\end{array}$} & \multirow{2}{*}{$\begin{array}{l}\text { Annuity } \\
\text { which will } \\
\text { amount to } \$ 1 \\
\text { in the } \\
\text { remaining } \\
\text { life. }\end{array}$} & \multirow{2}{*}{$\begin{array}{c}\text { * Amount of } \\
\text { an aunuity of } \\
\$ 0.05 \text { in re- } \\
\text { maining life. }\end{array}$} \\
\hline & $\begin{array}{l}\text { Amount in } \\
\text { amortization } \\
\text { tund. }\end{array}$ & $\begin{array}{l}\text { Value } \\
\text { remaining in } \\
\text { the physical } \\
\text { properties. }\end{array}$ & $\begin{array}{l}\text { Amount of } \\
\text { the annuity in } \\
\text { the remain- } \\
\text { ing life. }\end{array}$ & & \\
\hline 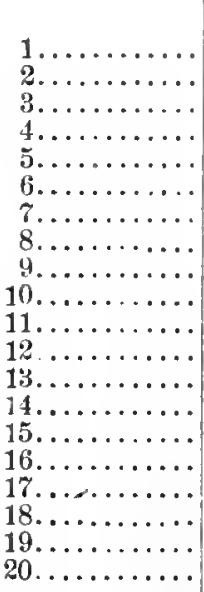 & $\begin{array}{l}\$ 0.000 \\
0.034 \\
0.069 \\
0.105 \\
0.143 \\
0.182 \\
0.223 \\
0.265 \\
0.309 \\
0.355 \\
0.403 \\
6.453 \\
0.505 \\
0.558 \\
0.614 \\
0.672 \\
0.733 \\
0.796 \\
0.861 \\
0.929 \\
1.000\end{array}$ & $\begin{array}{l}\$ 1.000 \\
0.966 \\
0.931 \\
0.895 \\
0.857 \\
0.818 \\
0.777 \\
0.735 \\
0.690 \\
0.645 \\
0.597 \\
0.547 \\
0.495 \\
0.442 \\
0.386 \\
0.328 \\
0.267 \\
0.205 \\
0.139 \\
0.071 \\
0.000\end{array}$ & $\begin{array}{l}\$ 1.000 \\
0.929 \\
0.861 \\
0.795 \\
0.733 \\
0.672 \\
0.614 \\
0.558 \\
0.505 \\
0.453 \\
0.403 \\
0.355 \\
0.309 \\
0.265 \\
0.222 \\
0.182 \\
0.143 \\
0.105 \\
0.069 \\
0.034 \\
0.000\end{array}$ & $\begin{array}{l}\$ 0.03353 \\
0.03614 \\
0.03899 \\
0.04220 \\
0.04532 \\
0.04994 \\
0.0546 \% \\
0.06014 \\
0.06655 \\
0.07415 \\
0.08329 \\
0.09449 \\
0.10853 \\
0.12661 \\
0.15079 \\
0.18463 \\
0.23550 \\
0.32036 \\
0.49020 \\
1.000 \\
\ldots \ldots\end{array}$ & $\begin{array}{r}\$ 1.489 \\
1.384 \\
1.282 \\
1.185 \\
1.091 \\
1.001 \\
0.915 \\
0.831 \\
0.751 \\
0.674 \\
0.600 \\
0.529 \\
0.461 \\
0.395 \\
0.332 \\
0.271 \\
0.212 \\
0.156 \\
0.102 \\
0.050 \\
\ldots \ldots\end{array}$ \\
\hline
\end{tabular}

* The annuity here noted is $\$ 1$ divided by the expectancy.

The value of the plant in its varied stages of depreciation, plus the amortization fund, should at all times be equal to the capital invested in it. The owner, if he gets an annuity, as here assumed, is entitled at all times to the interest, not on a plant valued at first cost or investment less depreciation, but on the entire first cost. $\mathrm{Had}$ he determined, instead of building the plant, to keep his funds invested in safe securities at ordinary interest rates, he would, at the end of $n$ years, have been in possession of his entire capital plus interest on the full amount thereof for the entire time. If, under the assumed facts, he were not allowed interest on the full amount inrested in the public service plant, an injustice would be done.

This is true even when replacement takes the place of amortization. The owner in this case is entitled to interest on the entire capital invested in the plant, and, at the end of the plant's usefulness, he is also entitled to a return of the capital itself. Suppose that a city constructs 
a plant, paying cash for it, and collects rates which will just yield a fair rate of interest on the investment. At the end of $n$ years the plant is replaced with a new one of the same capacity. As the city has not included in its rates theretofore charged an increment for amortization, it now finds itself in possession of a new plant and a total investment twice as great as the cost of the first plant. Applying the same principle to the second plant, rates should be doubled. This, of course, would be an absurdity. In the first instance they should have been fixed so that the remaining value of the plant, plus an actual or imaginary amortization fund, based on full expectancy (which may have been used in the meantime for other purposes), remains constant.

TABLE 5.-Amortization and Annuities. 30-Year Expectanct.

\begin{tabular}{|c|c|c|c|c|c|}
\hline \multirow{2}{*}{$\begin{array}{l}\text { At the end } \\
\text { of year. }\end{array}$} & \multicolumn{3}{|c|}{$\begin{array}{c}\text { ANNUAL A MORTIZATION INCREMENT FoR } \\
\text { EACH DOLLAR INVESTED }=\$ 0.01789 .\end{array}$} & \multirow{2}{*}{$\begin{array}{l}\text { Annuity } \\
\text { which will } \\
\text { amount to } \$ 1 \\
\text { in the } \\
\text { remaining } \\
\text { life. }\end{array}$} & \multirow{2}{*}{$\begin{array}{l}* \text { Amount } \\
\text { of an } \\
\text { annuity of } \\
\$ 0.033 \text { in } \\
\text { remaining } \\
\text { life. }\end{array}$} \\
\hline & $\begin{array}{l}\text { Amount in } \\
\text { amortization } \\
\text { fund. }\end{array}$ & $\begin{array}{l}\text { Value } \\
\text { remaining in } \\
\text { the physical } \\
\text { properties. }\end{array}$ & $\begin{array}{c}\text { A mount of } \\
\text { the annuity in } \\
\text { the remain- } \\
\text { ing life. }\end{array}$ & & \\
\hline 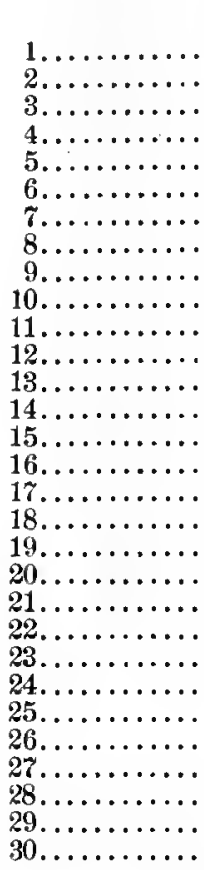 & $\begin{array}{l}\$ 0.000 \\
0.018 \\
0.056 \\
0.056 \\
0.076 \\
0.097 \\
0.118 \\
0.141 \\
0.164 \\
0.189 \\
0.214 \\
0.240 \\
0.269 \\
0.296 \\
0.326 \\
0.357 \\
0.389 \\
0.423 \\
0.456 \\
0.493 \\
0.531 \\
0.560 \\
0.611 \\
0.653 \\
0.697 \\
0.743 \\
0.790 \\
0.840 \\
0.890 \\
0.944 \\
1.000\end{array}$ & $\begin{array}{l}\$ 1.000 \\
0.982 \\
0.964 \\
0.944 \\
0.024 \\
0.903 \\
0.882 \\
0.859 \\
0.836 \\
0.811 \\
0.786 \\
0.760 \\
0.731 \\
0.704 \\
0.674 \\
0.643 \\
0.611 \\
0.576 \\
0.544 \\
0.506 \\
0.469 \\
0.430 \\
0.389 \\
0.347 \\
0.303 \\
0.257 \\
0.210 \\
0.160 \\
0.110 \\
0.056 \\
0.000\end{array}$ & $\begin{array}{l}\$ 1.000 \\
0.944 \\
0.890 \\
0.081 \\
0.790 \\
0.743 \\
0.697 \\
0.653 \\
0.611 \\
0.570 \\
0.531 \\
0.493 \\
0.456 \\
0.423 \\
0.389 \\
0.357 \\
0.326 \\
0.296 \\
0.269 \\
0.240 \\
0.214 \\
0.189 \\
0.164 \\
0.141 \\
0.118 \\
0.097 \\
0.076 \\
0.056 \\
0.036 \\
0.018 \\
0.000\end{array}$ & $\begin{array}{l}\$ 0.01783 \\
0.01888 \\
0.02001 \\
0.02124 \\
0.02257 \\
0.02401 \\
0.02559 \\
0.02731 \\
0.02920 \\
0.03134 \\
0.03358 \\
0.03614 \\
0.03899 \\
0.04220 \\
0.04582 \\
0.04894 \\
0.05467 \\
0.06014 \\
0.06655 \\
0.07415 \\
0.08329 \\
0.01449 \\
0.10853 \\
0.12661 \\
0.15079 \\
0.18463 \\
0.23550 \\
0.32036 \\
0.49020 \\
1.000 \\
\ldots \ldots \ldots\end{array}$ & $\begin{array}{l}\$ 1.869 \\
1.765 \\
1.665 \\
1.569 \\
1.477 \\
1.388 \\
1.303 \\
1.221 \\
1.142 \\
1.066 \\
0.993 \\
0.923 \\
0.855 \\
0.790 \\
0.727 \\
0.667 \\
0.610 \\
0.554 \\
0.501 \\
0.449 \\
0.400 \\
0.353 \\
0.353 \\
0.263 \\
0.221 \\
0.181 \\
0.142 \\
0.104 \\
0.068 \\
0.033 \\
\ldots \ldots \ldots\end{array}$ \\
\hline
\end{tabular}

*The annuity here noted is $\$ 1$ divided by the expectancy.

The same principle applied to a plant made up of a number of parts with various periods of expectancy will show that, in making appraisals for rate-fixing purposes, no reduction for depreciation 
should be made from capital actually and reasonably invested, provided, of course, that the amortization annuity is computed on the basis of full expectancy for each part.

TABLE 6.-Amortization and Annuities. 40-Year, Expectancy.

\begin{tabular}{|c|c|c|c|c|c|}
\hline \multirow[b]{2}{*}{$\begin{array}{l}\text { At the end } \\
\text { of year. }\end{array}$} & \multicolumn{3}{|c|}{$\begin{array}{l}\text { ANNUAL A MORTIZATION INCREMENT FOR } \\
\text { EACII DOLLAR INVESTED }=\$ 0.01052 .\end{array}$} & \multirow{2}{*}{$\begin{array}{c}\text { Aunuity } \\
\text { which will } \\
\text { amount to } \$ 1 \\
\text { in the } \\
\text { remaining } \\
\text { life. }\end{array}$} & \multirow{2}{*}{$\begin{array}{l}\text { *Amount of } \\
\text { an annuity of } \\
\text { \$0.025 in the } \\
\text { remaining } \\
\text { life. }\end{array}$} \\
\hline & $\begin{array}{l}\text { Amount in } \\
\text { amortization } \\
\text { fund. }\end{array}$ & $\begin{array}{l}\text { Value } \\
\text { remaiuing in } \\
\text { the physical } \\
\text { properties. }\end{array}$ & $\begin{array}{c}\text { Amount of } \\
\text { the annuity in } \\
\text { the remain- } \\
\text { ing life. }\end{array}$ & & \\
\hline 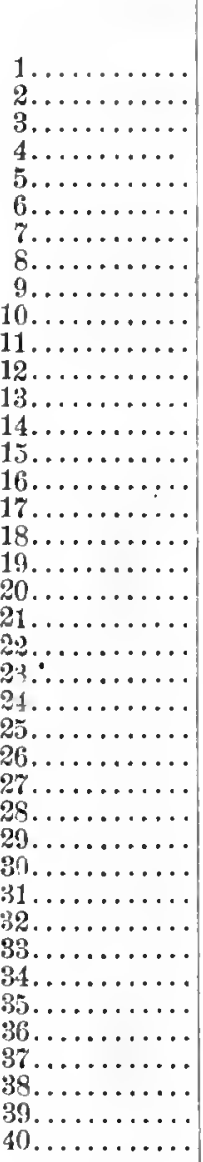 & $\begin{array}{l}\$ 0.000 \\
0.011 \\
0.021 \\
0.033 \\
0.045 \\
0.057 \\
0.070 \\
0.083 \\
0.097 \\
0.112 \\
0.126 \\
0.142 \\
0.158 \\
0.175 \\
0.193 \\
0.211 \\
0.230 \\
0.249 \\
0.270 \\
0.291 \\
0.312 \\
0.336 \\
0.360 \\
0.385 \\
0.411 \\
0.438 \\
0.466 \\
0.495 \\
0.526 \\
0.557 \\
0.590 \\
0.624 \\
0.660 \\
0.697 \\
0.735 \\
0.775 \\
0.817 \\
0.860 \\
0.905 \\
0.051 \\
1.000\end{array}$ & $\begin{array}{c}\$ 1.000 \\
0.989 \\
0.978 \\
0.967 \\
0.955 \\
0.943 \\
0.930 \\
0.917 \\
0.903 \\
0.888 \\
0.874 \\
0.858 \\
0.842 \\
0.825 \\
0.807 \\
0.789 \\
0.770 \\
0.751 \\
0.730 \\
0.709 \\
0.687 \\
0.664 \\
0.640 \\
0.615 \\
0.589 \\
0.562 \\
0.534 \\
0.505 \\
0.474 \\
0.443 \\
0.410 \\
0.376 \\
0.340 \\
0.303 \\
0.265 \\
0.2255 \\
0.183 \\
0.140 \\
0.095 \\
0.049 \\
0.000\end{array}$ & $\begin{array}{r}\$ 1.000 \\
0.951 \\
0.905 \\
\mathbf{0 . 8 6 0} \\
\mathbf{0 . 8 1 7} \\
0.775 \\
0.735 \\
0.697 \\
0.660 \\
0.624 \\
0.591 \\
0.557 \\
0.526 \\
0.495 \\
0.466 \\
0.438 \\
0.411 \\
0.385 \\
0.360 \\
0.396 \\
0.313 \\
0.291 \\
0.270 \\
0.249 \\
0.230 \\
0.211 \\
0.193 \\
0.175 \\
0.158 \\
0.142 \\
0.126 \\
0.112 \\
0.097 \\
0.083 \\
0.070 \\
0.057 \\
0.045 \\
0.039 \\
0.021 \\
0.011 \\
0.000\end{array}$ & $\begin{array}{l}\$ 0.01052 \\
0.01106 \\
0.01163 \\
0.01224 \\
0.01259 \\
0.01358 \\
0.01435 \\
0.01510 \\
0.01593 \\
0.01686 \\
0.01783 \\
0.01888 \\
0.02001 \\
0.02124 \\
0.02257 \\
0.02401 \\
0.02559 \\
0.02931 \\
0.02920 \\
0.03134 \\
0.03358 \\
0.03614 \\
0.03899 \\
0.04220 \\
0.04582 \\
0.04994 \\
0.05167 \\
0.06014 \\
0.06755 \\
0.07415 \\
0.03329 \\
0.09549 \\
0.10853 \\
0.12661 \\
0.15079 \\
0.18463 \\
0.23550 \\
0.32036 \\
0.49020 \\
1.000 \\
\ldots \ldots \ldots . .\end{array}$ & $\begin{array}{l}\$ 2.376 \\
2.260 \\
2.149 \\
2.042 \\
1.040 \\
1.841 \\
1.746 \\
1.655 \\
1.567 \\
1.483 \\
1.402 \\
1.324 \\
1.249 \\
1.177 \\
1.108 \\
1.041 \\
0.977 \\
0.915 \\
0.856 \\
0.799 \\
0.744 \\
0.692 \\
0.641 \\
0.589 \\
0.546 \\
0.501 \\
0.457 \\
0.416 \\
0.376 \\
0.337 \\
0.300 \\
0.265 \\
0.230 \\
0.197 \\
0.186 \\
0.135 \\
0.106 \\
0.078 \\
0.051 \\
0.025 \\
\ldots . . .\end{array}$ \\
\hline
\end{tabular}

* The annuity here noted is $\$ 1$ divided by the expectancy.

In other words: Though eminently proper to deduct depreciation when determining the value of a plant for an owner or a purchaser, it is fundamentally wrong to make such deduction when the plant is being appraised for rate regulation, unless, as will be hereinafter explained, the amortization be computed thereafter on the basis of the remaining life of the plant or of its parts. 
TABLE 7.-ANNuITIEs WIICH WILL AMount to THE REMAINing Value of Perishable Property in its Rejiaining Life.

For each $\$ 100$ of Original Investment; $4 \%$ Interest.

\begin{tabular}{|c|c|c|c|c|c|c|}
\hline \multirow{2}{*}{ At end of yeal. } & \multicolumn{2}{|c|}{ 10. YEAR EXPECTANCY. } & \multicolumn{2}{|c|}{ 20. YEAR Expectancy. } & \multicolumn{2}{|c|}{ 40-Year Expectancy. } \\
\hline & $\begin{array}{c}\text { Remaining } \\
\text { life. }\end{array}$ & Annuity. & $\begin{array}{c}\text { Remaining } \\
\text { life. }\end{array}$ & Annuity. & $\begin{array}{c}\text { Remaining } \\
\text { life. }\end{array}$ & Annuity. \\
\hline & 10 & $\$ 8.33$ & 20 & $\$ 3.36$ & 40 & S1 05 \\
\hline $1 \ldots \ldots \ldots \ldots \ldots \ldots$ & 9 & 8.66 & 19 & 3.49 & 99 & 1.09 \\
\hline $2 \ldots \ldots \ldots \ldots \ldots \ldots$ & 8 & 9.01 & 18 & 3.63 & 38 & 1.14 \\
\hline $3 \ldots \ldots \ldots \ldots \ldots$ & 7 & 9.37 & $1 \tilde{1}$ & 8.78 & 37 & 1.18 \\
\hline $4 \ldots \ldots \ldots \ldots \ldots \ldots$ & 6 & 9.75 & 16 & 3.93 & 36 & 1.23 \\
\hline $5 \ldots \ldots \ldots \ldots \ldots \ldots$ & 5 & 10.13 & 15 & 4.08 & 35 & 1.28 \\
\hline $6 \ldots \ldots \ldots \ldots \ldots \ldots$ & 4 & 10.54 & 14 & 4.25 & 34 & 1.34 \\
\hline $7 \ldots \ldots \ldots \ldots \ldots \ldots$ & 3 & 10.96 & 13 & 4.42 & 33 & 1.39 \\
\hline $8 . \ldots \ldots \ldots \ldots \ldots \ldots$ & 2 & 11.40 & 12 & 4.60 & 32 & 1.44 \\
\hline $9 \ldots \ldots \ldots \ldots \ldots \ldots$ & 1 & 11.85 & 11 & 4.78 & 31 & 1.50 \\
\hline $10 \ldots \ldots \ldots \ldots \ldots \ldots$ & .. & $\ldots$. & 10 & 4.97 & 30 & 1.56 \\
\hline $11 \ldots \ldots \ldots \ldots \ldots \ldots$, & .. & $\ldots \ldots$ & 9 & 5.17 & 29 & 1.62 \\
\hline $12, \ldots \ldots \ldots \ldots \ldots \ldots$ & .. & $\ldots \ldots$ & 8 & 5.38 & 28 & 1.68 \\
\hline $13 \ldots \ldots \ldots \ldots \ldots \ldots$ & .. & $\ldots \ldots$ & 7 & 5.19 & 27 & 1.75 \\
\hline $14 \ldots \ldots \ldots \ldots \ldots \ldots$ & .. & $\ldots \ldots$ & 6 & 5.82 & 20 & $1.8: 3$ \\
\hline $15 \ldots \ldots \ldots \ldots \ldots \ldots$ & .. & $\ldots \ldots$ & 5 & 6.05 & 25 & 1.89 \\
\hline $16 \ldots \ldots \ldots \ldots \ldots \ldots$ & . & $\ldots \ldots$ & 4 & 6.29 & 24 & 1.97 \\
\hline $17 \ldots \ldots \ldots \ldots \ldots \ldots \ldots$ & .. & $\ldots \ldots$ & 3 & 6.54 & 23 & 2.05 \\
\hline $18 \ldots \ldots \ldots \ldots \ldots \ldots$ & .. & $\ldots \ldots$ & 2 & 6.19 & 22 & 2.12 \\
\hline $19 \ldots \ldots \ldots \ldots \ldots \ldots$ & . & $\ldots \ldots$ & 1 & 7.08 & 21 & 2.22 \\
\hline $20 \ldots \ldots \ldots \ldots \ldots \ldots$ & $\cdots$ & $\cdots \cdots$ & . & $\ldots$ & 23 & 2.39 \\
\hline $81 \ldots \ldots \ldots \ldots \ldots \ldots$ & $\cdots$ & $\ldots \ldots$ & .. & $\cdots$ & 19 & 2.40 \\
\hline $22 \ldots \ldots \ldots \ldots \ldots$ & . & $\cdots \cdot$ & $\cdots$ & $\cdots$ & 18 & 2.49 \\
\hline $23 \ldots \ldots \ldots \ldots \ldots \ldots$ & . & $\cdots \cdots$ & .. & $\ldots$ & 17 & 2.59 \\
\hline $24 \ldots \ldots \ldots \ldots \ldots \ldots$ & $\cdots$ & $\cdots \cdot$ & . & $\ldots$ & 16 & 2.10 \\
\hline $25 \ldots \ldots \ldots \ldots \ldots \ldots$ & .. & $\cdots \cdots$ & . & $\ldots$ & 15 & 2.81 \\
\hline $26 \ldots \ldots \ldots \ldots \ldots \ldots$ & . & $\cdots \cdots$ & . & $\cdots$ & 14 & 2.92 \\
\hline $27 \ldots \ldots \ldots \ldots \ldots \ldots$ & • & $\cdots \cdots$ & $\cdots$ & $\cdots$ & 13 & 3.03 \\
\hline & . & $\cdots \cdot$ & . & $\cdots$ & 12 & 3.16 \\
\hline $20, \ldots \ldots \cdots \cdots \cdots \cdots$ & $\cdots$ & $\cdots \cdot$ & $\cdots$ & $\cdots \cdot$ & 11 & 3.28 \\
\hline & . & … & . & $\cdots$ & 10 & 3.41 . \\
\hline & - & $\cdots \cdot$ & . & $\cdots$ & 9 & 3.55 \\
\hline $\begin{array}{l}32, \ldots \ldots \ldots \ldots \ldots \ldots \ldots \ldots \\
33 . \ldots \ldots \ldots \ldots \ldots \ldots\end{array}$ & $\cdots$ & $\cdots \cdots$ & .. & $\cdots$ & 8 & 3.68 \\
\hline & $\cdots$ & $\cdots \cdots$ & $\cdots$ & $\cdots$ & 7 & 3.84 \\
\hline $\begin{array}{l}34 \ldots \ldots \ldots \ldots \ldots \ldots \ldots \\
35 \ldots \ldots \ldots \ldots \ldots \ldots\end{array}$ & - & $\cdots \cdot$ & $\cdot \cdot$ & $\cdots$ & 6 & 3.99 \\
\hline & 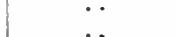 & $\cdots \cdot$ & $\cdots$ & $\cdots$ & $\begin{array}{l}5 \\
4\end{array}$ & 4.15 \\
\hline & $\because$ & $\cdots \cdots$ & 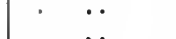 & $\cdots \cdot$ & 4 & 4.32 \\
\hline $38 \ldots \ldots \ldots \ldots \ldots \ldots$ & $\cdots$ & $\cdots \cdots$ & 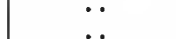 & $\cdots$ & 2 & $\begin{array}{l}4.49 \\
4.67\end{array}$ \\
\hline $39 \ldots \ldots \ldots \ldots \ldots \ldots$ & .. & $\ldots \ldots$ & $\because$ & $\cdots$ & $\tilde{1}$ & 4.86 \\
\hline $40 \ldots \ldots \ldots \ldots$ & . & $\cdots$ & .. & $\cdots$ & & \\
\hline & & & & & & \\
\hline
\end{tabular}

This can best be made clear by an illustration: Let it be supposed that the passenger rates and the freight tariff on a steamboat line are subject to regulation, and that some one going into the steamboat business builds a steamer for the service. Let it be assumed, too, that in connection with this business he requires no eapital investment other than the cost of the steamer, that terminal facilities, office space, and whatever else he needs are obtainable by rental. For the purpose of this illustration, let it be further assumed that the volume of business is such that there is no doubt about the income, so that the element of hazard is eliminated. 
If, now, the steamboat has a life of 20 years, it will gradually depreciate in value and will go out of service at the end of a 20 -year period. Ignoring its possible scrap value, which is immaterial for the purpose of this illustration, the following questions are to be considered.

At the end of 10 years, with interest at $4 \%$ per annum, and earnings just sufficient to yield interest plus an amortization, figured for a 20 -year life at $\$ 0.03358$ on each dollar of the investment:

1.-What will be the value of the steamboat to the owner at the end of 10 years?

2.-What will be the amount that a purchaser can afford to pay for the steamboat at the end of 10 years?

3.-What should the earnings be during the time the steamboat is in possession of the original owner?

4.-What should the earnings be during the time the steamboat is in the possession of a purchaser after 10 zears of service?

The first and second questions have already been answered. The owner, by one line of reasoning, finds the remaining value in the steamboat to be $59.7 \%$; the purchaser, by a different line of reasoning, finds the same value.

The third question, too, has already been answered. The original owner is entitled to a net return during the entire period of his ownership of $4 \%$ on his investment, which is at all times 100 per cent. No reduction is to be made for depreciation, because the fund which results from the accumulation of the amortization annuity, together with its interest, is available for no other purpose than the replacement of the steamboat at the end of its period of usefulness. It is dead capital, and remains dead until the property is disposed of or until required to replace the worn-out steamboat. The original owner, therefore, is entitled to a return of $4+3.358=7.358 \%$ per annum on his investment.

In considering the fourth question, it may at first appear as though the purchaser, having invested only $59.7 \%$ could claim a return on this investment alone-that he should be allowed, in addition to the amortization as above determined, net earnings of $\$ 2.388$ (4\% on $\$ 59.70$ ) per annum on what he paid for each $\$ 100$ of the original cost of the steamboat; that the valuation for rate-fixing purposes, in other words, should be the original investment less depreciation. Under the adoption of this view, it will be seen that, if the steamboat were sold re- 
-peatedly, there would be a constantly decreasing appraisal for ratefixing purposes.

In the last year of its service the valuation entitled to consideration in fixing earnings would be only 7 per cent. This view is unfair to the owner of the property, who should be assumed to be planning a continuation of the steamboat business. When he takes possession of the steamer, its value to him, as already set forth, is $59.7 \%$, but, as owner, he at once finds that, of his capital ordinarily available for other purposes, an amount equal to $40.3 \%$ of the cost of a new steamboat is tied up in his steamboat business. It has become dead capital, for all purposes except replacement, as long as he remains in the steamboat business. This $40.3 \%$ at interest at $4 \%$ is necessary to supplement the annuity regularly going into the amortization fund, together with which at the end of the 20-year period it will just replace the steamer. Whether or not the $40.3 \%$ is actually set apart is immaterial; the fact remains that ownership of the depreciating steamer renders this amount of capital unavailable or dead for any purpose other than replacement, and the owner, no matter when he comes into possession, is entitled, therefore, to interest on this $40.3 \%$ just as fully as. on the $59.7 \%$ which he paid for the steamer.

The demonstration of this fact may be made as follows: The purchaser of the steamboat, who buys the boat when it has a remaining period of usefulness of 10 years, invests, as has been explained, $\$ 59.70$ for each $\$ 100$ of the original cost of the steamboat. He is unquestionably entitled to interest on this sum, together with amortization, which at the assumed interest rate of $4 \%$ will be:

Interest at $4 \%$ on $\$ 59.70 \ldots \ldots \ldots \ldots \ldots \ldots \ldots \ldots \ldots . \ldots \ldots$ Amortization at $8.33 \%$ for the remaining 10 years, during which his investment is paid back to the purchaser.... 4.97

$$
\text { Total }
$$

This is exactly the same as though, instead of the value of the steamboat, the capital originally invested had been taken into account, in which case the original owner or purchaser would be allowed:

Interest at $4 \%$ on the investment of $\$ 100 \ldots \ldots \ldots \ldots \ldots . \$ 4.00$ Amortization annuity to retire $\$ 100$ of the investment within the life of the steamboat, that is, within 20 years..... 3.36 
Although it mas be superfluous, one more illustration of this principle will be given: Let it be supposed that the owner borrows money from a bank at $4 \%$ per annum to build a steamboat, and that he earns $4 \%$ plus the amortization increment of 3.358 per cent.

Of the $\$ 7.358$ to his credit at the end of each year's business for every $\$ 100$ of capital invested, he pays the bank $\$ 3.358$ on account of principal and so much of the remaining $\$ 4.00$ as may be necessary to meet the interest then due. This will be all of the $\$ 4.00$ the first year, and a decreasing amount thereafter until the end of the 20-year period, when his steamboat is retired. He then finds that he has already paid back to the bank on account of the borrowed capital twenty annuity increments of $\$ 3.358$, amounting to $\$ 67.16$, and that there is, therefore, still due to the bank $\$ 33.84$. He also finds that the various amounts remaining in his hands from year to year, $\$ 0.134$ at the end of the second year, $\$ 0.269$ at the end of the third year, $\$ 0.336$ at the end of the fourth year, and so on, together with interest thereon at $4 \%$, when computed for the 20 -year period will amount to the $\$ 33.84$, the balance due at the bank. The owner finds he has earned nothing. He has made no investment and has received no return, which is as it should be in this hypothetical case. The rates, however, throughout the entire 20 years were fixed on the principle that $4 \%$ per annum should always be allowed on $100 \%$ of the capital invested, together with the amortization annuity, but without any deduction for depreciation. They could not have been fixed lower without entailing loss to the owner.

The value of a revenue producing property when the earnings thereof include an amortization annuity has already been discussed. It remains to consider the case of a property which, in addition to the accepted reasonable rate of interest (net), is earning a replacement increment determined by some formula, as above explained, instead of the annuity computed from amortization tables.

In this event, each part of a plant as it wears out is replaced out of current earnings. The owner does not maintain an amortization fund, neither is any of his capital rendered dead or unavailable. To him the value of the property is at all times $100 \%$; so, too, in the case of a purchaser. Knowing that the replacement is covered fully in the earnings, he is willing to pay $100 \%$ for the plant, regardless of its depreciation. 
Take again the case of the steamboat with a life of 20 years. On the assumption that the replacement cost of the steamboat will be returned to him when the steamboat is worn out, a purchaser will pay for it at any time in its life 100 per cent. Of course, in the case of a single steamboat, it might be regarded as unreasonable to assume that in one or more remaining years of its usefulness it will earn enough in excess of reasonable interest on capital invested to pay for a new boat; but if, instead of one steamboat, there were twenty in use, and the annual replacement increment were one-twentieth of the invested capital, or one steamboat each year, then, without hesitation, the purchaser would value the property at 100 per cent.

When, therefore, the actual average annual replacement increment can be earned in excess of a reasonable interest on the invested capital, then the appraisal for an owner, for a purchaser, and for rate-fixing purposes, would be uniformly and always $100 \%$ of the capital invested. The term, "value," in this case, means the same to the original owner, to the purchaser, and to the ratepayer.

For rate-fixing purposes, the steamboat, or the business which the steamboat represents, is to be valued throughout the entire period of the steamboat's usefulness at $100 \%$; and the earnings, when amortization is included, should be $4+3.358=7.358 \%$ on this valuation.

Another case has already been considered. Suppose that, preceding the time of an appraisal for rate-fixing purposes, earnings have been inadequate to supply any amortization increment, and that it be determined thereafter to allow the actual annual replacement requirement to be earned. What, in this case, should be the appraisal?

The original investment being $100 \%$, there having been no amortization annuity in the past, there can be no transfer of the property at less than $100 \%$ without loss; but if; by reason of inadequate returns, the market. value could not be maintained at $100 \%$, and a sale has been made at less than this sum, the new owner will be compensated and protected if, on his investment, which is not original cost, he earns reasonable interest and an adequate amount for replacements. This must be so, because, in the future, actual replacement requirements being covered by the earnings, the worn-out parts will be replaced without cost to the owner. This replacement neither increases nor decreases his investment; but, if the property is extended and new parts are added, such additions represent newly invested capital to the full 
amount of their cost, and in such a case his investment, expressed as a percentage of the total cost, will gradually increase.

At all times, however, without causing loss to the new owner, that part of the plant which he bought at a depreciated value could be valued at his purchase price, while all extensions subsequent to the purchase should, for rate-fixing purposes, be appraised at 100 per cent. Such a course, however, would deprive the new owner of the opportunity for profit, of which he probably thought to avail himself when he bought a plant of depreciated value, and would place the rate-payer in the position of having made a profit at the expense of the original owner. This fact, however, explains why the market value of stocks and bonds is cited so frequently as an indication of value.

It may be held that a determination of value for rate-fixing purposes, on the principles herein set forth, is not a determination of value at all. This may be true, but it then becomes a matter of defining "value," and a distinction should be made between value and the appraisal of the investment on which rates may be properly based.

The term, "value," has been very generally used in matters involving the fixing of rates in the past. Perhaps when the facts herein set forth are better understood, more attention will be paid to the capital reasonably and properly invested.

The illustration with a steamboat which, though subject to constant depreciation in value, is rendering the same adequate service throughout its entire period of usefulness, was selected because thereby the fundamental principle involved is made plain. This principle is much less apparent when a plant made up of many parts of various ages and of various periods of usefulness is under consideration. For example, a plant more than 40 years old, of gradual growth, all parts of which have a life of 40 years, would have a selling value of $63.80 \%$, if the proper provision for amortization, based on full expectancy, has been made; but, in such case, it should earn reasonable interest on $100 \%$ of its cost.

A plant more than 20 years old, made up of many elements or parts, all having a useful life of 20 years, but constructed one-twentieth each year, should be worth $58.95 \%$ to a purchaser, but, with provision for amortization, as above, should earn a reasonable interest on $100 \%$ of its cost.

A plant more than 5 years old, all parts of which have a life of 
5 years, constructed one-fifth each year, should be worth $61.58 \%$ of cost to a purchaser, but when the allowance for amortization is based on full expectancy, a reasonable interest should be earned in addition thereto on $100 \%$ of the investment.

It follows from the foregoing, not only that for rate-fixing the appraisal may properly be of the capital invested, but that, in determining this capital, the aggregate replacement cost, within periods not greater than the expectancy of the several perishable parts of a public service plant, may have to be taken into account.

The amount which should be returned to the owner as a replacement allowance is the capital actually invested in the part of the plant replaced from time to time. It is not the original cost, but the cost at the last renewal, which is to be returned to him, and which he is expected to re-invest with such addition thereto or subtraction therefrom as changed conditions may compel.

The account, as far as a discarded appliance is concerned, is closed, and the new appliance which takes its place, in fact represents new investment; and in its appraisal no note whatever is to be taken of the conditions under which its predecessor was constructed, or installed.

The appraisal of capital invested, therefore, should deal with conditions as they have prevailed during a longer or shorter period antedating the time of the appraisal. When a complex plant is under consideration, prices used in estimating cost should be average prices and not those prevailing at any particular time.

Under a system of permitting the owner of public service properties to earn from year to year the actual average replacement requirements, the necessity for a close distinction between repair and replacement disappears. This is of some advantage, as it is at best difficult to discriminate between small items of replacement and large repair items.

By the foregoing reasoning the conclusion seems inevitable that there may be cases in which large public service properties, such as sewer systems, harbors, railroads, and the like, the ownership of which is not limited in time by franchise, may be regarded as more or less complex plants, having practically perpetual life. The appraisal for rate-fixing purposes is then at the full amount of capital reasonably and properly invested, and there will be no deduction therefrom for depreciation. There will be no amortization if constructed on a cash 
basis, and all repair and replacement requirements will then appear, in the expense of operation and-maintenance, but with due regard to all the elements that should be taken into account.

Real estate is usually considered as requiring no allowance for depreciation, because, as a rule, real estate does not depreciate in value. However, cases are conceivable where there is depreciation, where, possibly by reason of the advance in the arts and abandonment of certain properties, the encumbered ground on which useless improvements are located may have less value than its original cost.

In such cases, if they could be foreseen, there might well be some allowance for depreciation. Ordinarily, however, there is a gradual increase in the value of real estate. This increase, strictly speaking, should be regarded as earnings, a point to which reference will be made later. As a rule, the present value of real estate, in lieu of its first cost plus such improvements as grading, bulkheading, reclaiming against submersion, street and sewer work, and the like, may be entered on the appraisal. As the present value can generally be readily ascertained, this is usually adopted as a sufficiently close approximation of capital invested in real estate.

\section{Intangible VaLues.}

Ordinarily, there is neither occasion for nor propriety in adding, to an appraisal for rate-fixing purposes of a public service property, anything for intangible values, such as franchise, going concern, and the like. When an addition to the appraisal for these is made, it is most likely for the purpose of giving a name to an addition which is necessarily more or less arbitrary.

This statement, of course, does not apply when the State or a municipal authority has been paid for a franchise.* The cost of the franchise, in such a case, is a part of the legitimate investment of capital, and must be included in the appraisal. The same is true of water rights. Where adverse rights have to be quitted, or where, as under a new law in California, the State makes a charge for water rights, their cost is a legitimate expenditure, and should not be classed among the intangible values in the sense in which the term is here used.

Neither does the foregoing statement relating to intangible values

\footnotetext{
* In San Francisco, for example, franchises for street car lines are sold to the highest
} bidder. 
apply when the appraisal is made of a property having a definite earning capacity. The sum of all intangible values is then determined by capitalization of net earnings and by deducting from such capitalization the valuation of the physical properties.

When rates are being fixed, it is quite proper to allow earnings in excess of earnings on ordinary safe investment. Such allowance may be made either direct, as an addition to the allowed rate of interest, or in the roundabout way of an addition to the appraisal.

It is possible, of course, in the case of large earnings in the past, that a portion thereof should be considered as capital returned to the owner. In such a case the fact may be of some importance that an appraisal at $100 \%$ of the investment would already include some of the intangible value.

When the annual amortization increment has not been fully covered by the earnings, the deficiency is a loss. This can be made good to the owner only by increasing the earnings, which, as previously stated, is sometimes done by computing the interest to be earned, not on the invested capital alone, but on the investment plus the aggregate deficiency in the earnings of past years. Such deficiency of earnings, however, can hardly be regarded as an element of value.

Intangible values, of 'whatsoever nature, result from high earnings. In the case of public service corporations, they are arbitrarily created by agreeing to, and permitting, rates which produce a revenue in excess of the ordinary return on safe investments. They do not exist unless the rates are higher than those which would produce net earnings equalling an ordinary interest return on the properly invested capital.

It is eminently proper to treat expenditures such as the interest on capital during construction as an item of cost; yet the propriety of doing this is sometimes questioned. An inadequate interest return during the development stage is another matter. Expenditures may be incurred which.can be classed as development expense, such as advertisements and the salaries of business solicitors, but these are ordinarily and with perfect propriety classed as general expense, or are otherwise included in the operating expense, and enter into consideration when net earnings are estimated. In other words, they should be repaid from year to year as they are incurred, and should not be considered as a part of the capital on which the owner is entitled to a return. 
In some cases, it may be possible to segregate such expenditures and to determine, too, whether they, together with the aggregate loss of interest during the unproductive period in the history of a plant or of parts of a plant, have already been made good by high rates in the past. If this is found to be the case, the element of hazard is to a large extent eliminated.

The public service corporations, naturally, would prefer to have the losses during the lean years, and such expenditures as the advertising of the business, classed as investment of capital. The apparent investment is thereby increased and the apparent aggregate profits of the business figured from the beginning of the operations are thereby made to appear larger than they would otherwise.

The fact that interest during construction is properly considered a part of cost is, as a matter of course, as true of all work of extension and replacement as it is of original construction.

Where, as in California, the water companies and the gas companies operate under constitutional privileges, without special franchise, the hazard of the business should be covered in the earnings, and these earnings should amortize, in the course of time, a reasonable allowance for inadequate earnings, or other unavoidable losses of past years. This, of course, can be done by making an arbitrary addition to an appraisal, but then, as already stated, the hazard of the business is thrown in large measure on the ratepayer, and the rate of return must be relatively low. It is quite as effective to keep the appraisal low and make the rate of return relatively high.

There seems to be no question that the part of value usually designated as "going concern" is intended to apply to the advantage which an established business has over a corresponding prospective business, foreseen as the result of investment, but not yet established.

As long as the business is unprofitable, and as long as the rates charged do not yield a net return on the invested capital which exceeds the return obtainable from savings banks or from other investments of a character regarded as safe in the ordinary acceptance of this term, the business has no "going concern" value." This value, like franchise value, can result only from a capitalization of the excess of net earnings over the return on ordinary safe investments. - It is generally a purely fictitious value, without basis other than that which results from high net earnings, but may be, and often is, regarded 
and defined as that portion of the intangible value for which some sort of a demonstration can be offered, as, for example, the equity of making good early losses and the deficient earnings of the past, or some estimated cost of establishing the business at the time of the appraisal, including loss of interest during an assumed time which would be required for reconstruction. It is held, with some reason, that in equity it is proper to assume that, if the community which is served by a public service property had undertaken construction and management itself, it would have subjected itself to the same losses, or at any rate to the same chances of loss, as the owner of the property, who is in some measure at least to be regarded as agent and who, as such agent, should neither be made to suffer unavoidable losses nor yet be allowed to make unreasonable profits.

The special franchise, when one exists, defines the limits within which an owner must operate. If it does not permit rates which will make the net earnings adequate, then the losses must fall without recourse on the owner; if, on the other hand, the net earnings are greater than the returns on safe investments, then, with due regard for the time during which the rates are protected by the franchise, these earnings are the basis from which, with a fair degree of precision; the aggregate amount of intangible values may be determined. These values collectively must be the difference between the capitalization of the total net earnings (properly determined) and the capital which remains, at any particular time, as an investment in the property.

The early losses and deficient earnings, when they are added to the valuation, are regarded by the appraiser as a part of the investment which had to be made to get the business going-to establish itor at any rate to carry it along until it was on a paying basis. If this procedure should be generally accepted, it would result in giving to "going concern" the greatest value in those cases where, at the outset of the undertaking, conditions were the most unfavorable. This is an absurdity, because the valuation should be a valuation under present-day conditions, and the actual advantage which an established business has over another that would result from a duplication of the plant may be, and generally is, entirely independent of the conditions which prevailed when the established business was in its infancy.

It may be, of course, and sometimes has been held, that, if unsuc- 
cessful work. and early losses are not to be added to the cost of a property, interest during construction likewise should not be treated as cost; but, in one case, there is no limit to the possible amount of unproductive expenditure, while, in the other, a definite assumption applicable in practically all cases can be made. It is not unfair to assume, for example, that in case of water- or gas-works of mature age and gradual development, some period of time, most naturally for small investments one year, will cover the average time before they commence to be remunerative. Where large and complex works are under consideration, the cost for one-half of the period of construction may be a fair allowance. The amounts thus determined are incident to every construction, whether new or whether in the nature of a hypothetical replacement, and, therefore, with perfect propriety, may be added to cost. It is not so with the expenditures of uncertain and extremely variable amount which may be made for unsuccessful work. There may be none in one case, while in another they may be very large, as, for example, in the case of the failure of an expensive structure like a dam.

While the early losses and the expenditures for unsuccessful work are not a measure of going concern value, they are nevertheless of that class of expenditures which, in whole or in part, as already stated, should come back to the owner of the property sooner or later. To add them in the exact amount shown by the cost records in any particular case is not an invariably fair procedure. The owner who builds with care and under the best expert advice and has no: such losses is entitled to a reward for his good judgment and for the care with which he has executed the works. The "going concern", value of such works is certainly as great as the: going concern value of other works of a similar character and extent which, by reason, perhaps, of less care in design and execution, involved a large expenditure for unsuccessful work and for the development of the business.

The combined experience on all works of a similar character, however; should, in the long run, establish the addition which should in fairness be made to the earnings to umortize an assumed fair allowance for this class of expenditures within a reasonable and not too short time. This addition may be relatively large for one type of works and small for another. It seems fair to assume that it should be relatively small when the total values are high. 
Occasionally, a definite basis for at least a part of the value as an established business can be found. For example, there are cases in which the cost of making a connection with a water or gas main is a charge in whole or in part against the consumer. In such cases the cost of making the connection is no part of the capital invested by the owner of the water- or gas-works, and should not be included in an appraisal of the physical properties; but, to the extent of the cost of renewing the connections with a new system of mains, the established company has a distinct and easily recognized advantage over any new company. While not to be taken into account at all in making appraisals for rate-fixing purposes, it may, when intangible values under special franchises are to be determined, be regarded as a part of the aggregate intangible value obtained by capitalizing the excess of the earnings over the ordinary return on safe investments not involving management.

$\therefore$ It appears from the foregoing that, no matter how accurately the aggregate of the intangible values may be determined, it is frequently impossible to find any other than an arbitrary basis for separating them into such subdivisions as "going concern," "development of business," "franchise," "unification of system," and the like. Fortunately, such separation is rarely necessary, and, when attempted, is usually only for the purpose of giving a reason why an arbitrary allowance of earnings above those on ordinary safe investments is just and proper.

When the losses during lean years, or deficient earnings, or unproductive expenditures, such as water tunnels or wells which produce no water, structures that fail during erection; damage by fire, flood, earthquake, or explosions during erection, are added to the value as "going concern," this is unnecessary and forced. These, as has been stated, are losses, and, therefore, are to be considered and treated as the reverse of earnings. They cannot in all cases with propriety be added to the valuation of the physical properties, though it may be eminently proper, on account of such originally unforeseen circumstances, to estimate the cost of reproduction liberally.

In some form they should be taken into consideration in fixing rates. It is rarely practical to determine such losses with accuracy, and yet it is well known that very few public service plants commence operation without some untoward experience or without being com- 
pelled to do business for a time at a loss. Frequently, the expenditures for unproductive work are large, and yet this unproductive work should ordinarily be assumed to have been done under competent advice. It is assumed, in other words, that it could not be foreseen that what turned out to be unproductive work would have no value.

The easy way out of the trouble of providing compensation for such expenditures is the one frequently recommended, to add them to the valuation, giving them a name and treating them as a part of the intangible value; but, while this may appear reasonable in ordinary cases, where the expenditure for useless work and the losses in lean years have been small, other cases have occurred and can be foreseen, as already explained, in which the problem will not be as easy of solution. . It is never logical.

Where there has been loss due to some unforeseen condition, due perhaps in part to error of judgment and to lack of proper foresight by the owner, it is eminently proper to let a part of this loss fall on the owner. When he embarks upon the enterprise he must be supposed to do so with the fixed purpose of reaping a profit:

1st.-In the high rates which the people practically guarantee to the owner;

2d.-In the advance in real estate and other values which make up the business.

If, now, such anticipated increase in value is allowed to the owner and the rates are fixed with a view to covering the ordinary hazards of installation and operation, and to provide proper compensation for management, then the owner on his part must stand, in part at.least, the unforeseen losses, such as the destruction by flood of a partly finished dam, in the assurance that in the long run these losses will be made good, as far as they ought to be made good, by adequate compensation for the service which he renders.

It follows that all intangible values (as they may come into consideration apart from appraisals for rate-fixing purposes) should result from the inclusion of some more or less arbitrary allowance in the established rates such that earnings will exceed in some predetermined measure the earnings which would just yield the ordinary interest rate on safe investments when applied to the reproduction cost of the plant, or better yet, when applied to the actual capital 
reasonably and properly invested. When, for any purpose, consideration is given to intangible values thus determined, it will matter but little what name is used to designate them. It becomes comparatively easy, too, in such a case, to establish a proper relation between the tangible and intangible values, such that both owner and ratepayer may receive equitable treatment.

If it is proper to add anything for early losses, unproductive investments, and cost of developing business to an appraisal, then it is equally proper, in fairness to the ratepayer, to exclude from the appraisal all accessions of value, all appreciations which result from advance in the value of real estate and like causes, and it will also be fair and proper to keep the net earnings at and not above the ordinary return on safe investments.

When the cost of unproductive work, as just referred to, is added to the capitalization, it is with the idea that this addition shall be treated for all time as a part of the investment, and not as a loss, and that the ratepayer must bear the additional burden for all time.

When the cost of useless elements or early losses in the business are treated as losses, they should in a fair measure be made good in the course of time out of adequate earnings, and this should be done irrespective of whether every item of early loss or of every unprofitable investment can be remembered or not.

The most logical course to be pursued, and the one which is always open to "the appraiser, is to use the best available means for determining the amount of capital which is properly invested, then determine what the earnings should be to yield an ordinary return on the investment thus ascertained, and then to increase those earnings by: an arbitrary amount, which may vary within wide limits, not only to compensate for past losses and for the hazard during construction and operation, but also as a compensation for management.

In doing this, however, every endeavor should be made to determine correctly the cost of operation and maintenance. Maintenance is here used in its broadest sense, and must include amortization. Care must be taken, also, not to confound amortization with depreciation, because, as has been explained, an amortization annuity, figured at compound interest, is not available to retire invested capital until at the end of the life of a plant, and the existence of an amortization 
fund is not in itself a reason for decreasing the capital allowance on which interest is to be earned.

\section{Fundamental Pringiples.}

1. - The valuation of a public service property and its earnings must bear such relation to each other that there will be returned to the owner, within the life of the property, the capital which he has properly invested in it, and in addition thereto, interest at a reasonable rate, upon such amount of capital as from time to time actually and properly remains in the property as an investment.

2.-Amortization by the annuity method (the amortization or depreciation annuity being based on the full expectancy) is amortization at the end and only at the end of the period embraced in the expectancy. The invested capital remains uniform throughout the entire period.

3.- In the case of amortization by the annuity method, the value of a plant as it would be determined for a purchaser is the cost of replacement (or original investment) less the amount of the amortization or depreciation annuity at the time of purchase.

4.-Amortization by the straight-line, or direct percentage, method is amortization in annual installments. The invested capital is reduced from year to year.

5.-In the case of amortization by the straight-line, or direct percentage, method, value and the appraisal for rate-fixing purposes are determined in the same way.

6.-When the annual earnings are just adequate to meet operating expenses, interest, and the annual replacement, the amount set apart for replacements will not reduce the invested capital.

7.-A public service property which consists of a single perishable item may, at any time of its life, be appraised at $100 \%$ of the capital properly invested, provided that amortization, estimated by the annuity: method for the full expectancy, has been allowed from the beginning:

8.-A public service property which consists of a single perishable item may, at any time of its' life, be appraised at the investment less depreciation (determined by any method), and amortization may then be computed for the remaining value thus determined, but must be based on the remaining years of the property's usefulness.

9.-A public service property made up of numerous items, all of which have the same expectancy, may be appraised at $100 \%$ of the 
investment, and amortization should then be allowed from the beginning, and the full expectancy should be used in computing it.

10.-A public service property made up of numerous items, all of which have the same expectancy, may have each item valued separately, as under Paragraph 8, with deduction for depreciation, and with amortization'allowed for the, remaining life of each item.

11.-A public service property, of gradual growth and mature age, made up of numerous items of the same expectancy, when the assumption is justified that the annual rate of extension has been uniform, may be appraised at investment less an average depreciation, and amortization is then to be allowed for the equivalent remaining life of an equivalent single item.

12.-When a public service property is made up of many items of various expectancies, the property may be appraised at $100 \%$ of the investment, and, amortization being allowed from the beginning, this is to be estimated on the basis of the full expectancy of each group of items of equal expectancy.

13. - When a public service property is made up of many items of various expectancies, each item may be dealt with separately, as under Paragraph 8, or groups of items may be dealt with, as under Paragraph 11.

14.- When the special case is presented in which there has been no amortization earned in the past, it will be proper to substitute the annual actual replacement requirement in lieu of amortization. The appraisal should then be at $100 \%$ of the capital properly invested.

15.-When the amortization annuity is based on the full expectancy and remains at this amount throughout the life of a plant, then no part of the amortization can be applied to retire the investment until the close of the period of useful life, when the amortization fund will be equal to the investment. In case it be thus applied, a new amortization rate for the remaining life and the remaining value must be introduced into the calculation. Table $T$ gives such rates for a few expectancies.

16. - When the appraisal for rate-fixing purposes is investment less depreciation, and earnings have not included amortization in the past, then, under amortization computed by the annuity method for the full original expectancy, the owner will be operating at a loss. 
17.-Proper investments for franchises, for water rights, and the like, are always to be included in the appraisal.

18.-Intangible values should be disregarded, in making appraisals for rate-fixing purposes, excepting only when the rate of net return is deliberately fixed at or too near the rate earned by ordinary safe investments, in which case an arbitrary addition to the appraisal, under whatever name, should be made. The interest on this item of the appraisal will be the reward of the owner for management and for any hazard which the business may involve.

19.- The net earnings of a public service property should in some measure exceed the return from ordinary safe investments.

20. - The appraisal of real estate should be at.its present value.

21.-When the increase of the value of a public service property, due to increase in the value of real estate or like causes, is determinable in advance, such increase mas be taken into account as a part of the current earnings.

22.- When, in the past, there has been increase of value, due to increase in value of real estate or like causes, this is to be offset against losses during lean years. The increase in value represents reinvested earnings.

It is to be noted, as set forth in Paragraphs $8,10,11$, and 13 , that a valuation for rate-fixing purposes at less than the original investment of capital may be perfectly proper. It represents the remaining investment; but, when the original investment less amortization or depreciation is introduced into the calculation, amortization requires special consideration, because it must be entered at a new and increasing amount from y'ear to year. Reference may be had to Table 7, which makes this point clear:

Notwithstanding the great disadvantage attendant upon valuation at original investment less depreciation, such valuations are being made and are therefore being herein fully considered.

In explanation of the statement that the earnings of a public service property should be somewhat greater than those of ordinary safe investments, reference may again be had to the case of an owner of a public service property. who invests only borrowed money.' If he receives only such interest on the investment as he must pay to the bank, he will have rendered a service.without compensation, except such as he may be allowed in salaries, under operating expenses... In 
such case, it would be a proper business arrangement to compensate him for the risk of loss which he assumes, and for his management, and to make this compensation in some measure proportional to the net earnings. If the owner in the cited case is a stock company, this compensation will be the only element giving value to the capital stock of the company.

\section{The Appraisal at Cost of. Reproduction.}

The objection may be made that, in the practical application of these principles, the capital properly invested cannot always be determined with sufficient accuracy.

It is reasonable to expect that, under good and intelligent direction, and competent expert advice, every dollar invested in a public service property will have been properly expended. Under less able management, there may be a waste of capital, and the works, when completed, will then have cost more than they should. The book accounts, therefore, cannot be accepted as conclusive evidence, even when it can be shown that the cost account has been properly kept. What is wanted is a method or plan of valuation which can be applied under all circumstances in perfect fairness to both the owner of a property and to the ratepayer. There appears to be none better than that of estimating the capital, properly invested, by an appraisal of the public service property at cost of reproduction, item for item, using, however, as a basis for appraisal, not the prices of labor and material which prevail on any particular day, but the prices which represent averages for some considerable time in the past.

Under this method of appraisal, which is recommended as fair in estimating capital reasonably and properly invested, only properties in use are to be included in the appraisal, and under it the owner who has built with intelligence and economy finds himself liberally treated, while the owner who has built wastefully and has incurred useless expenditures is made to bear the penalty of his wastefulness.

Increase in value not represented by a direct investment of 'capital, as in the case of an appreciation of the value of real estate, may properly be regarded in the light of earnings when regulating rates. Such appreciation of value may also result from other causes, as in the case of an advance in the prices of material and labor, which would make the reproduction of a plant cost more than has actually been 
invested in it. On the other hand, there may be a decrease in value due to reduced prices of material or labor and the like." These changes are generally gradual and, when treated as income, or as expense, and distributed over a series of year', usually affect the general result but slightly.

In many cases, not only the increase in the value of real estate is small, but also the proportion of its value to the entire value of a property. In such cases, if there is uncertainty about first cost plus the cost of improvements, such as grading; filling; bulkheading, street and sewer work, the error made in ignoring the effect of a change in the value of the real estate will be small." A doubling of value in 40 years, for example, is equivalent to a rate of increase of $0.52 \%$ per year of the value at the end of the 40-year period. A doubling of value in 20 years is equivalent to a rate of increase of $1.68 \%$ per year of the value at the end of the 20-year period.

These percentages, if the real estate represents $10 \%$ of the total appraisal, would appear in the earnings as $0.17 \%$ and $0.05 \%$ per annum of the total appraisal; but, when appreciation of value is treated as earnings, then that portion of the earnings available for distribution is less than it would otherwise be, and the appreciation becomes in fact a reinvestment of earnings, and should be properly taken into account in making an appraisal of invested capital.

Thus, in the case of a property which has appreciated in value $100 \%$ in 40 years, if this appreciation has been the same in amount each year, and if it could have been determined in advance, there would have been entered into the calculation earnings by appreciation gradually decreasing as the property increased in value from 1.05. to $0.52 \%$ per annum. The rate of interest to be earned and distributed would have been decreased by these amounts. An appraisal at any time would then have taken the properties into account at their appreciated value.

In practical application of such a principle, difficulty arises in determining what allowance to make for the possible annual appreciation. No general rule can be laid down for this determination. It will probably be found that in most cases, in view of the small rate of appreciation, offset as it may be by losses and by depreciation not otherwise taken into account, this appreciation should go to the owner of the 
property as a more or less indeterminate part of the profit to which he is entitled.

Unless, therefore, there is good reason for taking into account the appreciation or the depreciation in the value of real estate as an addition to or a deduction from earnings, this element may be neglected. This is also true of all that portion of the plant which has increased in value by reason of an advance in the cost of labor and materials, in case the appraisal is based on the estimated cost of reproduction, as explained, because, in that event, the appraisal, being based on prices as they have prevailed during considerable time periods, will ordinarily show only moderate and gradual changes of value.

\section{Disadvantage of Annual Rate Regulation.}

In California the law requires that the water rates, to be charged by public service corporations which supply water to the inhabitants of cities and towns, shall be fixed annually by the proper authority. This requirement does not make for efficient service. It would be better, both for the owner of the public service property and for the ratepayer, to have rates regulated with less frequency. A 5-year interval would probably be about right. The certainty that an acceptable rate will prevail for at least a 5 -year period would be an inducement to the public service corporations to render satisfactory service. Extensions would be made more willingly, and the needs of the ratepayer would be more likely to receive proper consideration than under the prevailing system of annual rate regulation, which involves in constant uncertainty business relating to the immediate future. The owner of the plant, knowing that each year his profit may be cut off by an inadequate rate limit, hesitates to make any investment beyond what may be imperatively demanded, with the result that the service becomes unsatisfactory or inadequate.

\section{The Appraisal of the Investiment.}

It has been made clear in the foregoing that a valuation of the purely physical elements of a public service property (depreciation deducted), coupled with an allowance of amortization computed for the full expectancy, as is. frequently done, would be inadequate as a basis for rate regulation. This fact is generally recognized by engineers who are called on to make appraisals for such purposes, and 
no doubt the amounts added as intangible values are sometimes intended to make good such deficiency, at least in part, even when the appraiser does not know why his appraisal is inadequate:

The necessity in such cases for the addition of something to the value of the purely physical elements of a public service property undoubtedly exists; but on the method of determining the amount of the addition, there has not heretofore been agreement. This is due to the imperfect analysis which has been made of such investments, from the business man's standpoint, and to the ruling of the Courts, which hold that owners of public service properties are entitled to a fair return on the "value" of such properties.

If it be found that the ruling of the Courts is not subject to modification, or, in other words, that appraisals must be "value," as "value" would be determined by a purchaser, that is to say, for the tangible elements in most cases, cost or cost of replacement less depreciation; or something practically equivalent thereto, then the appraisers making the valuation, who adhere to the method of computing amortization on the full expectancy, will be constrained to find intangible values in one form or another which will swell the appraisal to where they would like to see it for rate-regulation purposes, that is, about, or somewhat above, the amount of capital reasonably and properly invested.

Of course, a special franchise granting excessive returns is out of consideration in this statement. In such a case, the intangible values are real values determinable by a capitalization of earnings and a subtraction of the value of the tangible parts of the property.

It follows, too, that ordinarily it makes very little difference whether the intangible value is called "going concern," or "franchise," nor how it is arrived at, nor in what proportion it is apportioned to these two classes of value, nor whether a part thereof be otherwise designated; as for example, "adaptation and solidification of roadbed," as "was done in a recent valuation of the railroads in Minnesota.

After all has been said, it will be found true that the adoption of the method of valuation for rate-regulation purposes at the investment without deducting depreciation (as herein advocated) will be always applicable, and, if properly applied, will protect the interests of both owner and ratepayer. It has a distinct advantage over other methods, which are involved in more or less obscurity and cannot be standardized. It will be resisted by certain corporations, the values of whose prop- 
erties, based on earning power, have been greatly inflated, because thereby - the facts showing the relation between net earnings and the capital properly invested in any enterprise are made apparent. It will be welcomed by the ratepayer and by all boards or commissions charged with regulating rates, and if generally adopted, will lead ultimately to a careful analysis of earnings by all owners of public service properties, in order that actual net earnings may be determined correctly. The relation of net earnings to the properly invested capital will always remain the mosi important factor to be weighed, when rates are to be regulated.

The excess of these earnings over the earnings which would represent a return on ordinary safe investments are the reward which the owner receives, as has been stated, for his management of the property and for assuming risks. By reason of the fact that the replacement or amortization requirement is necessarily more or less conjectural, the prospective net earnings cannot ordinarily be estimated closely. This is an additional reason why the rate of return should be made liberal. Any addition to the rate of return is then a purely arbitrary addition, and this addition capitalized, if there is certainty that it will be earned, is the real basis for the intangible values as they would be taken into consideration by a purchaser.

Of course, the proceeding can be reversed, and an arbitrary addition can be made to the appraisal, to which the rate of return is then applied in estimating what the earnings should be. It makes no difference, in the ultimate result, at which end the addition is made, and the appraiser in this matter may follow his own inclination.

\section{Recent Court Decisions.}

The United States Supreme Court, in Knoxville vs. Knoxville Water Company,* says:

"The first fact essential to the conclusion of the court below is the valuation of the property deroted to the public uses, upon which the company is entitled to earn a return. That valuation $(\$ 608,000)$ must now be considered. It was made up by adding to the appraisement, in minute detail of all the tangible property, the sum of $\$ 10,000$ for 'organization, promotion, etc.,' and $\$ 60,000$ for 'going concern.' The latter sum we.understand to be an expression of the added value of the plant as a whole over the sum of the values of its component

* United States Reports, Vol. 212, p. 9. 
parts, which is attached to it because it is in active and successful operation and earning a return. We express no opinion as to the propriety of including these two items in the valuation of the plant, for the purpose for which it is valued in this case, but leave that question to be considered when it necessarily arises. We assume, without deciding, that these items were properly added in this case. The value of the tangible property found by the master is, of course, $\$ 608,000$ lessened by $\$ 70,000$, the value attributed to the intangible property, making $\$ 538,000$. This valuation was determined by the master by ascertaining what it would cost, at the date of the ordinance, to reproduce the existing plant as a new plant. The cost of reproduction is one way of ascertaining the present value of a plant like that of a water company, but that test would lead to obviously incorrect results, if the cost of reproduction is not diminished by the depreciation which has come from age and use.

* "The cost of reproduction is not always a fair measure of the present value of a plant which has been in use for many years. The items composing the plant depreciate in value from year to year in a varying degree. Some pieces of property, like real estate, for instance, depreciate not at all, and sometimes, on the other hand, appreciate. But the reservoirs, the mains, the service pipes, structures. upon real estate, stand-pipes, pumps, boilers, meters, tools, and appliances of every kind, begin to depreciate with more or less rapidity from the moment of their first use. It is not easy to fix at any given time the amount of depreciation of a plant whose component parts are of different ages with different expectations of life. But it is clear that some substantial allowance for depreciation ought to have been made in this case."

†"A water plant, with all its additions, begins to depreciate in value from the moment of its use. Before coming to the question of profit at all, the company is entitled to earn a sufficient sum annually to provide not only for current repairs but for making good the depreciation and replacing the parts of the property when they come to the end of their life. The company is not bound to see its property gradually waste, without making provision out of earnings for its replacement. It is entitled to see that from earnings the value of the property invested is kept unimpaired, so that at the end of any given term of years the original investment remains as it was at the beginning. It is not only the right of the company to make such a pro. vision; but it is its duty to its bond and stockholders, and, in the case "of a public service corporation, at least,' its plain duty to the public. If a different course were pursued the only method of pro-

* Loc. cit., p. 10.

+ Loc. cit., p. 13. 
viding for replacement of property which has ceased to be useful would be the investment of new capital and the issue of new bonds or stocks. This course would lead to a constantly increasing variance between present value and bond and stock capitalization-a tendency which would inevitably lead to disaster either to the stockholders or to the public, or both. If, however, a company fails to perform this plain duty and to exact sufficient returns to keep the investment unimpaired, whether this is the result of unwarranted dividends upon over issues of securities, or of omission to exact proper prices for the output, the fault is its own. When, therefore, a public regulation of its prices comes under question, the true value of the property then employed for the purpose of earning a return cannot be enhanced by a consideration of the errors of the management which have been: committed in the past.".

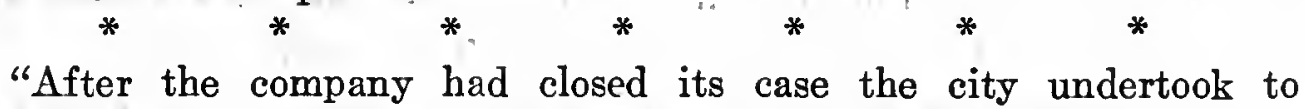
determine the present value of the company's property by the plain method of ascertaining the cost of reproduction, diminished by depreciation. In its case in rebuttal, the company followed the same method, though the results differed largely, and, as we have seen, no proper allowance for depreciation was made."

The United States Supreme Court, in Willcox et al., constituting the Public Service Commission of New York, vs. Consolidated Gas Company, says:*

"And we concur with the court below in holding that the value of the property is to be determined as of the time when the inquiry is made regarding the rates. If the property, which legally enters into the consideration of the question of rates, has increased in value since it was acquired, the company is entitled to the benefit of such increase. This is, at any rate, the general rule. We do not say there may not possibly be an exception to it, where the property may have increased so enormously in value as to render a rate permitting a reasonable return upon such increased value unjust to the public. How such facts should be treated is not a question now before us, as this case does not present it. We refer to the matter only for the purpose of stating that the decision herein does not prevent an inquiry into the question when, if ever, it should be necessarily presented."

In the same case, the United States Supreme Court holds that a valuation of $\$ 12000000$ for the franchise, to be added to a valuation of $\$ 47000000$ for physical properties, is excessive.

This value was arrived at, by the lower court, by assuming a constancy of relation between the value of the franchise and the value of the

* United States Reports, Vol. 212, p. 52. 
tangible property. The franchise value had been fixed in 1884, by agreement of the companies which consolidated, at $\$ 7781000$. This valuation received some sanction or endorsement by a legislative committee, which investigated the consolidation in 1885, and expressed the opinion that this valuation of the franchise was not more than its fair value.

At the time of the consolidation the physical properties were valued at $\$ 30000000$; the accepted value of the franchise at that time, therefore, was $26 \%$ of the value of the tangible properties.

By applying $26 \%$ to the increased valuation in 1906 of the tangible properties; or to $\$ 47000000$, the lower court reached the conclusion that the franchise value had increased to more than $\$ 12000000$, the value disapproved by the Supreme Court. The Court says:*

"But although the State ought, for these reasons, to be bound to recognize the value agreed upon in 1884 as part of the property upon which a reasonable return can be demanded, we do not think an increase in that valuation ought to be allowed upon the theory suggested by the court below. Because the amount of gas supplied has increased to the extent stated, and the other and tangible property of the corporations has increased so largely in value, is not; as it seems to us, any reason for attributing a like proportional increase in the value of the franchises.

"Real estate may have increased in value very largely, as also the personal property, without any necessary increase in the value of the franchises. Its past value was founded upon the opportunity of obtaining these enormous and excessive returns upon the property of the company, without legislative interference with the price for the supply of gas, but that immunity for the future was, of course, uncertain, and the moment it ceased and the legislature reduced the earnings, to a reasonable sum the great value of the franchises would be at once unfavorably affected, but how much so it is not possible for us now to see. The value would most certainly not increase.

"What has been said herein regarding the value of the franchises in this case has been necessarily founded upon its own peculiar facts, and the decision thereon can form no precedent in regard to the valuation of franchises generally, where the facts are not similar to those in the case before us. We simply accept the sum named as the value under the circumstances stated."

The Supreme Court, in these recent opinions, does not refer to the method used in estimating the depreciation or amortization increment

* Loc. cit., pp. 47 and 48. 
which must have entered into the calculation of net return. If this was properly determined in the Knoxville case on the basis of the remaining useful life of the several parts of the water-works, then the opinion of the Court relating to the valuation in that case is eminently proper; but the statement of facts in connection with this point is not clear. Neither does the Court have anything to say about it. The Court no doubt assumed that the method of computation was a correct one. In other words, if error was committed at all it was not the error of the Court.

It may be assumed, therefore, that the decision was rendered just as it would have been if amortization had been correctly determined (as it may have been), and as far as the ultimate result is concerned, the decision of the Court is in accord with the principles which have herein been noted; but, for the sake of standardizing and simplifying the method of arriving at the desired result, the Supreme Court might with propriety, when opportunity arises, qualify the opinion expressed in the Knoxville case so that all questions of the permissibility, either to make the appraisal of value for rate-fixing purposes with depreciation deducted, or, as an alternative, to make the appraisal a fair appraisal of the amount of invested capital, using in each case the proper method of computing the amortization annuity, will be set at rest.

\section{Comparison of Various Methods of Computing Interest and Amortization.}

To make it clear that the two methods of valuation for ratefixing purposes lead to identical results, a pipe line of mature age may again be used for illustration, and reference may also be had to the case of the steamboat already cited. The expectancy of the pipe line is 40 years; it has been constructed progressively one-fortieth each year. There will be one-fortieth of the pipe 40 years old. This has served its time and is of no value. Another fortieth has served 39 years, and its remaining value (after deducting the amount in the amortization fund due to this fortieth) will be $4.8 \%$ of the cost of replacing it. Another fortieth, 38 years old, will have a depreciated value of $9.5 \%$, and so on. The last fortieth, being new, will have full value. The average value, as has already been stated, will be $63.8 \%$, or $\$ 63.80$ for each $\$ 100$ of the total investment. The remaining life 
which must be assumed for an equivalent unit of this value is 18.0 years.

The computation, on the theory of valuation approved by the U. S. Supreme Court, will now be as follows:

Depreciated value of the pipe line for each $\$ 100$ of

the investment..................... $\$ 63.80$

Amortization increment to be applied annually, which will amount to $\$ 63.80$ in the remaining 18.0 years at 4 per cent............................... $\$ 2.50$

Net earnings on $\$ 63.80$ at the assumed rate of $4 \%$ per

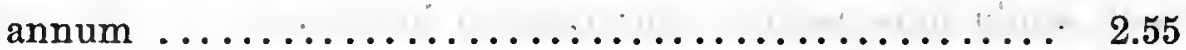

Total earnings in excess of operating expenses........ \$5.05

The computation, on the principle of valuing the investment without deduction for depreciation, will be as follows:

The investment will be................. $\$ 100.00$

The amortization increment to be applied annually, which will amount to $\$ 100$ in 40 years at $4 \%$ will be..... $\$ 1.05$ The net earnings on $\$ 100$ of the investment at $4 \%$ will be. 4.00

The total earnings in excess of operating expenses, etc... $\$ 5.05$

The earnings, including amortization, estimated by the two methods are identical. They are also identical in the case of a single depreciating item, as in the case of the steamboat at 10 years, or at any other period of its life. They will always be identical, whether the plant is large or small, simple or complex.

The simple method of making appraisals should, in the end, find general acceptance, and when the fact of the absolute agreement of this method with that laid down in the Knoxville case is properly brought to the attention of the Courts, it may be expected that it will obtain their approval.

In Table 8 , and by the diagram, Fig. 3 , the results of computing earnings according to five different methods are presented. All figures in Table 8 apply to $\$ 100$ of invested capital. The interest rate on safe investments is taken at $4 \%$ per annum. Similar tables and diagrams could have been prepared for other expectancies than 20 years, and for other rates of interest, but this single table will suffice to make clear the fundamental principles which are involved, 
and particularly the fact that the results by the simplest method of all, No. 1, always coincide exactly with the results by Method No. 3, the latter being in unquestioned conformity with the opinion of the U. S. Supreme Court, as recently expressed in the Knoxville case.

The first method of computing earnings, as illustrated in Table 8 for a 20-year life at $4 \%$ per annum, as has been fully explained, is based on a valuation at all times at $100 \%$ of the investment. The amortization fund is supposed to be held as a part of the property, transferable with it, and the amortization increment is not written off as depreciation. The several amounts paid into the amortization fund are not available to the owner until replacement is necessary at the end of the term of the plant's usefulness. The moment they are applied as a retirement of capital, it becomes necessary to compute amortization for the remaining value and the remaining life. When this is done annually, the result is as shown under Method No. 3.

The second method is an approximation which is not generally applicable. It is proper for a complex plant of mature age, when it can be shown that there has been no opportunity to accumulate an amortization fund; when, in other words, the allowance for amortization has not exceeded the requirement for replacement. A modification of this method results from the application of the formula for replacement, as elsewhere noted, to be used in the case of plants of a uniform rate of growth.

The introduction of the annual replacement requirement properly determined by any method, in place of amortization, would make Method No. 2 of computing earnings generally applicable in all cases in which past amortization increments have not exceeded the replacement requirements.

The third method is that which literally conforms to the recent Supreme Court decisions, already quoted. Depreciation is taken into account in making the valuation, and amortization is estimated for this valuation and the remaining life. This agrees absolutely with Method No. 1. It is based strictly on the assumption that the amortization is synonymous with depreciation, and is deducted from the investment as each annual increment is received. The annual, gradually increasing amortization or depreciation increment, under Method No. 3, can be ascertained by formula as follows: 
Let $a$ represent the amortization annuity for the full or original expectancy (the same as under Method No. 1).

$i$ represent the rate of interest used in determining the annuity.

$n$ be the number of the year for the end of which the depreciation increment is to be estimated.

$A_{i}$ represent the depreciation increment for the year, $n$ :

Then: $A_{i}=\frac{100 a}{i}\left[\left(\frac{100+i}{100}\right)^{n+1}-\left(\frac{100+i}{100}\right)^{n}\right]$

For $i=4$, that is, for an interest rate of $4 \%$, this will be:

$$
A_{4}=25 a\left(1.04^{n+1}-1.04^{n}\right)
$$

For $i=3$, there will be:

$$
A_{3}=33.33 a\left(1.03^{n+1}-1.03^{n}\right)
$$

For $i=5$, there will be:

$$
A_{5}=20 a\left(1.05^{n+1}-1.05^{n}\right)
$$

TABle 8.-Methods of Calculating Annual Interest and Amortization for an Expectancy of Twenty Years."

\begin{tabular}{|c|c|c|c|c|}
\hline \multirow{3}{*}{ At the end of year. } & \multicolumn{4}{|c|}{ VALUATION=INVESTMENT WITHOUT DEDUCTION FOR DEPRECIATION. } \\
\hline & \multicolumn{4}{|c|}{ Amortization Based on Expectancy. } \\
\hline & $\begin{array}{l}\text { Valuation for } \\
\text { each } \$ 100 \text { of } \\
\text { investment. }\end{array}$ & $\begin{array}{l}\text { Interest at } 4 \% \\
\text { per annum. }\end{array}$ & $\begin{array}{l}\text { Annual } \\
\text { amortization } \\
\text { increment. }\end{array}$ & $\begin{array}{l}\text { Net earnings, } \\
\text { including } \\
\text { amortization. }\end{array}$ \\
\hline 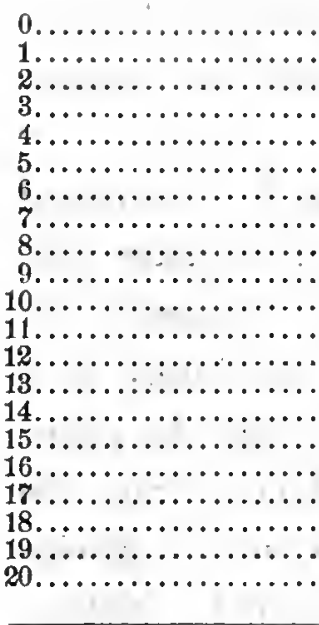 & $\begin{array}{l}\$ 100.00 \\
100.00 \\
100.00 \\
100.00 \\
100.00 \\
100.00 \\
100.00 \\
100.00 \\
100.00 \\
100.00 \\
100.00 \\
100.00 \\
100.00 \\
100.00 \\
100.00 \\
100.00 \\
100.00 \\
100.00 \\
100.00 \\
100.00 \\
100.00\end{array}$ & $\begin{array}{r}\$ 4.00 \\
4.00 \\
4.00 \\
4.00 \\
4.00 \\
4.00 \\
4.00 \\
4.00 \\
4.00 \\
4.00 \\
4.00 \\
4.00 \\
4.00 \\
4.00 \\
4.00 \\
4.00 \\
4.00 \\
4.00 \\
4.00 \\
4.00 \\
4.00\end{array}$ & $\begin{array}{r}\$ 3.35 \\
3.36 \\
3.36 \\
3.36 \\
3.36 \\
3.36 \\
3.36 \\
3.36 \\
3.36 \\
\mathbf{3 . 3 6} \\
\mathbf{3 . 3 6} \\
\mathbf{3 . 3 6} \\
3.36 \\
\mathbf{3 . 3 6} \\
\mathbf{3 . 3 6} \\
3.36 \\
\mathbf{3 . 3 6} \\
\mathbf{3 . 3 6} \\
3.36 \\
\mathbf{3 . 2 6} \\
\mathbf{3 . 3 6} \\
\\
\end{array}$ & $\begin{array}{r}\$ 7.36 \\
7.36 \\
7.36 \\
7.36 \\
7.36 \\
7.36 \\
7.36 \\
7.36 \\
7.36 \\
7.36 \\
7.36 \\
7.36 \\
7.36 \\
7.36 \\
7.36 \\
7.36 \\
7.36 \\
7.36 \\
7.36 \\
7.36 \\
7.36 \\
\end{array}$ \\
\hline Averages.... & $\$ 100.00$ & $\$ 4.00$ & $\$ 3.36-\quad:$ &.$\$ 7.36$ \\
\hline
\end{tabular}
Method No. 1.

For each $\$ 100$ of original investment. Interest 4 per cent. 


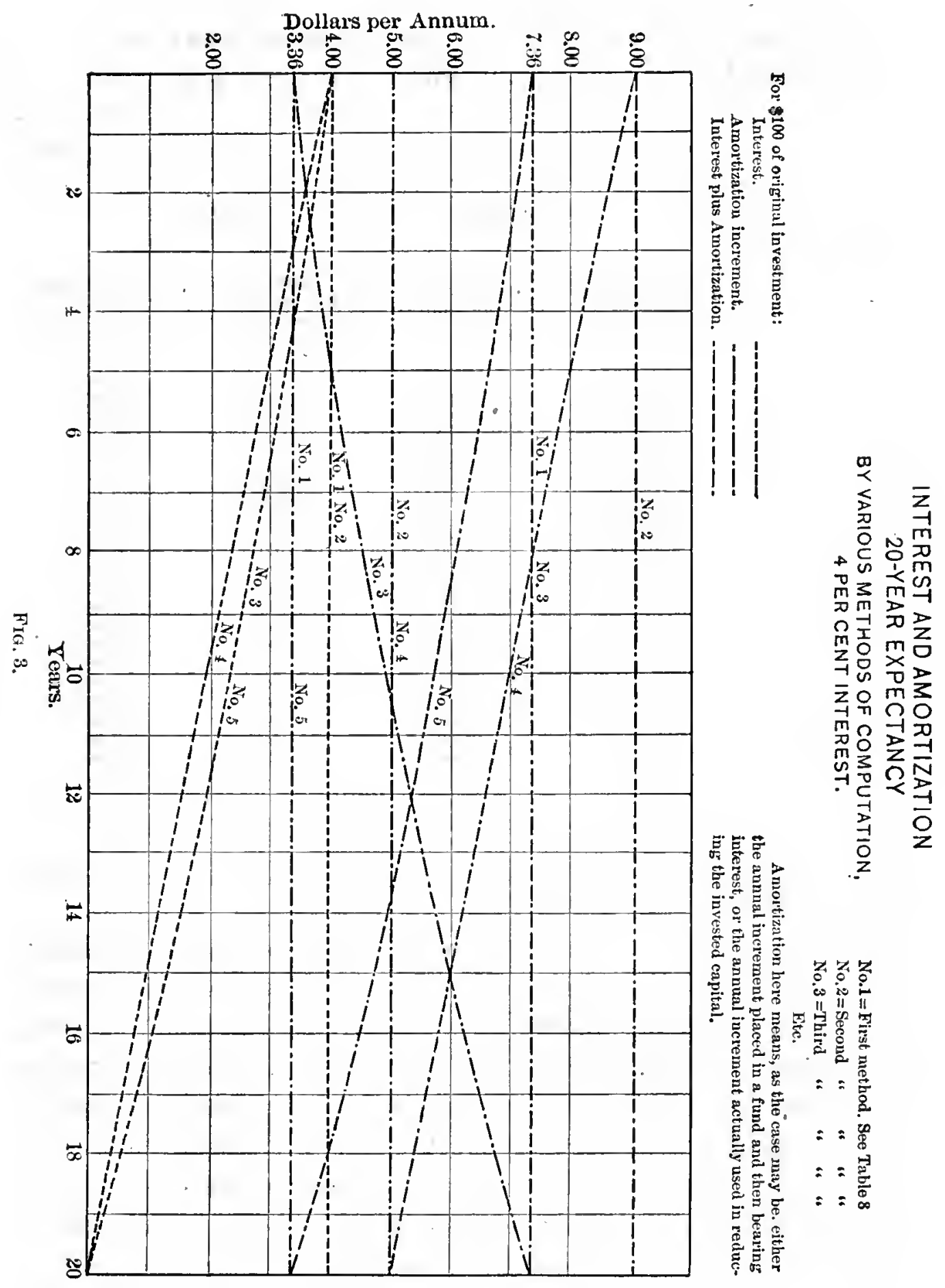


TABLE 8 (Continued).-Methods of Calculating Annual Interest and Amortization for an Expectancy of Twenty Years.

Method No. 2.

(An approximation method applicable in special cases only.)

For each $\$ 100$ of original investment. Interest 4 per cent.

\begin{tabular}{|c|c|c|c|c|}
\hline \multirow{3}{*}{ At the end of year. } & \multicolumn{4}{|c|}{ VALUATION=INVESTMENT WITHOUT DEDUCTION FOR DEPRECIATION. } \\
\hline & \multicolumn{2}{|c|}{ Amortization by Straight } & \multicolumn{2}{|c|}{ Percentage. } \\
\hline & $\begin{array}{l}\text { Valuation for } \\
\text { each } \$ 100 \text { of } \\
\text { investment. }\end{array}$ & $\begin{array}{l}\text { Interest at } 4 \% \\
\text { per aunum. }\end{array}$ & $\underset{\text { Annual }}{\text { amortization }}$ & $\begin{array}{l}\text { Net earnings, } \\
\text { including } \\
\text { amortization. }\end{array}$ \\
\hline 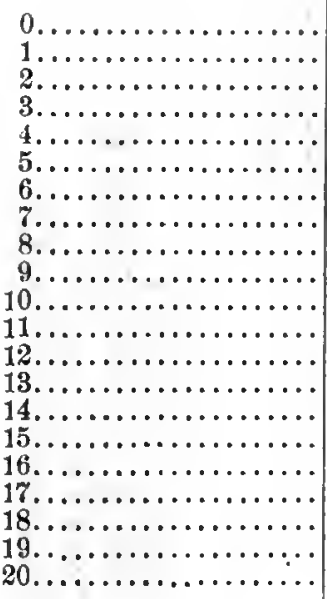 & $\begin{array}{r}\$ 100.00 \\
100.00 \\
100.00 \\
100.00 \\
100.00 \\
100.00 \\
100.00 \\
100.00 \\
100.00 \\
100.00 \\
100.00 \\
100.00 \\
160.00 \\
100.00 \\
100.00 \\
100.00 \\
100.00 \\
100.00 \\
100.00 \\
100.00 \\
100.00\end{array}$ & $\begin{array}{r}\$ 4.00 \\
4.00 \\
4.00 \\
4.00 \\
4.00 \\
4.00 \\
4.00 \\
4.00 \\
4.00 \\
4.00 \\
4.00 \\
4.00 \\
4.00 \\
4.00 \\
4.00 \\
4.00 \\
4.00 \\
4.00 \\
4.00 \\
4.00 \\
4.00\end{array}$ & $\begin{array}{r}\$ 5.00 \\
\mathbf{5 . 0 0} \\
\mathbf{5 . 0 0} \\
\mathbf{5 . 0 0} \\
\mathbf{5 . 0 0} \\
\mathbf{5 . 0 0} \\
\mathbf{5 . 0 0} \\
\mathbf{5 . 0 0} \\
\mathbf{5 . 0 0} \\
\mathbf{5 . 0 0} \\
\mathbf{5 . 0 0} \\
\mathbf{5 . 0 0} \\
\mathbf{5 . 0 0} \\
\mathbf{5 . 0 0} \\
\mathbf{5 . 0 0} \\
\mathbf{5 . 0 0} \\
\mathbf{5 . 0 0} \\
\mathbf{5 . 0 0} \\
\mathbf{5 . 0 0} \\
\mathbf{5 . 0 0} \\
\mathbf{5 . 0 0}\end{array}$ & $\begin{array}{r}\$ 9.00 \\
9.00 \\
9.00 \\
9.00 \\
9.00 \\
9.00 \\
9.00 \\
9.00 \\
9.00 \\
9.00 \\
9.00 \\
9.00 \\
9.00 \\
9.00 \\
9.00 \\
9.00 \\
9.00 \\
9.00 \\
9.00 \\
9.00 \\
9.00\end{array}$ \\
\hline Averages............ & $\$ 100.00$ & $\$ 4.00$ & $\$ 5.00$ & $\$ 9.00$ \\
\hline
\end{tabular}

* In the case of a plant of mature age, made up of numerous parts, amortization as here noted is the annual replacement requirement.

The fourth method, based on a valuation which takes depreciation into account and allows an annual amortization increment determined by the direct percentage method, has the serious defect of requiring large earnings in the early years of a plant's life and smaller earnings toward the end of its life. This defect is fatal to its general application. It may find occasional application, however, as a convenient method of approximating the required earnings in the case of complex plants of mature age, but, even then, as is shown by the line of averages in the table, the probability is that it will be in some measure unfair to the owner. It will give results in strict accord with those of Methods Nos. 1 and 3 at only a single period of the life of a plant, as for example, at 4.2 years for a plant (or an item) having a 10-year 
life; at 8.2 years for a plant having a 20 -year life, and at 14.5 years for a plant having a 40-year life, and so on.

The fifth method is incorrect, and is decidedly unfair to the owner. It is to be condemned under-all circumstances, notwithstanding the fact that it gives nearly. correct results in the early years of a plant's life.

\section{Table 8 (Continued).-Methods of Calculating Annual Interest} and Amortization for an Expectancy of Twenty Years.

Method No. 3.

For each $\$ 100$ of original investment. Interest 4 per cent.

\begin{tabular}{|c|c|c|c|c|}
\hline \multirow{3}{*}{ At the end of year. } & \multicolumn{4}{|c|}{ VALUATION=INVESTMENT Less Depreciation. } \\
\hline & \multicolumn{4}{|c|}{ Amortization Based on the Remaining Life. } \\
\hline & $\begin{array}{l}\text { Valuation for } \\
\text { each } \$ 100 \text { of } \\
\text { investment. }\end{array}$ & $\begin{array}{c}\text { Interest at } 4 \% \\
\text { per annum. }\end{array}$ & $\begin{array}{c}\text { Annual } \\
\text { amortization } \\
\text { increment. }\end{array}$ & $\begin{array}{l}\text { Net earnings, } \\
\text { including } \\
\text { amortization. }\end{array}$ \\
\hline 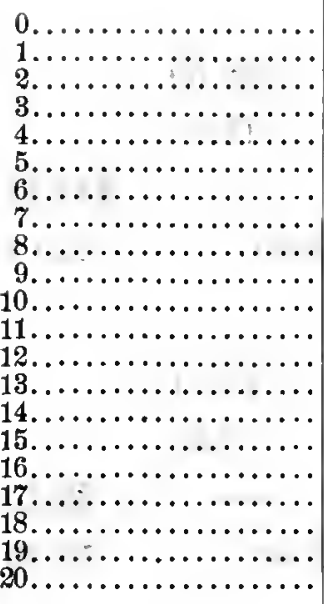 & $\begin{array}{r}\$ 100.00 \\
96.64 \\
93.15 \\
89.52 \\
85.94 \\
80.81 \\
77.73 \\
73.48 \\
69.06 \\
64.46 \\
59.68 \\
54.71 \\
49.54 \\
44.16 \\
38.57 \\
32.76 \\
26.71 \\
20.42 \\
13.88 \\
7.08 \\
0.00\end{array}$ & $\begin{array}{r}\$ 4.00 \\
3.86 \\
3.73 \\
3.58 \\
3.43 \\
3.2 \% \\
3.11 \\
2.94 \\
2.76 \\
2.58 \\
2.39 \\
2.19 \\
1.98 \\
1.78 \\
1.54 \\
1.31 \\
1.07 \\
0.82 \\
0.56 \\
0.28 \\
0.00\end{array}$ & $\begin{array}{r}\$ 3.36 \\
3.49 \\
3.63 \\
3.76 \\
3.93 \\
4.09 \\
4.25 \\
4.42 \\
4.60 \\
4.78 \\
4.97 \\
5.17 \\
5.38 \\
5.59 \\
5.82 \\
6.05 \\
6.29 \\
6.54 \\
6.80 \\
7.08 \\
7.36\end{array}$ & $\begin{array}{r}\$ 7.36 \\
7.36 \\
7.36 \\
7.36 \\
7.36 \\
7.36 \\
7.36 \\
7.36 \\
7.36 \\
7.36 \\
7.36 \\
7.36 \\
7.36 \\
7.36 \\
7.36 \\
7.36 \\
7.36 \\
7.36 \\
7.36 \\
7.36 \\
7.36 \\
7.36\end{array}$ \\
\hline Averages........... & $\$ 58.95$ & $\$ 2.36$ & $\$ 5.00$ & $\$ 7.36$ \\
\hline
\end{tabular}

The averages at the bottom of Table 8 are the valuations and amounts which apply in the case of equal groups of items of every possible age. The average amortization noted for Method No. 3 is the same as the amount which would be estimated by the straight percentage method. This is true for any life, not alone for the 20-year period, to which the table applies. In other words, when amortization hás been properly allowed from the beginning, in the case of a complex plant as described, the earnings are to include interest on the 
remaining investment and amortization computed by the straightpercentage method.

$\therefore$ In the case of a plant made up of many parts of various periods of useful life, the practice is sometimes followed of estimating depreciation for each group of parts of equal life ( $n$. years) at one- $n$th of the remaining book value.

Under such practice, the average book value of each $\$ 100$ of original investment, if the plant has mature age and its parts are uniformly distributed to all possible ages, will be about as follows:

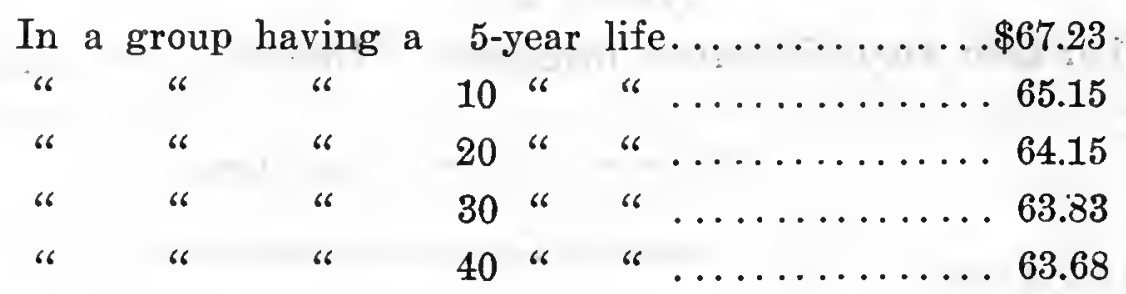

Interest and amortization (in this case the assumed depreciation) would be figured as follows:

5-Year Life:

Interest on $\$ 67.23$ at $4 \% \ldots \ldots \ldots \ldots \ldots \ldots=\$ 2.69$

Amortization, $20 \%$ of $\$ 67.23 \ldots \ldots \ldots \ldots \ldots=13.45$

Whereas interest plus amortization should be, at least... 22.64 10-Year Life:

Interest on $\$ 65.15$ at $4 \% \ldots \ldots \ldots \ldots \ldots \ldots=\$ 2.61$

Amortization, $10 \%$ of $\$ 65.15 \ldots \ldots \ldots \ldots \ldots=6.52$

Whereas interest plus amortization should be, at least.... 20-Year Life:

Interest on $\$ 64.15$ at $4 \% \ldots \ldots \ldots \ldots \ldots \ldots=\$ 2.57$

Amortization, $5 \%$ on $\$ 64.15 \ldots \ldots \ldots \ldots \ldots \ldots=3.21$

Whereas interest plus amortization should be, at least... 40-Year Life:

Interest. on $\$ 63.68$ at $4 \% \ldots \ldots \ldots \ldots \ldots \ldots \ldots=\$ 2.55$

Amortization, $2.5 \%$ on $\$ 63.68 \ldots \ldots \ldots \ldots \ldots=1.59$

Whereas interest plus amortization should be, at least... 
Table 8 (Continued).-Methods of Calculating Annual Interest and Amortization for an Expectancy of Twenty Years.

Method No.4.

For each $\$ 100$ of original investment. Interest $4^{\circ}$ per cent.

\begin{tabular}{|c|c|c|c|c|}
\hline \multirow{3}{*}{$\begin{array}{c}\text { At the end of } \\
\text { year. }\end{array}$} & \multicolumn{4}{|c|}{ VALIATION=INVESTMENT LeSS DEPRECIATION. } \\
\hline & \multicolumn{4}{|c|}{ Amortization Based on Straight Percentage. } \\
\hline & $\begin{array}{l}\text { Valuation for } \\
\text { each } \$ 100 \text { of } \\
\text { investment. }\end{array}$ & $\begin{array}{c}\text { Interest } \\
\text { at } 4 \% \\
\text { per annum. }\end{array}$ & $\begin{array}{c}\text { Annual } \\
\text { amortization } \\
\text { increment. }\end{array}$ & $\begin{array}{l}\text { Net earnings, } \\
\text { including } \\
\text { amortization. }\end{array}$ \\
\hline 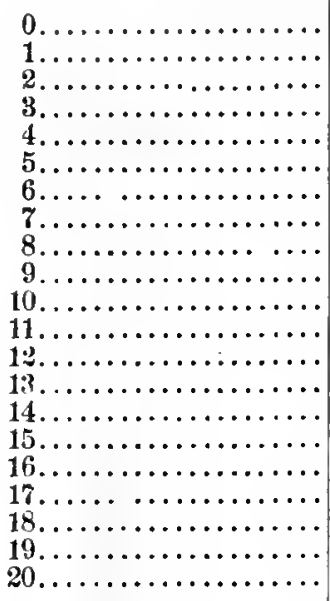 & $\begin{array}{r}\$ 100.00 \\
95.00 \\
90.00 \\
85.00 \\
80.00 \\
75.00 \\
\mathbf{7 0 . 0 0} \\
65.00 \\
60.00 \\
55.00 \\
50.00 \\
45.00 \\
40.00 \\
35.00 \\
30.00 \\
25.00 \\
20.00 \\
\mathbf{1 5 . 0 0} \\
10.00 \\
\mathbf{5 . 0 0} \\
0.00\end{array}$ & $\begin{array}{r}\$ 4.00 \\
3.80 \\
3.60 \\
3.40 \\
3.20 \\
3.00 \\
2.80 \\
2.60 \\
2.40 \\
2.20 \\
2.00 \\
1.80 \\
1.60 \\
1.40 \\
1.20 \\
1.00 \\
0.80 \\
0.60 \\
0.40 \\
0.20 \\
0.00\end{array}$ & $\begin{array}{r}\$ 5.00 \\
\mathbf{5} .00 \\
\mathbf{5} .00 \\
\mathbf{5} .00 \\
5.00 \\
\mathbf{5 . 0 0} \\
5.00 \\
\mathbf{5 . 0 0} \\
\mathbf{5 . 0 0} \\
\mathbf{5 . 1 0 0} \\
\mathbf{5 . 0 0} \\
\mathbf{5 . 0 0} \\
\mathbf{5 . 0 0} \\
\mathbf{5 . 0 0} \\
\mathbf{5 . 0 0} \\
\mathbf{5} .00 \\
\mathbf{5 . 0 0} \\
\mathbf{5 . 0 0} \\
\mathbf{5 . 0 0} \\
\mathbf{5 . 0 0} \\
\mathbf{5 . 0 0}\end{array}$ & $\begin{array}{l}\$ 9.00 \\
8.80 \\
8.60 \\
8.40 \\
8.20 \\
8.00 \\
7.80 \\
7.60 \\
7.40 \\
7.20 \\
7.00 \\
6.80 \\
\mathbf{6 . 6 0} \\
6.40 \\
6.20 \\
6.00 \\
5.80 \\
5.60 \\
5.40 \\
\mathbf{5 . 2 0} \\
\mathbf{5 . 0 0}\end{array}$ \\
\hline Averages.. & $\$ 50.00$ & $\$ 2.00$ & $\$ 5.00$ & $\$ 7.00$ \\
\hline
\end{tabular}

The amortization increment computed by Method No. 5 is clearly inadequate.

It is now possible to prepare tables for various expectancies which will show the required earnings (not including any allowance for management), including amortization, computed by methods which have been shown to be proper.

Table 9 is based on Method No. 1 (Table 8). The property is appraised for rate-fixing purposes at $100 \%$ of the investment, and the original expectancy is made the basis of computing the annual amortization increment. In this table the interest column is not, strictly speaking, based on the true value of the property, neither is the amortization annuity noted in the following column in strict conformity with the growth of an annuity fund, but the sum of the two columns is the correct sum of these two increments which are to be 
covered by the earnings. (The same rate of interest is supposed to apply throughout.)

TABLE 8-(Continued).-Methods of Calculating Annual Interest and Amortization for an Expectancy of Twenty Years.

Method No. 5.

(Always erroneous.)

For each $\$ 100$ of original investment. Interest 4 per cent.

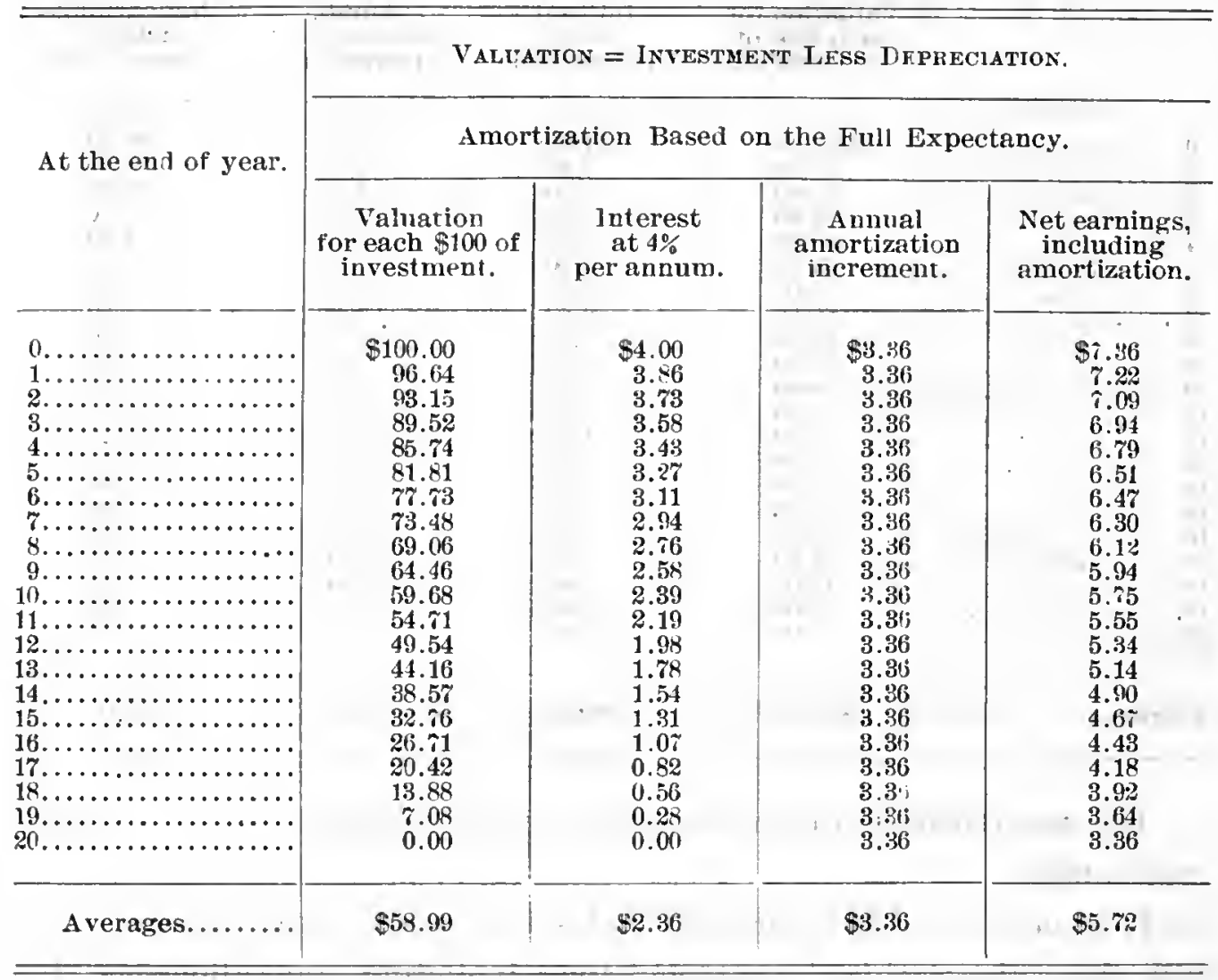

Table 10 and Fig. 4 are based on Method No. 3 (Table 8). The property is appraised with deduction of depreciation. The appraisal thus made will; in the case of a property of mature age and a sufficiently large number of parts, conform with the figures in the "Remaining value" column. The annual amortization increment is computed by the use of amortization tables, from the remaining life and the remaining value. The results presented in this table are obtained by methods of valuation in accord with the recent decision of the U. S. Supreme Court; and there is perfect agreement in the ultimate result with those obtained by Method No. 1 . 
Table 11 is for use when a plant has attained mature age and no part of the invested capital has been repaid. The annual amortization increment is here equal to the annual replacement requirement. It is not, therefore, to be applied as a reduction of the investment. If, however, there has been a partial repayment of capital invested, as in the case of aid extended by bond issues or otherwise, then the appraisal should be correspondingly reduced.

All these tables are based on $4 \%$ per annum, as the rate of return on ordinary safe investments. The earnings, as noted in the tables, do not include any allowance for management, nor for unusual risk and the like, which are to be made in each case as circumstances may warrant, either as has been explained, by the subterfuge of adding arbitrarily assumed intangible values to the appraisal, or by making an addition direct to the interest rate which is applied to the appraisal.

TABLE 9.-Interest and Amortization for Any Plant of ANY AGE.

Method No. 1 (Table 8).

Generally Applicable.

For each $\$ 100$ of original investment. Interest 4 per cent.

\begin{tabular}{|c|c|c|c|c|}
\hline $\begin{array}{c}\text { Expectancy, in } \\
\text { years. }\end{array}$ & A ppraisal. & Interest. & $\begin{array}{l}\text { Amortization } \\
\text { annuity. }\end{array}$ & $\begin{array}{l}\text { Interest plus } \\
\text { amortization. }\end{array}$ \\
\hline 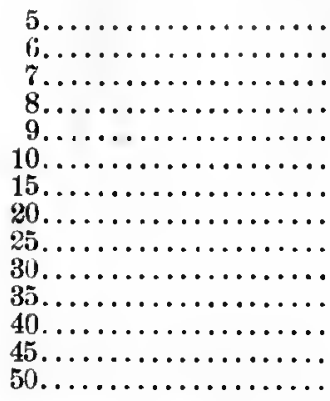 & $\begin{array}{r}\$ 100 \\
100 \\
100 \\
100 \\
100 \\
100 \\
100 \\
100 \\
100 \\
100 \\
100 \\
100 \\
100 \\
100\end{array}$ & $\begin{array}{l}\$ 4.00 \\
4.00 \\
4.00 \\
4.00 \\
4.00 \\
4.00 \\
4.00 \\
4.00 \\
4.00 \\
4.00 \\
4.00 \\
1.00 \\
4.00 \\
4.00\end{array}$ & $\begin{array}{r}\$ 18.443 \\
15.079 \\
12.661 \\
10.853 \\
9.449 \\
8.329 \\
4.994 \\
3.358 \\
2.401 \\
1.783 \\
1.398 \\
1.052 \\
0.426 \\
0.655\end{array}$ & $\begin{array}{r}\$ 22.46 \\
19.08 \\
16.66 \\
14.85 \\
13.45 \\
1 \% .3: 3 \\
8.99 \\
7.36 \\
6.40 \\
5.78 \\
5.36 \\
5.05 \\
4.83 \\
4.66\end{array}$ \\
\hline
\end{tabular}

It is worthy of note, in the case of numerous parts of the same expectancy uniformly distributed to all possible ages, as will be seen by reference to Table 10, that, when depreciation is estimated by the annuity method, and is properly deducted from the invested capital, under Method No. 3, the annual amortization or depreciation increment is the same as though determined by the straight-line method.

The method of appraisal and computation of earnings illustrated in Table 11 is substantially correct for a plant of mature age when 
the annual replacement requirement may be substituted for the amortization. It is not likely that there will have been an excess of income during the early years of a plant's service. The early years are generally lean years, which are ordinarily expected to produce less than the desired income. Therefore, apart from exceptional cases, it may be generally assumed that a plant when it has reached mature age should be earning the replacement requirement in addition to a reasonable rate of interest on the investment.

\section{TABLE 10.-Interest AND Amortization.}

Average values for plants of numerous parts uniformly distributed to all possible ages.

Method No. 3 (Table 8).

For each $\$ 100$ of original investment. Interest 4 per cent.

\begin{tabular}{|c|c|c|c|c|c|}
\hline Expectancy. & $\begin{array}{l}\text { Remaining } \\
\text { life of equiva- } \\
\text { lent single } \\
\text { item, in years. }\end{array}$ & $\begin{array}{c}\text { Average } \\
\text { remaining } \\
\text { value. }\end{array}$ & $\begin{array}{c}\text { Interest on } \\
\text { remaining } \\
\text { value. }\end{array}$ & $\begin{array}{l}\text { Amortization } \\
\text { annuity for } \\
\text { remaining } \\
\text { life. }\end{array}$ & $\begin{array}{l}\text { Interest plus } \\
\text { amortization. }\end{array}$ \\
\hline 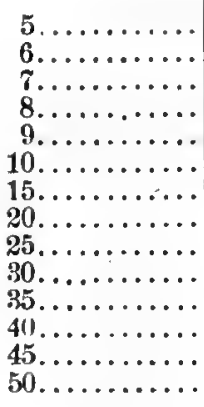 & $\begin{array}{r}3.0 \\
3.5 \\
4.0 \\
4.5 \\
4.9 \\
5.3 \\
7.6 \\
9.9 \\
12.0 \\
14.1 \\
16.0 \\
17.9 \\
19.7 \\
21.5\end{array}$ & $\begin{array}{r}\$ 61.58 \\
60.30 \\
59.38 \\
58.83 \\
58.45 \\
58.23 \\
58.18 \\
58.95 \\
60.03 \\
61.25 \\
62.53 \\
63.80 \\
65.10 \\
66.38\end{array}$ & $\begin{array}{l}\$ 2.463 \\
2.412 \\
2.375 \\
2.353 \\
2.334 \\
2.369 \\
2.327 \\
2.358 \\
2.401 \\
2.450 \\
2.501 \\
2.552 \\
2.604 \\
2.655\end{array}$ & $\begin{array}{r}\$ 20.000 \\
16.667 \\
14.286 \\
12.500 \\
11.111 \\
10.000 \\
6.667 \\
5.000 \\
4.000 \\
3.333 \\
2.857 \\
2.500 \\
2.222 \\
2.000\end{array}$ & $\begin{array}{r}\$ 22.46 \\
19.08 \\
16.66 \\
14.85 \\
13.45 \\
12.33 \\
8.99 \\
7.36 \\
6.40 \\
5.78 \\
5.36 \\
5.05 \\
4.83 \\
4.66\end{array}$ \\
\hline
\end{tabular}

If, however, it can be shown that the investment has been cut down by excessive earnings or by a direct repayment of capital, as in the case of municipal or State aid by contribution of funds to the owner, then the interest rate should be applied only to the remaining investment.

Method No. 4, Tables 8 and 11, is practically, equivalent to a computation of the replacement requirement for inclusion in the earnings. When, however, a new plant of numerous parts is in question, all the expectancies of which are $n$ years, it would be better to grade the replacement.increment from nothing at the beginning to one- $n$th of the investment in the $n$th year. 
TABLE 11.-Interest and Amortization.

For Plants of Mature Age in Case that the Amortization Earued in the Past lias not Exceeded the Replacemeut Requirements.

Method No. 4 (Table 8).

For each $\$ 100$ of original investment. Interest 4 per cent.

\begin{tabular}{|c|c|c|c|c|}
\hline Expectancy. & Appraisal. & Interest. & $\begin{array}{l}\text { Annual amorti- } \\
\text { zation or } \\
\text { replacement } \\
\text { requirement. }\end{array}$ & $\begin{array}{l}\text { Ioterest plus } \\
\text { amortization. }\end{array}$ \\
\hline 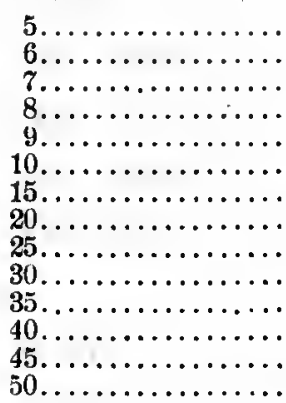 & $\begin{array}{r}\$ 100 \\
100 \\
100 \\
100 \\
100 \\
100 \\
100 \\
100 \\
100 \\
100 \\
100 \\
100 \\
100 \\
100\end{array}$ & $\begin{array}{l}\$ 4.00 \\
4.00 \\
4.00 \\
4.00 \\
4.00 \\
4.00 \\
4.00 \\
4.00 \\
4.00 \\
4.00 \\
4.00 \\
4.00 \\
4.00 \\
4.00\end{array}$ & $\begin{array}{r}\$ 20.00 \\
16.67 \\
14.29 \\
12.50 \\
11.11 \\
10.00 \\
6.67 \\
5.00 \\
4.00 \\
3.33 \\
2.86 \\
2.50 \\
2.22 \\
2.00\end{array}$ & $\begin{array}{r}\$ 24.00 \\
20.67 \\
18.29 \\
16.50 \\
15.11 \\
14.00 \\
10.67 \\
9.60 \\
8.00 \\
7.33 \\
6.86 \\
6.50 \\
6.22 \\
6.00\end{array}$ \\
\hline
\end{tabular}

The practice has heretofore been so general of assuming that the amortization annuity, based on the original expectancy, was an adequate amortization allowance, that there may be cases in which such allowance was from year to year erroneously deducted from the investment as depreciation, Method No. 5, Table 8. Let the case be considered where this has been done for a plant with a 20-year useful life. When this plant is 10 years of age the owner will have received ten annual amortization payments of $\$ 3.36$. These, under this assumption, were applied to reduce the capital invested when he received them. At the 10-year period, therefore, there is a value of $\$ 67.40$ left in the plant for each $\$ 100$ of original investment. The earnings should be interest on this amount at $4 \%$, or $\$ 2.70$ plus the amortization for $\$ 67.40$ for the remaining 10 years, or $(\$ 67.40 \times 0.0833)=$ $\$ 5.61$, making $\$ 8.31$. If the plan of allowing interest on the reduced valuation plus the original amortization increment of $\$ 3.36$ had been followed, the earnings of $(\$ 2.70+\$ 3.36)=\$ 6.06$ would be inadequate.

\section{Conclusion.}

Thus far, no distinction has been made between expectancy and the actual life. All computations have been made as though there were absolute conformity between the actual life and the expectancy. 
This, however, is never strictly true, because some items of every group will go out of use before they are of mature age, while others will survive their expectancy.

The amortization annuity estimated for the actual life of a large number of items will not necessarily agree with the amortization annuity based on average probable life. That there must be disagreement will readily be seen when a single item is taken into consideration. This may be one of those doomed to fail early; or it may be one of the large number which will reach a mature age; or it may be among the smaller number which serves long after the expected age has been passed. Taking all probabilities into account, when the item is new, it will be found that the amortization rate which should apply will always conform to an actual life somewhat less than the expectancy.

It is not proposed to follow this matter further, nor to attempt a specific illustration which would necessarily have to be based on some assumption relating to mortality unsubstantiated by experience; but there may be found in this fact some justification for making liberal allowance for amortization from the beginning of a plant's service.

According to the Court opinions previously quoted, there is a distinct recognition by the United States Supreme Court of the propriety of including intangible values in the appraisal for rateregulation purposes. The Court, however, indicates no method by which the value of a franchise is to be determined: It states distinctly that the opinion in the New York gas rate case is not to be considered a general precedent.

There is also a distinct recognition of the fundamental principle that the value of the investment should be maintained as at the beginning. This is strictly correct if it is intended to apply to the value of the properties as a business and not to the tangible properties alone. There is hardly room to doubt that this is the actual meaning intended to be conveyed, because a little farther on the Court says that the tangible properties of water-works and the like begin 'to depreciate on the day they go into use. Such depreciation of the tangible properties, as referred to by the Court, cannot be offset or made good by any amount of repair work; because, to all intents and purposes, the depreciated items may continue for a long time to be rendering just as adequate service, and often even better service; than when first in- 
stalled. To be kept at $100 \%$ of the investment, the appraisal would at all times have to be the value of the physical properties plus the amortization fund.

The difference between the value of the tangible property and the invested capital might, perhaps, according to this interpretation of the language used by the Court, be a proper measure of the intangible values; but, if thus measured, they serve merely as an excuse for bringing the valuation up to the investment, and, in that event, the amortization increment must be based on the full expectancy of the plant. In applying such a principle, account must be taken of the gradually decreasing value of the tangible elements. The steamboat in the last year of its life would be valued at $7 \%$, and the intangible values appurtenant to the steamboat business would aggregate 93 per cent. No one would pay more than $7 \%$ for the boat, yet, as has been demonstrated, the rates may properly be based on a valuation of the steamboat business at 100 per cent.

This, of course, is an extreme case, but it illustrates the principle. Perhaps no Court has ever been asked to allow so large a proportion of intangible value. Yet the principle remains the same, whether at 5 years the intangible value is $18 \%$ of the entire appraisal, or whether at 19 years it is $93 \%$ thereof. This undesirable feature should condemn the use of intangible values to bring the appraisal up to the actual investment.

It will be much better to use the equivalent and uniformly applicable method of determining by the best available means what amount of capital is properly and reasonably invested. The attempt to draw sharply the line which separates the tangible from the intangible value should be discouraged.

If it were customary to maintain the amortization fund, perhaps by investment in outside securities, as an integral and inseparable part of the property, growing as depreciation increases and subject to transfer with the property as a part thereof, in case of a sale, then the fundamental principle, already fully explained, that the appraisal at all times should be at $100 \%$ of the investment, would be readily understood. It would then be clear that the earnings of the amortization fund would go into the property for replacement purposes, and that at all times the owner would be entitled, in addition to such earnings, to a proper rate of return on $100 \%$ of the investment, that is 
to say, on the value remaining in the physical property plus the amortization fund.

The Supreme Court distinctly lays down the principle that, as a general rule, increase in value should go to the owner of a property. This is a confirmation of the views previously set forth. First, that; strictly speaking, the increase should be treated as reinvested earnings; second, that, under the difficulty which will always exist of predicting from past experience what the future may bring, it will rarely be possible to estimate the future increment of earnings due to appreciation with sufficient certainty to take it into account in estimating the prospective surplus or revenue over expense, and, whenever this cannot be done, such increase of value will, in fact, go, as the Supreme Court says it should, to the owner; but, when, as an exception to the rule, which exception is pointed out by the Court, the property has increased enormously in value, then the fairness of taking account of the increase as a part of the earnings becomes apparent.

The foregoing is based throughout on the assumption that the ordinary rate of interest on safe investments is alone taken into account, and that any addition to this rate will be made as a direct addition to the earnings computed at this ordinary rate. The addition: may be expressed either in percentage of the original investment, or in percentage of the remaining investment, or true value, as ordinarily understood and as defined by the U. S. Supreme Court in the Knoxville case. The latter may be found desirable, when, as should ordinarily be the case, the amortization has been earned from the beginning, but, for this purpose alone, a close estimate of actual value is not essential.

The results presented in Table 8 are made the basis of the curves shown in Fig. 3. Particular attention is asked to the lines marked No. 1 and No. 3. The sum of the ordinates of the two No. 3 lines, representing "interest" and "amortization," is always the same, and agrees throughout with the sum of the ordinates of the horizontal "interest" and "amortization" lines for No. 1. The diagram indicates plainly the extent of the departure of the other methods of calculation from the correct ones.

Method No. 1, according to which the appraisal for rate-fixing purposes is the investment without any reduction for depreciation, has certain advantages over Methods Nos. 3 and 4; the only other 


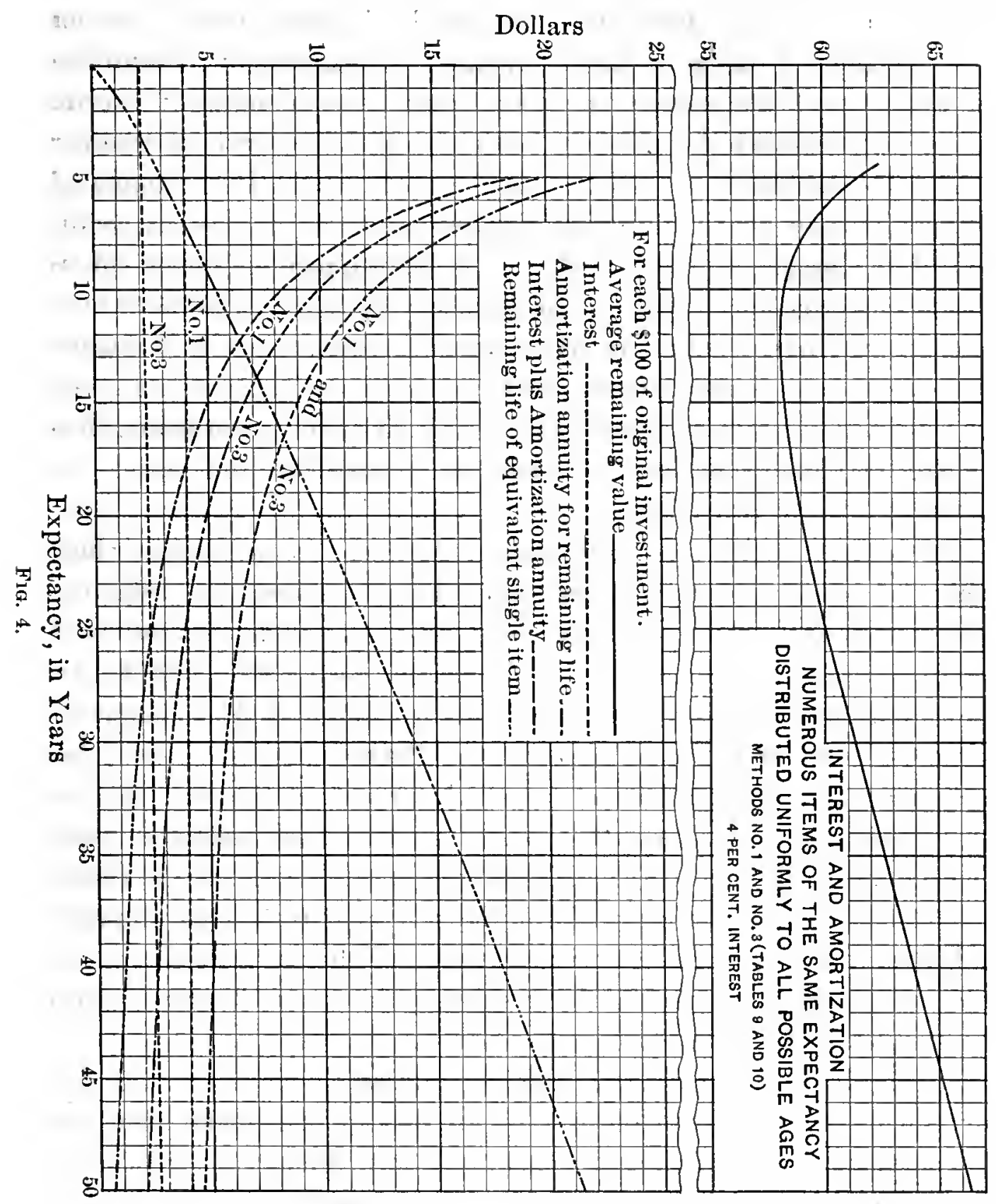


strictly correct methods of calculating allowable earnings, which may be briefly stated as follows:

Method No. 1 is always applicable when it can be shown that earnings have been adequate in the past, no matter whether the property is a single item, or is composed of many items; whether the expectancy is-long or short; whether the expectancy is uniform for all parts of the property or not; whether the plant is of mature age or not; whether the property has attained full growth or whether it is still growing at a uniform rate; or otherwise. It is simple of application, and-does not involve determination of the present condition of the property, provided that it is maintained in proper condition to render adequate service. It furnishes all the information necessary for intelligent action in fixing rates, because when it is known what the net earnings, above operating expenses, must be to yield the return which money should earn in ordinary safe investments, then an arbitrary addition can be made, to compensate the owner for management and risk of loss.

In contrast with these advantages, Method No. 3, under which "value" as ordinarily understood must be determined by deducting depreciation from the investment, requires a special determination of value for each item of which the property is composed, and a new determination every year for every item, or in special cases, for every group of items of the same expectancy. Each item has a new value each year and a remaining life which grows continually shorter. Amortization, therefore, must be estimated on a new basis each year. The judgment of the expert is called into play to determine the condition and probable remaining life of the several parts of the property, and after the complex calculation is made, if the same basic rate of interest is used throughout, the result should agree absolutely with the simpler Method No. 1.

When, for any reason, the rate of interest to be earned on the investment is higher than the rate of interest applied to the amortization annuity (in estimating depreciation) then, under Method No. 3, the net earnings will follow a descending scale. The rates to be charged, full compensation being assumed, will be higher in the early years of a plant's life than in its last years. This is an undesirable feature, resulting from the application of Method No. 3. It is avoided under Method No. 1. Herein is found an additional reason for the 
general adoption of the method of appraisal for rate-fixing purposes under which no deduction from the invested capital need be made for depreciation.

An advantage that may properly be claimed for Method No. 3 lies in this, that it discloses, more or less approximately, the part of the capital remaining in the property, and therefore, actual value of its tangible elements as such value would be estimated by a purchaser.

Method No. 4 not only has the same disadvantages as No. 3, but it is not acceptable, as has been explained, owing to the decrease of the earnings with increasing age of the plant. Its results do not, as do those of No. 3, agree from year to year with those of Method No. 1.

No. 5 is a method of approximation which is applicable whenever a plant, made up of numerous parts, has mature age, and it can be shown that in the past the earnings have been inadequate to supply an amortization fund, in excess of replacement requirement, which fund approximates $40 \%$ of the total investment in perishable properties; and when no part of the invested capital has been otherwise returned to the owner.

When the practice shall have been established of writing off nothing from the investment for depreciation, there will be a modification of the ordinary system of keeping accounts. It will then be desirable to open an "amortization and replacement account," which will be debited with the amount of the amortization actually earned, and there will be credited against it every item of replacement. The discarded items will be credited to the account of "invested capital" at their cost, and this account will be debited with the cost of the new items which replace the old.

It will be practical, too, to combine the replacement and the repair accounts whenever for any reason this may appear desirable. The depreciated value, according to the book accounts, under such a system, can at any time be found by subtracting the amount in the amortization fund from the invested capital. 


\section{SCUSSION}

Mr. William Brokaw Bamford, M. Am. Soc. C. E. (by letter).-It is Bamford. axiomatic, for the correct application of the principle set forth by the author, or for the equitable appraisal or valuation of any property, that the "expectancy" or probable life of the property be determined within reasonable limits. The writer is contemplating the presentation of a paper on the probable life or endurance of property, and, for the purpose of this discussion, will point out only certain general principles.

The "expectancy" or "actual life" of any property or individual can only be determined by summarizing the probable "endurance" of the various elements which may affect in any way the "actual life." For a property, as for an individual, the result at best is but an approximation. Nevertheless, it is possible to tabulate facts obtained over a series of years so that tables of the probable life of a property can be prepared.with as reasonable a degree of accuracy as those which determine the probable life of the individual.

Until methods for properly forecasting the actual life of property are put on as stable a basis as the preparation of mortality tables for human life, we will have difficulty in adjusting equitably and scientifically, the various financial questions connected with public service as well as private property.

For the purpose of clearness in discussing the subject, the writer has preferred to devise and use the term "endurance" rather than "actual life," "expectancy," or "depreciation."

The "endurance" of a property may be said to be its power and ability to prolong its life or existence against the adverse forces or influences of any kind which threaten it. It is its power to remain in the same state without perishing. The endurance may be considered as being ultimately established by the "actual life" of the property.

It is indisputable that if a property has no endurance it cannot last, and that its endurance is due to various factors which tend to prolong or shorten its life. The elements which influence the endurance of a property might be divided into the physical causes which threaten its existence as a structure (depreciation or deterioration) and the various economic or commercial causes which threaten its life as a property (obsolescence). In addition, there are certain hazards which threaten its life, which might be summarized as follows:

(A). Physical Endurance of Property (depreciation or deterioration)-threatened by:

(1) stability of structure; 
(2) physical deterioration;

(a) in materials composing structure,

(b) in methods of construction.

(B). Economic or Commercial Endurance of Property (obsolescence)-threatened by:

(1) obsolescence due to improvements in machinery, processes, etc.;

(2) obsolescence due to lack of serviceability for use;

(3) obsolescence due to changed industrial and social conditions;

(4) actual cost too excessive for present value.

(C). Hazards to Endurance of Property:

(1) destruction by fire;

(2) destruction by act of God-earthquake, cyclone, flood, etc.;

(3) destruction by domestic violence or foreign wars.

Thus it will be seen that "endurance" or actual life is threatened and controlled by elements composing the three divisions of $(A)$ physical endurance, $(B)$ economic endurance, and $(C)$ hazards. The actual life, therefore, will be terminated by the element which has the least amount of "endurance." In a rapidly growing community and progressive age, economic endurance is usually shorter than physical endurance. In the present age evidences of this are seen on every hand, obsolescence terminating the actual life of property the physical endurance of which may still be of "indeterminable duration."

All questions of depreciation, as usually considered at the present time, should be resolved into attempts to establish a standard for the endurance or actual life of the property. In the majority of engineering investigations of the endurance of property, however, the primary efforts, are directed toward solving the endurance of the physical or structural elements, to the neglect or subordination of the economic or commercial elements and hazards.

Neither the physical nor the economic endurance can be considered alone in determining the actual life of property; both must be determined, together with the hazards, and that one having the least endurance will be the one to govern the case in question. The probable physical life is no guide to the probable economic life; while the actual economic life is a positive check to the actual-not the potential-physical life.

It is true, of course, that the probable economic life is more difficult to determine accurately in advance than the probable physical life; but, as with all forms of insurance, it is possible to apply the law of averages so that the resultant will be equitable to the public service companies as well as to the public. 
Mr.

In its practical application it would be advisable. to have a State commission to establish uniform standards for the determination of probable economic life and "endurance," which should be subject to periodic adjustments. Such a procedure is not novel, as the English Local Government Board has undertaken just such a work in establisbing periods for the redemption of authorized bonds for local improvements.*

Without the possibility of establishing the "expectancy", or "endurance" of property equitably, the very admirable methods proposed by the author will prove valueless. It is hoped that in the future more attention will be given to "endurance," rather than to concentrating efforts solely on physical "depreciation."

Mr. James $\nabla$. Охтову, EsQ. (by letter).-The writer has read this Oxtoby. paper with interest, and wishes to express his appreciation of the work which Mr. Grunsky has done toward making clearer the facts regarding the element of depreciation in making appraisals of public utility properties.

It is conceded that an owner of a public utility is entitled to earn a reasonable return on his investment. He must also receive from the business, on its being wound up, or on its sale, an amount equal to the principal of his investment. If depreciation of plant is provided for on a sinking-fund basis, the interest which the depreciation fund earns is part and parcel of that fund, which must be added to it annually in order to bring it up to the required amcunt at the end of the depreciation period. Otherwise, the fund becomes at once impaired. The annual amount paid into the sinking fund by the business is smaller than it otherwise would be, because it is expected that the earnings of the fund will be added to it; and that, by compounding the interest yearly, the fund, at a predetermined date, will equal the amount of the depreciation. If the owner uses any part of this fund, whether principal or interest, he is really using part of the principal of his investment.

In appraising a plant for rate-making purposes, " $j$ ts value is its reproduction value, and not its reproduction value less depreciation. The entire depreciation must be earned from the public. If the sinking-fund method is used in computing the amount of the yearly depreciation, it is apparent that the fund must exist and must be made to earn its own increment. Some students of this question have stated that the depreciation fund has already been earned from the public, and that including the depreciation fund in the valuation would be requiring the public to pay dividends on moneys already paid in by it This is not true where the sinking-fund method is used. By that method the public is asked to pay, not the full amount of the yearly

\footnotetext{
* Engineering News, Vol. 54, p. 462.
} 
depreciation, but only a part thereof, the compound interest earned on what the public has so paid making up the deficiency.

$\mathrm{Mr}$

This confusion of ideas seems to result from the failure to distinguish between the repayment and, withdrawal of investment from year to year, and the establishment of a sinking fund which does not mature until some date in the future. In the first case the investor has got back his money and can apply it to other uses. In the second case his money is withheld from him, being locked up in the sinking fund; and he is not only unable to apply it to other uses, but must see to its being invested in absolutely safe securities not affected by depreciation, in order that at maturity the fund may be adequate to meet the liability for which it was provided.

A similar confusion of ideas affects many students when they are called on to state a fair price for a utility expropriated as a going concern. They err in stating the price as reproduction less depreciation, the vendor to retain the depreciation fund. In practice the depreciation fund is locked in securities which may or may not be then marketable for their assumed value. The law authorizing expropriation should impose on the purchaser the burden of marketing these securities promptly, or of purchasing them himself. Otherwise, the investment made by the vendor is not fully released. In this the writer intentionally omits reference to the equitable requirement of a higher price in expropriation proceedings than in rate-making proceedings.

Assume an investment of $\$ 25000$ made in a plant, which, at the end of twenty years, will have a depreciated or junk value of $\$ 5000$. Assume $6 \%$ as fair return on the plant investment and, for convenient figuring, assume that it is possible to invest a sinking fund in safe securities paying 6 per cent. Table 12 is based on these assumptions, and on the further assumption that the sinking-fund method of calculating depreciation is correct.

From the foregoing it is evident that if the owner is required to accept as profit less than $\$ 1500$ yearly, he has been deprived of a reasonable return on his $\$ 25000$ investment.

A plant probably could not continue to operate usefully without replacement before the end of the depreciation period, but this illustration, taken with the many which Mr. Grunsky has furnished, demonstrates the principle that if the annual depreciation is computed on a sinking-fund basis, it is inequitable to use depreciated value alone as the basis for the reasonable return to which the owner is entitled.

If the depreciation is computed on the straight-line basis, the interest which the depreciation fund earns is really an earning. If depreciation thus computed is paid to and withdrawn by the owner, he is entitled to earn his fair return only on the remaining value. 
Mr. The owner of a public utility; however, is bound to keep up the plant oxtoby. to a high degree of efficiency and must rehabilitate it when necessary, which practically precludes withdrawal.

\section{TABLE 12.}

\begin{tabular}{|c|c|c|c|c|c|}
\hline Year. & $\begin{array}{l}\text { Value of } \\
\text { plant at end of } \\
\text { year, by } \\
\text { assumption. }\end{array}$ & $\begin{array}{c}\text { Return of } 6 \% \\
\text { on } \\
\$ 25000 .\end{array}$ & $\begin{array}{l}\text { Annual } \\
\text { depreciation } \\
\text { sinking fund, } \\
6 \% \text { basis. }\end{array}$ & $\begin{array}{l}\text { Interest on } \\
\text { fund at } 6 \%\end{array}$ & $\begin{array}{l}\text { Total } \\
\text { depreciation } \\
\text { fund at } \\
\text { end of year. }\end{array}$ \\
\hline $\begin{array}{r}0 \\
1 \\
2 \\
3 \\
4 \\
5 \\
6 \\
7 \\
8 \\
9 \\
10 \\
11 \\
12 \\
13 \\
14 \\
15 \\
16 \\
17 \\
18 \\
19 \\
20\end{array}$ & $\begin{array}{rl} & \\
\$ 25 & 000.00 \\
24 & 456.31 \\
23 & 880.00 \\
23 & 269.11 \\
22 & 621.58 \\
21 & 935.22 \\
21 & 207.60 \\
20 & 436.37 \\
19 & 618.82 \\
18 & 752.46 \\
16 & 834.16 \\
16 & 860.5 \% \\
15 & 828.46 \\
14 & 734.48 \\
13 & 574.86 \\
12 & 345.07 \\
11 & 042.09 \\
9 & 660.93 \\
8 & 196.90 \\
6 & 645.02 \\
5 & 000.00\end{array}$ & $\begin{array}{cc}\$ 1 & 500.00 \\
1 & 500.00 \\
1 & 500.00 \\
1 & 500.00 \\
1 & 500.00 \\
1 & 500.00 \\
1 & 500.00 \\
1 & 500.00 \\
1 & 500.00 \\
1 & 500.00 \\
1 & 500.00 \\
1 & 500.00 \\
1 & 500.00 \\
1 & 500.00 \\
1 & 500.00 \\
1 & 500.00 \\
1 & 500.00 \\
1 & 500.00 \\
1 & 500.00 \\
1 & 500.00\end{array}$ & \begin{tabular}{|r|} 
\\
$\$ 543.69$ \\
543.69 \\
$\mathbf{5 4 3 . 6 9}$ \\
$\mathbf{5 4 3 . 6 9}$ \\
$\mathbf{5 4 3 . 6 9}$ \\
$\mathbf{5 4 3 . 6 9}$ \\
$\mathbf{5 4 3 . 6 9}$ \\
$\mathbf{5 4 3 . 6 9}$ \\
$\mathbf{5 4 3 . 6 9}$ \\
$\mathbf{5 4 3 . 6 9}$ \\
$\mathbf{5 4 3 . 6 9}$ \\
$\mathbf{5 4 3 . 6 9}$ \\
$\mathbf{5 4 3 . 6 9}$ \\
$\mathbf{5 4 3 . 6 9}$ \\
$\mathbf{5 4 3 . 6 9}$ \\
$\mathbf{5 4 3 . 6 9}$ \\
$\mathbf{5 4 3 . 6 9}$ \\
$\mathbf{5 1 3 . 6 9}$ \\
$\mathbf{5 4 3 . 6 9}$ \\
$\mathbf{5 4 3 . 6 9}$
\end{tabular} & $\begin{aligned} \ldots \ldots \\
\ldots 32.68 \\
67.20 \\
103.85 \\
142.70 \\
183.88 \\
227.54 \\
263.81 \\
322.86 \\
374.85 \\
429.95 \\
488.37 \\
550.29 \\
615.93 \\
685.50 \\
759.89 \\
837.47 \\
920.34 \\
1008.19 \\
1101.33\end{aligned}$ & $\begin{array}{rl}\$ 543.69 \\
1 & 120.00 \\
1 & 730.89 \\
2 & 378.42 \\
3 & 064.78 \\
3 & 792.40 \\
1 & 563.63 \\
5 & 381.12 \\
6 & 247.54 \\
7 & 165.81 \\
8 & 139.48 \\
9 & 171.54 \\
10 & 265.52 \\
11 & 425.14 \\
12 & 654.93 \\
13 & 957.91 \\
15 & 339.07 \\
16 & 803.10 \\
18 & 354.98 \\
20 & 000.00\end{array}$ \\
\hline
\end{tabular}

Mr. Grunsky demonstrates that if the depreciation fund is used for replacements, which themselves at once commence to depreciate, the sinking-fund method is impracticable. The fact is that depreciation is not an exact quantity, but must be determined by the exercise of fair judgment. Its amount at any time is the difference between actual investment and present value. It is highly improbable that, during a series of years, the actual depreciation of a plant will coincide with the accumulation of money by a sinking-fund rule. A public service plant should be maintained from its earnings so that its present value will always equal its original cost. If not, the difference should be in a depreciation fund, by whatever method it is computed; and a fair return should be computed on the total value which serves the public, whether this value is in plant or in depreciation reserve. Real earnings by the depreciation reserve are a part: of the earnings of the plant. The increment, however, of a fund which is accumulating on a sinking-fund basis is not an earning.

In this discussion the writer has, in general, merely stated in his own way ideas which appear in the paper. His appreciation of the argument contained therein has been his excuse for doing so..

Mr. Charles H. Higgins, M. Am. Soc. C. E.-This paper should receive Higgins, the careful attention of the members of this Society, for it deals with matters far more fundamental than a reading of the title or introduc- 
tion might lead one to belicve. In fact, nowhere has the speaker $\mathrm{Mr}$. found the main issue stated clearly, but a student of these matters Higgins. cannot read this paper carefully without finding the author constantly returning to this undefined issue. Whether it be veiled purposely or merely clouded because not clearly seen by the author, it cannot escape being the point of such overwhelming importance in this paper as to challenge attention.

On page 773 occurs the following sentence:

"Perhaps the use of the term, 'value,' in this connection is unfortunate, because it is not clear why 'value,' as ordinarily defined (which is not always synonymous with capital reasonably and properly invested), should be made the criterion of allowable earnings."

And, again, on page 820 :

“* * * and to the ruling of the Courts, which hold that owners of public service properties are entitled to a fair return on the 'value' of such properties.

"If it be found that the ruling of the Courts is not subject to modification, or, in other words, that appraisals must be 'value,' as 'value' would be determined by a purchaser, that is to say, for the tangible elements: in most cases, cost or - cost of replacement less depreciation, or something practicallv equivalent thereto, * * *."

In these lines the real meat of the matter may be found, the author taking issue with the decisions of the United States Supreme Court.

Stripped of all verbiage, this paper deals then, not with the methods of making appraisals of public service properties under the existing law as interpreted by the Supreme Court, but with what, in Mr. Grunsky's opinion, the law should be. The latter may well be an equally proper matter for discussion before this Society, but it is certainly very different from the former.

To present this matter clearly, the speaker will illustrate. As early as 1898, in the leading case of Smyth $v$. Ames,* in the Nebraska maximum rates cases, the Supreme Court laid down the principle that the basis of all calculations, as to the reasonableness of rates, must be the fair value of the property used, and specified certain matters to be taken into consideration in ascertaining the fair value: the original cost of construction, the amount expended in permanent improvements, the amount of market value of the bonds and stock, the present, as compared with the original, cost of construction, the probable earning capacity of the property under the particular rates prescribed, and the sum required to meet operating expenses; all to be given such weight as would be just and right in each case. Justice Harlan was careful to add: "We do not say that there may not be other matters to be regarded in estimating the value of the property." 
The following year, in the case of the San Diego: Land Company Higgins. $v$. National City, ${ }^{*}$ the Court held "what the Company is entitled to demand in order that it may have just.compensation is a fair return upon the reasonable value of the property at the time it is being used for the public." The Supreme Court, then, as early as 1899, had adopted present value as the standard, leaving undetermined how a reasonable value is to be ascertained and what constituted a fair return.

Again, in 1903, in San Diego Land and Town Company v. Jasper, $\dagger$ the Court said:

"It no longer is open to dispute under the Constitution that what the Company is entitled to demand, in order that it may have just compensation, is a fair return upon the reasonable value of the property at the time it is being used for the public.".

In a masterly review of the subject of regulation of railway rates, Judge Swayze, of the Supreme Court of New Jersey, says:

"Novel questions of this character will arise with increasing frequency, and require the most careful consideration. Like most other questions. in every department of law, they are in their origin rather questions of fact than questions of law, although in course of time the rules become settled and thus become rules of law... In their origin and as zet many are questions, of sound business management and engineering science. The law prescribes reasonable return upon a reasonable valuation. What is a reasonable return and what is a reasonable valuation must vary with the circumstances of each particular case." $\ddagger$

It may be accepted then as an established rule that the appraisal of a public service property to be used in fixing rates should show the fair value of the property.

Now, Mr. Grunsky argues that for the fair "value" of the Supreme Court there should be substituted something which he calls "capital properly and reasonably invested," stating, as a fundamental principle, that:

"The valuation of a public service property and its earnings must bear such relation to each other that there will be returned to the owner, within the life of the property, the capital which he has properly invested in it, and in addition thereto, interest at a reasonable rate, upon such amount of capital as from time to time actually and properly remains in the property as an investment."

In this Mr. Grunsky takes issue with the Fourteenth Amendment as interpreted by the Supreme Court since 1898.

The author's "fundamental principle" quoted above, if applied, as

* 174 U. S., 739 .

+189 U. S., 439.

† Quarterly Journal of Economics, May, 1912 
outlined in the paper, would cut both ways. In determining what is termed "capital reasonably and properly invested" according to the author's plan, earnings and dividends, or interest, are considered apparently from the beginning, and, if these dividends have been less than what is determined as a reasonable rate of return, the difference is considered as remaining in the property as invested capital. On the other hand, in the case of past earnings above the determined rate, Mr. Grunsky speaks as follows: "It is possible, of course, in the case of large earnings in the past, that a portion thereof should be considered as capital returned to the owner." In other words, the author would appear to propose, not only the determining by a State of a reasonable rate for the present and future, but actually to make it retroactive.

Mr. Grunsky seems inclined to treat all investors as if they were owners of State bonds. For a lucid explanation of the relative positions of the holders of different classes of securities and their relation to the public, nothing better in its way can be found than the Report of the Railroad Securities Commission, of which President Hadley, of Yale University, was Chairman.

To the speaker's mind, the Courts, in fixing on fair valuation as the basis for all calculations, have taken the only position economically sound.

The speaker accepts the conclusion of Judge Swayze already quoted: "The law prescribes reasonable return upon a reasonable valuation. What is a reasonable return and what is a reasonable valuation must vary with the circumstances of each particular case." This states clearly the proposition before an engineer making an appraisal or valuation for use in the fixing of rates under the law as it exists to-day, and there are enough technical difficulties yet to be settled by engineers. The broader question dealt with in this paper is very interesting, but should not be confused with methods under the law as established.

Henry Floy, M. Am. Soc. C. E.-The speaker cannot agree with Mr. the views expressed by Mr. Higgins. Mr. Grunsky has brought out quite clearly a very important question, which must still be fought out and decided by the Supreme Court, and that is, the basis of "fair value." The various opinions rendered by the Supreme Court have not yet fairly and squarely determined the question as to whether or not "fair value" shall be taken as that derived from a consideration of accruing, theoretical depreciation, or something in addition to such value. The speaker is inclined to agree with the author that the investor is entitled to a return on his investment, or the cost of reproduction, if his property is kept in good operating condition. Present value accurately 
Mr. obtained from a consideration of accruing; depreciation must vary from

Floy. day to day, thus forming a fluctuating and impractical value on which to base rates or capitalization. Such fluctuating value is too unstable and unfair ultimately to be received and accepted for fair value, as the author has brought out.

It is very difficult, even for lawyers, to interpret the decisions of the Court, and surely it is much more difficult for engineers to ascertain exactly what these decisions of the Supreme Court which have been referred to-the Consolidated Gas case and the Knoxville Water case-mean in the last analysis. It would seem as if; by these decisions, the Court intended to convey the idea that something more than a theoretically depreciated value should be made the basis on which a return is to be allowed.

It is possible that, if "the recall" is established, some new decisions may be expected; yet, at the present time, we may feel confident that the Courts, regardless of how excessive the returns have been in the past, would maintain the position that present and future returns will be based on the fair value of the property. The Courts will not attempt to reduce earnings in the present below the fair return on the fair value of the property, even though the owner for some years previously has been earning more than a fair return.

A return of $4 \%$ has been mentioned in the discussion, but the Supreme Court has never yet named anything less than.6\%, and that for conditions such as exist for a monopoly in New York City. Of course, a fair return for any particular property depends on that property, and one like the Consolidated Gas Company in. New York City - a monopoly in the greatest city in America-is not running as much risk in the way of securing a return as.some. other property in a small town in the West, and the Courts and Commissions have recog: nized this fact. The Commission of New York City, for example, has in certain decisions explicitly stated that certain gas and electric corporations were entitled to a return of $7 \frac{1}{2}$ or $8 \%$ on the total value of their properties. This means that the stockholder may obtain a very much higher rate of interest for his holdings, while the bondholders, who have a prior lien on the property, are willing to accept a 4, 5, or $6 \%$ return for their share of the investmeit.

In the matter of valuing real estate, the Courts have quite generally held that, in determining present value, the owner is entitled to appreciation, and this theory was distinctly enunciated in the Consolidated Gas case, where the U. S. Circuit. Court approvingly quotes the language of the Supreme Court in another case to the effect that "the value of the property at the time it is being used" should be taken.

It must be recognized that fair values may be different for different 
purposes. The property of a corporation which is to be assessed for Mr. the purpose of special franchise tax in New York City, for example, ${ }^{\text {Floy. }}$ would have a different value from that computed for other purposes, because a franchise tax relates only to the property in the street, which may be a relatively small part of the total property of the corporation. The value of property for rate-making purposes, in a similar way, may not be the same as that for capitalization, because a part of the property may be held simply as an investment or in connection with an allied business, so that the value for rate-fixing purposes, in such case, would be quite different from the value proper for capitalization. These questions of "fair value" are of comparatively recent origin, and are by no means easy of solution. Until a few years ago, no one appreciated or considered the fact that the operation of public utility property was a matter of much public concern. Public utilities were given grants and encouraged to make investments with the expectation of large returns, certainly 8 or $10 \%$, possibly 15 or $20 \%$; but lately, as the corporations have developed and become in many instances monopolies, either through crushing out competition or buying up their competitors, the public has been compelled to deal with the situation on a basis radically different from that formerly allowed. This has resulted in the development of what may be called a theory, which we are attempting to make a science, with regard to the control and operation of public utility properties, so that the situation is quite different from anything that existed fifteen or twenty years ago. To-day we look upon a public utility corporation as entitled to special privileges, such as the use of public streets, the right of condemnation, permission to exist perhaps as a monopoly, in return for which, in view of some assurance of reasonable profit, we limit the return on the value of the property to a fair amount, which, while greater than that 'received from a Government bond or municipal security, is nevertheless smaller than would be judged reasonable for an industrial concern, where the risks are greater. In brief, the peculiar conditions surrounding any specific corporation must be considered both in fixing the fair value of the property and fair return thereon.

J. Martin Schreiber, M. Am. Soc. C. E.-The author has presented a remarkable analysis, and has approached the subject in a liberal manner, which is certainly required for a rate investigation, if a sound conclusion is to be expected.

The greatest difficulty is in the practical application of the principles which have been set forth. In discussing the paper by Mr. Riggs, ${ }^{*}$ the speaker brought up the question of fair values in relation to present physical values. Also, in a recent investigation of the depreciation of certain elements of physical property, he interviewed

* Transactions, Am. Soc. C. E., Vol. LXXII, p. 1. 
Mr. leading specialists eminently fitted to give the information desired. schreiber. Some of these men replied that they would not even attempt to designate the correct life, if changes in the art were to be considered; and, of course, an estimate of the life of property without the consideration of obsolescence would be valueless. To take a practical case: It is reported* that, in the recent valuation of the Elevated Railroads of Chicago, the value, exclusive of roadway and overhead charges, submitted by the Chicago Harbor and Subway Commission; was $\$ 26354217$; the appraisement by the A. L. Dunn Company was $\$ 40750892$, and the valuation by George F. Swain, M. Am. Soc. C. E.; was $\$ 34634396$. Now, it does not appear to be fair to the stockholders to be asked to abide by any method showing such variations. It should be admitted that a fair valuation, representing moneys properly invested for property which has been built up by the piecemeal method, with equipment constantly changing on account of the development of the art, along with unreliable book records, with their varying accounting methods, is a very difficult proposition. This is especially true when one must take into consideration the vague item of overhead charges; thus far, that item has generally been determined by setting apart an arbitrary percentage. For this reason the speaker is of the opinion that a valuation, particularly of old properties, for rate purposes based on earning power, is more reliable than the method which takes the values of actual physical properties as the governing data. Also, the value for rate making should not, necessarily, be ascertained by the same plan as the value for taxes: or bonds.

Assuming that a fair valuation is known, another very pertinent practical question is: "What is to be allowed to the stockholder?"- The speaker believes that the general tendency is to place too low a limit on proper earnings. One should not expect to raise money to finance projects which carry with them a large element of risk at savings account dividends, even if the utility appears to be reasonably safe. The investor knows full well that there are still such contingencies as strikes, earthquakes, floods, and lean years, and that it is absolutely impossible to anticipate these conditions; besides, if one expects the country to develop, one must also encourage the honest man with the brains and energy.

Mir. William J. Boucher, Assoc. M. Am. Soc. C. E.-During a part Boucher of 1911, the speaker had certain work in connection with an appraisal of the lines of the Illinois Central Railroad in Illinois. The values given to the right of way in Chicago, from Randolph to 12th Streets, presented some interesting phases.

When the road was constructed, about 1853 , this section was built on piles and over the waters of Lake Michigan, to a terminal at Randolph Street. This space has since been filled in; the width of the

*Electric Railway Journal, May. 18th, 1912, p. 829. 
right of way varies from 100 to $400 \mathrm{ft}$., is depressed some $12 \mathrm{ft}$. below the general level, and is contained between retaining walls, beyond which, on the east and west sides, lies Grant Park: The railroad occupies a most unique and valuable grant for about 7 miles south from Randolph Street, lying, as it does, along the shore of the Lake, giving space for eight running tracks, a roundhouse and car-cleaning and storage yards. It is a popular notion, which the speaker cannot verify, that the land cost the railroad company nothing, but was granted as an inducement to enter the city.

The westerly edge of the right of way through Grant Park is 500 $\mathrm{ft}$. or more from the property line of Michigan Avenue, the nearest property which is ever for sale and has a definite, taxable value. The Company, in its appraisal, placed a square-foot value (seemingly very high) on all the right of way, in addition to improvement values, such as filling, which the Company had done, beginning at Randolph Street and increasing toward the south until it reached a maximum opposite Jackson Boulevard, where property values along Michigan Avenue are the highest, and then decreasing again until 12th Street was reached.

The question then arises: How were the values arrived at for property: which had probably never cost the railroad company anything, which is located $500 \mathrm{ft}$. from the nearest property for a comparison of values, and which to-day could not be acquired for railroad purposes in any manner or under any circumstances? And, further, is a railroad company justified in placing a value in excess of $\$ 36000000$ on such a property for appraisal purposes?

Another matter regarding railroad finances has often interested the speaker: One frequently sees, in the daily press, announcements of the sale of bonds of various railroads, which read somewhat as follows:

"The A. B. \& C. R. R. is offering for sale $\$ 1000000$ of $4 \%$ bonds, secured by various underlying securities (mentioned). Of this amount, $\$ 500000$ is to be applied to renewals of bridges and rails and $\$ 500000$ for new cars and new locomotives."

The question that arises is this: Is such use of a bond sale proper, if depreciation on rails, bridges, cars, and locomotives has been charged off? Why not use the funds from such depreciation account? Why is it proper or necessary to issue bonds for these ordinary renewals, which in the usual course of events must be taken care of, and must be expected? It has always seemed to the speaker to be improper. Where is it going to lead the corporation, and where will it end, to keep adding to the capital account and paying interest on worn-out and scrapped material?

R. D. Coombs, M. AM. Soc. C. E.-In a hypothetical ease, such as a corporation having paid for a number of years a very high dividend

Mr. Boucher. 
Mr. rate, should those dividends be deducted from the capital before fixing Coombs. the amount on which they could properly be paid?

To consider an exaggerated case, suppose some corporation had been paying about $50 \%$ dividends for four or five years; if the Court decides that the corporation can charge only such a rate as will enable it to pay a fair percentage on present value, must those $50 \%$ dividends for four or five years be deducted?

Mr.

A. H. Van Cleve, M. Am. Soc. C. E.-Mr. Grunsky has undoubtVan Clere. edly rendered a great service to the Engineering Profession in setting forth so clearly the methods to be used in the appraisal of public service property for rate-making purposes. While there are marked differences of opinion as to the methods which should be used in such cases, the author's examples and tabulations illustrate so completely the principles which he advocates that his results and the methods of reasoning which lead up to them are entirely clear. His statement of fundamental principles is especially valuable, but the speaker begs to differ with him in respect to Principle No. 18 as applied in a water-power development the output of which is used for supplying electrical current to the public. That principle is stated as follows:

"Intangible values should be disregarded, in making appraisals for rate-fixing purposes, excepting only when the rate of net return is deliberately fixed at or too near the rate earned by ordinary safe investments, in which case an arbitrary addition to the appraisal, under whatever name, should be made. The interest on this item of the appraisal will be the reward of the owner for management and for any hazard which the business may involve."

In the case of a water-power development, the value of the water right, which is an intangible value, is one of the most important items to be considered in determining the value of the plant, not only for purposes of sale, but for the determination of the rates which may be properly charged by the owners of that plant for the service which they render; and the consideration of this item is essential, regardless of the question of the rate earned by ordinary safe investments. To neglect the value of a water right would work a grave injustice to its owner, for, in many cases, if only the tangible values of the several parts of the plant are considered by the rate-making body, and the returns to the owner are estimated at an ordinary rate of interest thereon, together with due allowance for amortization and all other items which may properly be included, it would result in compelling him to furnish service to the public at a rate far below that for which the same service could be furnished by a plant producing the same power from any source other than water.

It is true that the author, in Principle No. 17, states: "Proper investments for franchises, for water rights, and the like, are always to be included in the appraisal." It is frequently the case, however, that, although no investment has been made directly for the acquisition 
of the water right, the value, nevertheless, exists, and should always be considered in a valuation. The correctness of this principle may perhaps be most clearly demonstrated by an example:

Let it be assumed that $\mathrm{A}$ is the owner in fee simple of lands lying between two streams, the water in one of which is at a material elevation above that in the other; that this property has been in his possession for many years, and that the price paid for the land was the fair and reasonable value of it for farm purposes; that $\mathrm{A}$ as a riparian owner has the right to withdraw water from the upper stream and discharge it into the lower stream; and that he lias complied fully with all the legal requirements necessary for this purpose. $\mathrm{A}$ is then the possessor of a water right for which no expenditure has been made by him. Let it be assumed, further, that in a city located within reasonable transmission distance there is a market for the electrical current which can be produced by the water which may be withdrawn from the upper stream adjoining A's property and discharged into the lower stream, and that A determines to grasp the opportunity to make use of a water right which, before the advances in the art of transmission, was practically valueless, owing to the lack of any market in the immediate vicinity of his property. Having obtained the necessary franchise in that city, in due course he enters into contract for the sale of this power to the municipality and to the citizens thereof, and the plant which he has built, therefore, becomes a public service property. In the course of time a rate-making body is called on to decide as to the fair and just returns which he shall receive on his investment, and the value of the water right becomes-as it will be shown-by far the most important factor in determining those rates. In order to simplify the illustration, let it be assumed that the just returns are to be determined for power at the city limits after the voltage has been reduced for safe distribution, and thus eliminate from consideration the cost of the distributing plant.

It is found that the plant is capable of developing at all times 25000 e.h.p. at the switch-board, and that the original cost and also the replacement value of the tangible values included in the plant are equivalent to $\$ 40$ per e.h.p., that the corresponding tangible value of the transmission line is $\$ 6$ per e.h.p., and that of the step-up and stepdown transformer station and switch-board apparatus represents an investment of $\$ 14$ per e.h.p., or a total of $\$ 60$ per e.h.p. of actual investment in tangible property. The load factor is found to be $50 \%$, and $13 \%$ the average loss in transmission and transformation. The power available for sale at the city limits, therefore, is 21750 e.h.p., and the average power sold throughout the year is 10875 e.h.p., or $43.5 \%$ of the total installed capacity.

Assuming the average life of the plant to be 20 years, and that $5 \%$ is a fair and reasonable return on the investment, the annual fixed charges and operating expenses per electric horse-power would 
Mr. then be fixed by the body called on to appraise the property for ratemaking purposes about as follows, the figures being based on the investment per electric horse-power:

Interest on $\$ 60$, at $6 \% \ldots \ldots \ldots \ldots \ldots \ldots \ldots . \ldots \ldots$

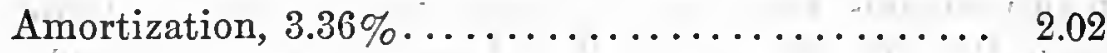

Táxes and insurance, $1 \frac{1}{2} \% \ldots \ldots \ldots \ldots \ldots \ldots . . .60$

Maintenance and repairs................. 1.00

General expenses.................... 0.70

Operation (wages and supplies) ............. 1.00

Total....................... \$9.22

This figure is based on the total capacity of the plant, and is equivalent to $\$ 21.20$ per electric horse-power of the average power sold, or less than one-third of a cent per kilowatt-hour. In other words, if the owner of the property were allowed a fair and reasonable return on his actual investment in tangible property, he would be required to furnish power at the city limits at less than one-third of a cent per kilowatthour, a result which is manifestly absurd. It is evident that, although his actual investment in tangible property may have been determined properly, nevertheless, that investment does not in any sense represent the real value of his holdings, on which the rate of return should be determined, and that this error is due to the omission from consideration of the value of a water right which cost him nothing.

Furthermore, it would certainly seem to be a poor law which would omit from consideration, in an appraisal for rate-making purposes, a value on which the owner is taxed; and the Courts of New York State, in the case of The People ex rel. Niagara Falls H. P. \& M. Co. vs. Smith,* have held that a riparian right is taxable. To deny an owner a return on a value for which ho is taxed, whether that value is tangible or intangible, is a principle which certainly would not hold in law.

The correctness of including the value of a water right in the value of property on which a franchise tax is to be levied has been upheld in the case of The People of the State of New York ex rel. vs. the New York State Tax Commissioners.t This case was carried to the Court of Appeals, and the contention of the State Board of Tax Commissioners was fully upheld. It may be interesting to note that, in this case, not only was the value of the water right given due consideration as affecting the value of the entire plant of the power company, but it was further held that the value of that water right should properly be apportioned to the several parts of the plant in the same ratio as that which the tangible values of those parts held to the

*70 App. Div., 543; 175 N. Y., 469.

+ At an extraordinary term of the Appellate Division, November 22d, 1909, Hon. L. W. Marcus, Justice, presiding. 
tangible value of the entire plant. The principle of including in the value of a water-power plant the value of the water right, therefore, has not only the approval of common sense, but the sanction of the Courts.

Assuming that the value of a water-power is to be considered in the appraisal of a property for rate-making purposes, the question then arises as to the method by which that value shall be determined. If an actual investment has been made for the acquisition of the right, and it is held that the original cost represents a fair and reasonable value thereof, the case is a simple one, and the principle to be applied has been most clearly and ably set forth by Mr. Grunsky; but, on the other hand, if no outlay has been made for the water right; as in the illustration just given, the problem is a complex one, and no doubt there would be a great difference of opinion as to the manner in which the true value should be ascertained.

The speaker ventures to suggest a method which he has used, and believes determines fairly the procedure to be followed. Reverting to the foregoing illustration, first determine, for the sake of comparison, what annual returns a rate-making body would allow the owner of a modern steam plant for the development of the electrical current for which a sale could be effected in the city under consideration, namely, 10875 e.h.p., average use. Let it be assumed that the investment per electric horse-power of rated capacity is $\$ 60$; but, as the total capacity of the plant, for the purpose of comparison with the water-power development, need be only 21750 e.h.p.- - the amount of power which the latter could deliver at the city limits at a suitable voltage- the actual investment per electric horse-power for purposes of comparison should be $\$ 52.30$. It is understood, of course, that, in determining the rate of return which the owner of a steam plant should receive on his investment, the higher value should be used, but, as the comparison is between a steam and a water-driven plant, the lower value will be used in this illustration. As the life of a steam-driven plant will be less than that of the water-driven plant, it will be assumed, for the sake of comparison, that the life of the former is 15 years.

The comparative fixed charges and operating expenses for the steam plant having a capacity equivalent to that of the water-driven plant will be approximately as follows:

Interest on $\$ 52.20$, at $6 \% \ldots \ldots \ldots \ldots \ldots \ldots \ldots 3.13$

Amortization, $5 \% \ldots \ldots \ldots \ldots \ldots \ldots \ldots \ldots . \ldots \ldots . \ldots \ldots$

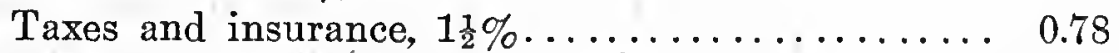

Maintenance and repairs.................. 1.30

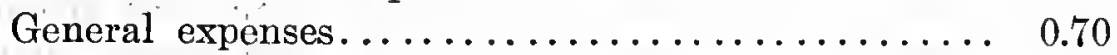

Fuel (coal, $\$ 2.25$ per gross ton) . . . . . . . . . . . 13.13

Wages and supplies.................. 2.00

Total........................\$23.65 
Mr. Van Cleve.

The speaker recognizes the fact that there may be a material difference of opinion as to the amount which should properly be charged to the items of maintenance, fuel, and wages, but it is believed that the foregoing figures are conservative in that they do not exaggerate the operating expenses of a steam plant, under the conditions set forth, as compared with those of a water-driven plant. This is shown further by the fact that the total annual fixed charges and operating expenses per electric horse-power are equivalent to only 0.7 cent per $\mathrm{kw}$-hr. of power development, which is certainly a reasonable figure for a plant of the capacity assumed.

Assuming the correctness of the foregoing illustrations, it: would appear that the annual return which would be :allowed by the rate-making body to the owner of a steam plant would be $\$ 23.65$, while, if the value of the water right be disregarded, the owner of the water-driven plant would be allowed to receive for exactly the same service only $\$ 9.22$, an annual difference of $\$ 14.43$. The unfairness of such a proposition is self-evident. If the owner of the water-power plant is to be allowed to receive a like return for like services, the value of the water right must be determined by capitalizing the difference between the annual yearly expenditures as above set forth, which is $\$ 14.43$. If it has been determined that the reasonable interest on money invested is $6 \%$, a like rate should be used in capitalization. If, however, the value of the water right is to be taxed at $1 \%$, the rate of capitalization to be used should be $7 \%$, on which basis the value of the water right is $\$ 206.14$ per e.h.p. of rated capacity, an amount far in excess of the investment per electric horse-power in tangible property. To omit this value from consideration in appraising the property for rate-making purposes would lead to a far greater error than to omit the entire value of the tangible property.

While the speaker is not aware that the Courts have passed definitely on the correctness of the foregoing principle for determining the value of a water right, this method has been brought before the Courts in the case of the Fulton Light, Heat and Power Company vs. The State of New York, and in the Franchise Tax case previously referred to. From the award given in the former case, it would appear that the Courts certainly gave grave weight to the above method which was used in determining the value of a water right. In the finding of the trial judge in the case of The People of the State of New York ex rel. vs. The New York State Tax Commissioners, and in the decision of the Court of Appeals thereon, no definite approval of the foregoing method for determining the value of the water right was given, but, on the other hand, there was no criticism of it, and it was concluded definitely that the right had a value which should be considered. Owing to the fact that the appellant set forth no theory as to the value of the water right, but stated merely that he had owned the 
canal for 30 years, and did not know what it was worth, it was shown that there was no necessity for the Courts to pass on the correctness Mr. Van Cleve. of the theory advanced by the respondents.

While the speaker is aware that opinions will differ as to the methods to be used in determining for rate-making purposes the value of water rights, he has suggested the foregoing in the hope that it may lead to discussion and suggestions, and the advancement of other theories.

There can be no doubt that the question is one which cannot be passed over lightly, and that it will become of increasing importance in the future, as water-power development is proceeding rapidly, and engineers will be called on more and more frequently, in making appraisals for rate-making purposes, to determine the value of the water right on which the owner of a public service corporation is entitled to returns. The fact that the water right cost the owner nothing, or that his investment for its acquisition was merely a nominal one, should have no real bearing on such determination.

The speaker is aware that the illustration which he has used herein may be considered as an extreme one-although supported by fact in actual plants now in operation-but the real question is not as to whether the details are in accord with the opinions of all, but rather as to whether the general principles to which attention has been called are correct.

W. Kiersted, M. Am. Soc. C. E. (by letter).-The painstaking manner in which Mr. Grunsky has treated the question of the appraisal of public service properties, particularly for rate-fixing purposes, is decidedly interesting at a time when the valuation of public utilities occupies so prominent a part of the work of engineers associated with municipal and public service corporations. The views appertaining to matters of valuation in its various aspects are certainly at variance, although perhaps not exactly divergent. Much is being written on the subject, and the efforts of one who has given appraisal as much study as the author appears to have done, in order to outline fundamental principles and proper rules of action, are certainly most welcome, and should receive the hearty encouragement of every one interested therein.

In 1897, the writer's paper, "The Valuation of Water-Works Property,"* and the discussion thereon, developed a divergency of views which was to be expected at that time. Since 1897 the many calls on engineers to value water-works properties and other public utilities, for rate-fixing, purchase, and other purposes, have so inspired the study of the various problems entering into the valuation of public utilities that to-day sufficient experience and knowledge should have been

* Transactions, Am. Soc. C. E., Vol. XXXVIII (1837), p. 115. 
Mr. accumulated to admit of outlining more uniform methods of valuation Kiersted. for any and all purposes than have prevailed heretofore, were the experience in this line of work to be directed methodically, through concerted action, to outlining essential and fundamental principles and general.rules of work.

There may be no intentional bias on the part of most engineers, acting individually, in their efforts to formulate fundamental principles and rules affecting, and guiding in, the appraisal of public service properties for rate-fixing and other purposes; but is it not true that the individual sometimes becomes imbued almost involuntarily with the idea that certain methods or theories representing the fruits of much labor and of frequent use are right simply because they are familiar; is it not true that frequently the individual discovers himself attempting to adapt lines of practice to a theory worked out in a sort of academic way, instead of first studying thoroughly the practical side of the questions involved and formulating rules and methods in accordance with well-established and good lines of practice; and is it not true that the assumptions or illustrations often set forth to illustrate a theory are in part or wholly incompatible with the ordinary and permissible lines of practice, particularly in arguments presented in defense of a theory?

It seems to the writer that one of the essential things to be done, in advance of expending efforts to prescribe rules and methods to guide in the valuation of public utilities, is to determine what the fundamental principles governing questions of this kind may be, not necessarily those elaborated in the office, but those determined through an intimate knowledge of all the questions and all the problems entering into the organization, construction, operation, maintenance, and development of any public utility. Until these principles shall have been fully determined and clearly defined, it is difficult to conceive how any practical theory or rules of procedure can be laid down.

In almost every article or discussion relating to the valuation of public utilities, the term "life" is freely used, as though a public utility was constructed for the purpose of serving a specific want only for some definite period of time. This is fundamentally wrong, for every public utility must live as long as there is need for the use of it, whether the period of time be one year, a century, or longer. The error is confusing, and arises from applying to a composite structure a line of reasoning relating solely to the life limitations of various elements or units going to make up that structure, apparently without regard to its wholly indeterminate life. It is known from experience that certain units of a composite property subject to heavy wear and tear become useless in time, others become incapacitated and are no longer able to perform the functions which are expected of them as part of that property, and others are abandoned because progress in the arts 
and new inventions compel the substitution of new methods and new devices for those in use. In this manner, experience guides in placing a life limit on particular units of a composite property; but the same experience does not sanction the placing of similar limitation on the life of a public utility considered as a whole. The unit may have an approximately determinate life, while the composite structure possesses a wholly indeterminate life.

For instance: a municipality is a complex and composite organization, under State and Federal regulation, made up of individual units, each unit performing some particular function in the body politic; each unit contributes to the support and progress of the municipality; and each unit, while concentrating efforts toward its own business success, is contributing constantly to the progress of the organized unit in which it lives. All the units are blended into one great regulated force, under such regulations and restrictions for mutual support that the elimination, by death, failure, or disappearance, of any unit of the human fabric no more than temporarily affects the progress of the community as a whole. Every municipal public utility is organized and developed for the public need; it thrives upon and is in every way a part of the community. If the conditions which promote the prosperity of the community flag, it may ceasc to grow, and may even retrograde, creating a business depression which is felt by all the public service corporations, and affects in one way or another even the humblest individual. On the other hand, the prosperity of the one follows in the wake of the prosperity of the other. There is no limit of life to the community and its public utilities, as far as human vision goes, but there is a limit to the life and period of usefulness of the individual units in the community and of the personality of those engaged in operating its public utilities.

In like manner, the various elements going to make up a composite property like a water-works, street-car system, or similar public utility contributing to the welfare, advancement, comfort, and convenience of the community, stand in precisely the same relation to the composite structure as the human element does to the community in which it lives, prospers, and performs some specific function.

It seems to the writer, therefore, that a fundamental error is committed when the term "expectancy," or "life," is applied to any composite structure as it would be applied to an element or unit of that structure which is known from experience to have a more or less fixed and definite period of service. The structure as a whole is an enduring one, as long as there is a demand for it in the community which it serves. To remain serviceable, it must be extended and improved from time to time; its worn-out units must be replaced with new, larger, and better ones; new methods of operation must be substituted for old and antiquated ones; business organizations must improve, in order to meet 
Mr. the demands of advancement in economics; and betterments must be Kiersted. made from time to time, to meet the various rules and regulations imposed by those who have been made the guardians of the public welfare and the public health and comfort. In short, any public utility, to be of service to the community which it is organized and constructed to serve, must be maintained in an efficient, up-to-date condition; and, in order to do this, renewals, replacements, and extensions must be made periodically. It cannot die; and it cannot be allowed to retrograde, as long as the community depending on it lives and prospers and the need for it continues.

Again, the progress of any community is by no means uniform. Certain conditions promote a rapid growth at one period which adverse conditions at a subsequent period may check temporarily. Such periods of growth and stagnation arise in the development of any public utility; nearly every decade registers a jump in structural costs arising from numerous replacements and general betterments in the line of progress. A composite property possessing an average age of 15 years may within 2 or 3 years have this average age nearly halved. Very seldom, in a progressive city, does the average age exceed 20 years. An illustration of how quickly the arerage age of a composite structure may change is that of a water-works property which was purchased in 1909 at an appraised value of $\$ 1100000$, in round numbers, when the average age was 15.5 years. In 1912, after extensions had been made aggregating more than $\$ 820000$, the average age of the physical property was 8.7 years. The original construction of this property was started in 1883; extensive changes were made in 1886 , again in 1898 , and again in 1909. Between the periods of heavy expenditures there were longer periods of a more moderate rate of expansion.

Another case illustrating the irregular growth of a public utility is that of the water-works of Kansas City, Mo. The original works were built by the National Water-Works Company about 1875, with a water-supply connection in the Kaw River; in 1886 new water-supply works were constructed on the banks of the Missouri River, and, at the same time, extensive general improvements were made; in 1895 the city purchased the water-works from the private company, and made some large extensions; in 1905 further extensive and.costly improvements were made, followed by other costly improvements in 1911. Aside from these expensive periodical extensions, pipe-line extensions progressed continuously, although somewhat irregularly. In 1912 all the pumping engines purchased in 1895 had been replaced by larger and more expensive machinery; one of the pumping stations had been entirely abandoned, and the other had been modified extensively. The purchase price in 1895 was $\$ 3100000$; the cost of the physical property to-day is $\$ 8000000$, in round numbers; and the average age is approximately 17 years. 
Both these illustrations are of public utilities in cities where the growth and development may have been more rapid than in some cities in other localities; but, however this may be, they afford a practical example of how public utilities are developed-the difference in the rate of development, between a rapidly growing and a slowly growing city, being one of degree only. Replacements and rehabilitation periods may be at more frequent intervals in a city of rapid growth than in one of slow development, and the average age of a composite property may be somewhat longer in the latter than in the former, but there can be no such condition in practice as a public utility standing still and progressively growing old. If a community retrogrades, the value of the individual units of city property, of the city property as a whole, and of all its public utilities, must depreciate; and the owner of a public utility must witness the value of his investment grow less and less as the community continues to retrograde.

These two considerations, namely, the indeterminate life of a composite structure like almost any public utility, and the comparatively short average age under almost any conditions to be found in any one of our American cities, are believed to be essential and fundamental, and to underlie all practical methods of appraising public utilities.

The estimated cost of duplicating the physical property of a public service corporation is not in itself a measure of the value of the property; it is simply an essential element of the value of such a property. The more completely replacements and substitutions of perishable and incapacitated units may have been made and the entire plant may have been maintained in a serviceable condition, the nearer does the fairly estimated cost of the reproduction of the physical property represent its full reproduction value as an element of total value of the entire property. It is seldom, however, that this is the situation when an appraisal is to be made, and consideration should be given to the measure or degree in which the physical property falls short of this ideal condition.

The author regards real estate, or rather the increment of value of real estate over and above the purchase price, as reinvested earnings open to consideration in an appraisal for rate-fixing purposes. "This view seems to be entirely consistent with that generally entertained at the present day, and with the theory of valuation based on the cost of reproduction of the physical property under conditions as of the date of valuation. It would follow, naturally, from the same line of reasoning, that any of the physical conditions which increase the actual cost of reproducing any unit or any aggregation of units of the physical property, as compared with the cost at the time of construction, may also be considered with equal consistency as reinvested earnings, and, accordingly, should be included in the capital account subject to consideration for rate-fixing purposes. For instance: the 
Mr. cost of laying water pipes under paved streets and in streets where the Kiersted. working force is subject to great interference on account of the presence of underground structures, notwithstanding the fact that the pipes were actually laid in unpaved streets before the existence of many of the present-day underground structures, has usually been regarded as a proper element of value in connection with cases where the valuation has been for purchase and sale, and has been occasionally questioned in connection with rate cases solely. It would seem, however, that if enhancement of value in one particular is to be considered in rate cases, enhancement of value in other directions should be open to equal consideration. Furthermore, if enhancement of value in any particular is legitimate and fully consistent with the theory of valuation on the basis of reproducing the physical property under presentday conditions, it would appear that, on the other hand, it is also perfectly proper that all questions of depreciation of the value of the physical property should be given equal weight. If it is fair to allow enhancement of value, it must be equally fair to consider depreciation of value; both are part and parcel of any method of valuation based on the cost of reproduction under the physical conditions existing as of the date of valuation.

The computation of depreciation, as applied to the appraisal of public utilities, has been rendered somewhat complex and rather inconsistent by the infusion of sinking-fund methods. The limited franchise under which many of the public utilities have been constructed and operated may have served to suggest the use of the sinking-fund method in computing depreciation. The application might be proper enough were the property to pass out of existence at the expiration of a limited franchise, and were the rates to be charged for public and private service sufficient to return to the investor the invested capital with interest; but it is seldom or never the case that the physical property expires with the franchise. There have been a very few instances where an investment has been irreparably injured by a city (after refusing either to purchase, the property or renew an expired franchise).constructing competitive works and virtually crowding the owner of a public utility out of business. Occasions of this kind are so few as to be scarcely worthy of consideration in a comprehensive view of the subject, and have usually resulted from either an unfortunately drawn franchise ordinance or a bitter contention precipitated between the owner of the public utility and the city.

Sinking-fund computations find well-defined application to financial problems like those of the redemption of municipal, state, and national bonds, and to problems like those involved in life insurance; but the application of such a method to the financial management of any public utility compels a complication of accounts which scarcely any management of a public utility. would care to introduce. Its applica- 
tion in this regard is not only cumbersome, but conflicts with the actual conditions of practice. Moreover, it is likely to prove inequitable. It compels the assumption of a life period for each of the numerous units entering into the composition of a property, and the computation of depreciation by well-known sinking-fund methods for some definite portion of an assumed life term for each of the various units.

The assumption of a life period for the units of a composite property and the computation of depreciation of the various units on the sinking-fund basis is equivalent to computations of depreciation on composite property having an equivalent life period. The operation of the sinking fund, as applied to the depreciation of a property having a composite life of 60 years, is shown by Table 13.

TABLE 13.

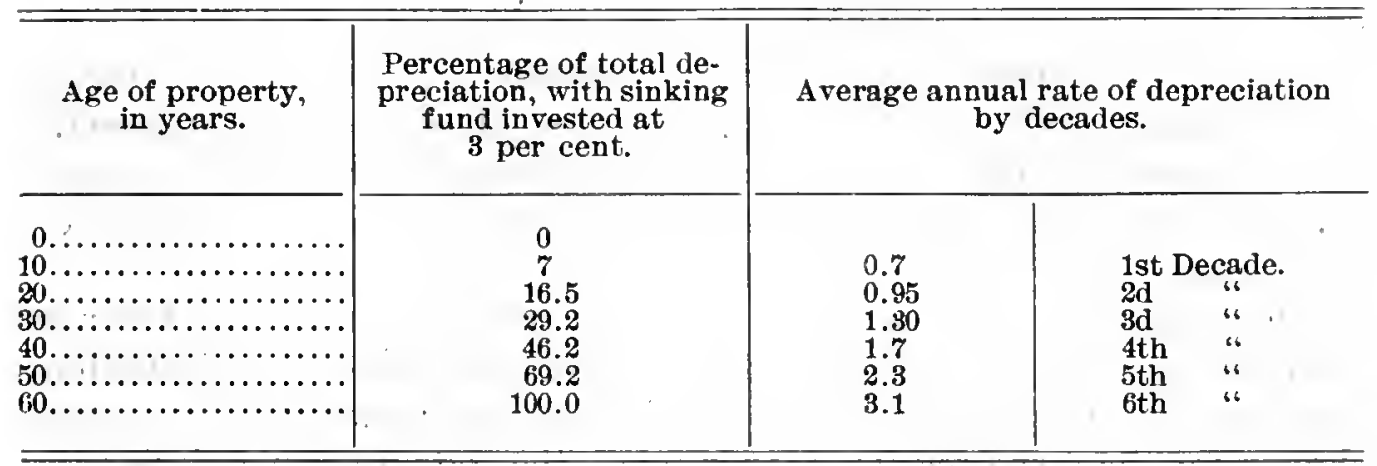

The average of the six decades is $1.67 \%$ per year, corresponding with the straight-life method of depreciation for a 60-year life.

The average rate of depreciation as thus computed is irregular; it is moderate in the earlier years and very rapid in the later years of the life of any unit, and, in the long run, is likely to result in an inequitably proportioned depreciation, a progressive increase of rates. to meet interest on sinking-fund investments, and any number of incongruities in accounting and in attempting to harmonize practice with theory. The fact is that the sinking-fund method of computing depreciation assumes the plant to grow old continuously, and finally to wear out and pass out of existence, whereas, in reality, the plant usually grows more efficient as it grows older, through necessary and indispensable replacements of its various units, and the property becomes more valuable.

The sinking-fund method really has no place in computations of the rate of depreciation of a composite property. As long as worn out, incapacitated, and obsolete units and methods of operation are replaced progressively with new, improved, and larger units and methods, and the property as a whole is extended and enlarged from time to time, to meet the demands of a growing community, there seems to be little 
Mr. ground for further consideration of depreciation, unless it may be Kiersted. that referred to as deferred maintenance.

By deferred maintenance is meant deterioration other than that which can be taken care of in the ordinary course of events by : current expenditures covering ordinary wear and tear and ordinary replacements. For instance: as time goes on, the discharging capacity or serving capacity of the distributing pipes in a system of water-works is reduced materially by the tuberculation of their interior walls, and this necessitates a cleaning process, or reinforcements, or replacements. Such deterioration is usually allowed to progress until inferior service compels the use of comprehensive and extensive cleaning and, replacement.

The average annual cost of replacements of four water-worlss properties, the histories of which are well known to the writer, when distributed over the average age period of the respective properties, is $0.6 \%$ of the cost of reproduction.

In another instance, a water-works property, which had been started in 1865 and in 1907 was found to have many of the older pipes heavily coated internally, received a special depreciation of $0.33 \%$ per annum of the cost of reproducing the physical property, representing deferred maintenance.

The aggregate annual cost, covering replacements and deferred maintenance, as above stated, of $0.93 \%$ of the cost of reproduction, represents a rate of depreciation which is under rather than over that which may be expected to approximate the rate of depreciation of these particular properties, for the reason that some of the minor replacements are not accounted for.

It may be stated, further, that the foregoing replacements are of the important parts of water-works, like pumping machinery, buildings, boilers, settling basins, water-supply intakes, and other important units which are subject to replacement or radical changes at long intervals. They do not in any degree embrace the expenditures covering ordinary repairs and current maintenance. These costs, wholly in excess of that above estimated, would by themselves approximate 0.8 to $1 \%$ per annum of the cost of reproducing the physical property. In all probability an allowance of $2 \%$ on the cost of reproducing the physical property of a water-works would represent the amount of money to be set aside annually for general maintenance; about half of this would be used to cover current maintenance expenditures, the other half could be set aside as a fund to replace the wornout and incapacitated units, as becomes necessary in the ordinary course of events.

The writer does not presume to offer these figures for general application, although, for the particular properties considered, and for similar ones, they may not be far wrong. They serve the purpose of 
illustrating what the writer believes is a simple method of computing the depreciation of the physical part of a water-works property, and one which will commend itself to the bookkeeper as well as to the superintendent and other officers operating a public utility of this particular, kind. By varying the annual percentage rate in harmony with the average rate of decay of the various elements going to make up the physical property of public utilities of other types, the same method may become equally applicable. Part of the money annually set aside from the earnings for general maintenance may be apportioned to meet the annual costs of current maintenance and repairs; another part may be a fund for use in making replacements, and for any similar work which would serve to perpetuate and insure the highest degree of efficiency and the continued usefulness of the physical property.

A straight-line method of this kind for computing depreciation avoids all the incongruities and inconsistencies of the sinking-fund method; it is equitable; it is practical, and in accord with the present methods of operating public utilities; and it simplifies bookkeeping, and can perhaps meet general requirements in this direction more nearly than any other.

In estimating the present value of the physical property of any public utility, it would simply be necessary to estimate the average age of the composite property which is being appraised, and deduct, as depreciation from the estimated cost of reproduction, an amount found by applying the annual percentage rate covering replacements and deferred maintenance multiplied by the age of the composite structure. The annual percentage rate should be determined from general experience and from particular knowledge of the property under appraisement.

The monopolistic character of many public utilities eliminates from consideration the question of the influence of competition to such a degree as to render the method of computing depreciation herein proposed more nearly applicable than would be the case were a property subject to the unrestrained influence of sharp competition, as may be the case in many private lines of business.

Passing to the question of the value of a public utility: It is clear that a distinction may exist as to the value for rate-fixing purposes and for purchase and sale, particularly when circumstances are such that franchise value can properly be taken into consideration. Where the power to regulate rates is exercised in accordance with law by a municipality annually, as in California, or by a commission, there can be no franchise value; but it does not follow that such an element of value of a public utility as that ordinarily termed "going value" or "going concern value" can be similarly excluded, for the simple reason 
Mr. that it should not properly be classed as part of the intangible value, Kiersted. particularly when computed irrespective of earnings. Where incomeor, more properly speaking, net income-is used as a basis and means of computing "going value," so called, it is open to this criticism; to a degree at least, because it may partake in part of the nature of franchise value, if the prevailing rates are high and the assumed period of time covered in the use of earnings in computing going value is abnormally long. In no event should an appraisal for rate-fixing purposes consider any element of value based on earnings or income. It does not follow, however, that there is no element of value over and above the cost of reproducing the physical property together with usual overhead charges which it is customary to add to such computations, which should be as open to consideration in appraisals for rate-fixing purposes as for purchase and sale.

In defining what the writer means, he quotes from his testimony in a recent case where a commission jointly estimated the cost of reproducing the physical property of a water-works, allowing all enhancement of value due to existing market and physical conditions, and deducting for depreciation. The element of value referred to in that line of testimony was defined as "going concern value."

"The method of computing 'going concern value' assumes that the knowledge of the general public with regard to the water service is fully developed, it assumes that the business of the existing plant, its patronage, etc., remains intact until delivered to the new plant. No longer time is needed for the recovery of business than is necessary to render the new property administratively and mechanically fit and serviceable for conducting the entire business of the old property, allowing proper time and capital for making the service connections, the getting of machinery into proper working order, elimination of all defects of construction, the duplication of the office records, and the perfection of the business and mechanical organization."

Nearly all the elements of value entering into the computation of the "going concern value," as above described, represents tangible property in one form or another, and may very properly embrace an additional element of operating capital. As thus described, the going value has no relation to the earnings of the property, the reproduction cost of which is being estimated. It may be computed as a percentage of the cost of reproducing the physical property, or in any similar manner.

As thus defined, the going value loses all connection and relation with so-called intangible value; in fact, many of the units entering into or going to make up this going concern value are susceptible to decay, as are other portions of the physical property, and, in ratefixing cases, should have a percentage of earnings set aside to cover general maintenance as well as interest on the money thus invested. 
In appraisals for purchase and sale, there is an additional element of value which may be properly considered, in order to compensate a successful and efficient management. Just what this increment of value should be can only be determined in specific instances, in the light of all the facts relating to the business organization and the progressiveness of the municipality furnishing the patronage for the public utility under appraisement. While this increment of value would not be considered in rate-fixing cases as part of the capital investment, the rates could be adjusted so as to support through surplus earnings an increment of value sufficient to invite investments in a public utility of the kind under appraisement, and to encourage intelligent and efficient management. A community which has had the benefit of such a management can well afford to pay something more, for a property which is well organized and well managed, than it would be willing to pay for one where the situation is reversed.

On the other hand, a mismanaged property, where earnings have been sufficient to pay a fair return on the invested capital and maintain the property in an efficient condition, but have been diverted from the natural and proper channels, should expect and should receive nothing short of heavy depreciation of value in an appraisal of the property, either for rate-fixing purposes or for purchase and sale. Such considerations as these, entering into the investigations leading to a final conclusion on the value of a public utility, as they properly should enter, involve the intelligent judgment of the appraiser, and force him out of the "strait-jacket" of reasoning through mathematical formulas or any set of rules based thereon.

It does not always follow, however, that the value, either for ratefixing purposes or for purchase and sale, will be invariably equitable when computed on the basis of the cost of reproduction, for the simple reason that, in exceptional cases, it may give a value in excess of that at which a community can either afford to purchase, or support through its patronage. One instance of this kind in the writer's experience is of a town which retrograded, losing perhaps $40 \%$ of its population during the period in which the public utility had been in operation. In this instance there could be no question but what the public utility corporation would have to share in the shrinkage of values resulting from reduced patronage and the inability of the town to meet obligations which otherwise they could have met had the town continued to increase in population and taxable value at the same average rate as it did during its prosperous career.

In view of the many uncertainties surrounding the appraisal of public utilities, it would seem to be well-nigh impossible to formulate any set of rules to guide appraisers in estimating value except those which are of very general application and embrace the more fundamental principles relating to and governing work of this character. 
Mr.

The writer is not one who believes the Courts have led engineers into error in performing their part of the work relating to the appraisement of public utilities. The whole province of the engineer in a matter of this kind is to assist the Court by his evidence, and when engineers of wide experience, but representing opposing interests, present views widely at:variance on matters regarding which they are supposed to have an intimate knowledge, the Court is certainly to be excused if the evidence is practically set aside or only partly considered. As a rule, the estimates of engineers of experience on the cost of reproducing a physical property should not and will not vary materially. In fact, a joint conference of engineers representing opposing parties will frequently result in a joint agreement as to values, except possibly on the question of the overhead charges which it is customary to allow in the appraisement of public utilities; and on questions involving going value-elements of value which can be settled quite as readily by the Court itself after hearing individual testimony. Joint agreement on most or all of the technical details, in advance of the hearing of evidence and the filing of a joint report as the evidence of all the engineers, would greatly abbreviate the work of all concerned, and perhaps simplify and materially assist the work of the Court itself, but, unfortunately, in most instances, counsel of the opposing parties do not sanction the joint conference.

One word more, in order to make more clear the writer's position with regard to capital investment: The earnings covering depreciation, in the sense in which the writer has used depreciation, are expected, among other things, to return to the investor the cost of abandoned property. Accordingly, as property is abandoned it should be charged off the capital investment account, and, in a similar manner, any unit substituted for an abandoned unit should be added to capital investment account. Thus the accounts would show the total investment as well as the active or present investment at any date of valuation.

Whatever of criticism there may be in these remarks attaches to the writer with perhaps even more force than to Mr. Grunsky, for the writer has used the sinking-fund method in computing depreciation in numerous instances, but believes that in it he has observed fallacies which should be eliminated, even though it involves the discarding of sinking-fund methods and the radical modification of past lines of procedure. He has nothing but thanks and congratulations to offer the author for presenting in such a comprehensive manner the results of his labors, and hopes that the issues which are thereby raised will be discussed fully and, finally, will result in simplifying and improving the methods used in the valuation of public service properties.

C. E. Grunsey, M. AM. Soc. C. E. (by letter).-The point which the writer particularly desired to emphasize in the paper was that when 
rates are to be fixed the investor in public service properties is entitled to adequate protection. The method of securing this protection intelligently was described, and the writer tried to make clear that there should always be an allowance in some form and under some name to compensate the owner of the public service property for hazard, and for management both during construction and under operation. This compensation should appear in the rate of interest to be earned rather than in the appraisal on which interest is to be allowed. Placing it in the appraisal is a convenient way of making the earnings, expressed in percentage thereof, appear low. In whatever way this may be handled, something more than ordinary interest on the properly invested capital should appear in the earnings, if these have been equitably fixed.

There is no intent to advocate the taking of any property without due compensation, as Mr. Higgins seems to infer from parts of the paper. When the broad principle is laid down therein that the owner of a public service property is entitled to be protected to the extent of his investment, first, in the matter of receiving thereon a proper return, and, second, in having the invested capital itself protected and ultimately returned, this is not to be understood in a strictly restrictive sense. There may be elements not covered by actual investment, which are, nevertheless, essential parts of the property and represent investment even though never actually paid for by the owner, and not appearing as having cost him anywhere near their market value. In such cases, however, it will generally be well to inquire into the circumstances attending their acquisition.

Water rights, such as Mr. Van Cleve cites, are to be considered as property which has value. As part of a public service property, they may or may not represent actual investment. Such water rights, nevertheless, are to be classed as elements to be included in the appraisal. Probably no hard-and-fast rule can be laid down for determining their value in the sense of what it might reasonably be assumed that they would cost if they had to be acquired from other owners. The circumstances attending the valuation, particularly of undeveloped water rights, are so varied, involving as they do all the uncertainties of present and future demand for power, that any satisfactory and conclusive suggestion along this line is hardly to be hoped for at this time.

In California the flowing water belongs to the people, but the riparian owner on a stream has certain paramount rights. A distinction is to be made, therefore, between a water right in the broad sense in which it is here generally referred to, when it is strictly a grant by the people on a par with a franchise, and, in the more restricted sense, comparable with the illustration used by Mr. Van Cleve, in which case the power right is the property of the riparian owner. In the one 
$\mathrm{Mr}$. case the water right deserves the same treatment as a franchise; in Grunsky. the other case the fact that it has a market value is easily recognized, and its appraisal is a comparatively simple matter.

In reply to the question which Mr. Boucher asks concerning the appraisal of property such as a valuable right of way which cost little or nothing, the circumstances in each case should be taken into account. In the case which he cites, the railroad is not entitled, in strict equity, to a return on the full amount, that the property : would cost to-day, but only on a fair allowance for investment. In other words, there should be some limit to the right to a return on the unearned increment represented by the present high value of the right of way, if such value be measured by what it.would cost if it had to be acquired to-day. This view appears to be in accord with the rulings of the Courts, which would give to the public service concern, practically as a bonus; the appreciation 1 in the value of such properties. What shall be considered excessive appreciation, is a question which had best be answered only as special cases arise.

A similar question is that relating to the treatment of donations. Take, for example, a water company which is called on to extend its service into new territory not yet built on, the owners of which construct a distributing system of pipes and house connections and all that goes toward a.satisfactory service and donate the same without cost to the water company. To add the cost of such property at once to the capital invested by the water company might work hardship and be unfair to the older consumers. When the new territory is developed, and the consumers, resident therein, take a fair share of the water, it may well be asked whether or not in fixing rates the fact should be taken into account that a part of the system was donated by the water users themselves. It would be equitable to deduct donations from the appraisal, allowing, however, adequately for the upkeep of the entire system, including depreciation. On the other hand, there is good basis for the view that it makes no difference how the property is acquired, and that the appraisers for rate-fixing purposes should ignore the fact that some of it may have cost nothing.

The difficulty that confronts the rate-fixing body in matters of this kind arises from the generally accepted theory of the pastas advanced by owners of public service properties-that they are entitled, as profit, to whatever they can get in the shape of bonus and also to the full amount of the unearned increment, represented by increased value of the elements which go to make up the whole of the property. In order to avoid controversy in the future, these matters should be made clear, and it is by the general recognition of fundamental principles that this can be brought about and misunderstandings aroided.

The question is asked by Mr. Coombs as to whether high dividends 
paid in the past should be taken into account in making appraisals. In a general way, yes. Consideration may be given to this fact just Mr. as well as to the fact that there have been lean years. Ordinarily high dividends would hardly be construed as repayment of invested capital; but when such dividends have been paid to the detriment of the property, when proper foresight has not been exercised in making provision for its expansion, when the requirement for deferred maintenance is high, it may be that such conditions are due in part to the high dividends that have been paid, and this is then a circumstance to be considered.

The method of dealing with depreciation, as indicated by $\mathrm{Mr}$. Kiersted, is noted in the paper as applicable to any public service property in which the depreciation may fairly be considered equivalent to the average annual replacement requirement. This is set forth in Paragraph 14 of the fundamental principles and elsewhere. The bookkeeping in such a case would be as Mr. Kiersted describes it.

Such elements of value as those enumerated by Mr. Kiersted under his definition of "going concern" may properly be included in a valuation, and perhaps the designation, "going concern," is properly applied to them. Against their inclusion no protest is raised. The protest which is implied in the paper relates to the addition of intangible values, whether under this or other designations, to a demonstrable investment, or, as is more frequently the case, to an estimated value less depreciation, in order to bring the same up to what the appraiser thinks it ought to be. If there is to be any addition to the investment appraisal, let this be clearly stated, and it will make no difference under what designation it is added; or, as pointed out in the paper, let the appraisal be made without deduction of depreciation, and let the percentage rate of earnings be sufficiently high to do full justice to the owner of the property.

In closing, the writer wishes to express his appreciation of the reception which his paper has received and to thank those who have contributed to the discussion for emphasizing and making more clear some of the thoughts which were but imperfectly presented.

In this connection attention may be called to Mr. Kiersted's amplification of the writer's brief comment on the perpetual life of composite public service properties. This idea was incorporated by the writer, in 1901, in a report on the appraisal of the properties of the Spring Valley Water Company, which is the company supplying San Erancisco with water. If properly applied the assumption of perpetual life will be found helpful in many cases where, for a plant taken as a whole, no fixed or definite term of life can be assumed.

In the case of a complex plant, such as was then under consideration, it was reasonable to fix its probable life at so long a period that it might be called perpetual. Parts of it would deteriorate 
Mr. and go out of use; parts of it; except for the highly improbable Grunsky: case of its being killed by' a competing system, would continue in service practically for all time: As a whole, therefore, and for ratefixing purposes, it could be considered as being always in good condition. There was no need of writing off depreciation. The replace-, ment of such parts as went out of use could be cared for under maintenance and operation.

This idea naturally resulted in the adoption of a method of calculation described in the paper as the method under which no deduction. need be made for depreciation in valuing public service properties for' rate-fixing purposes. 



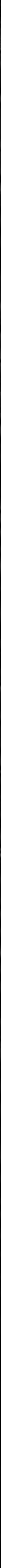





$\frac{3}{2}$

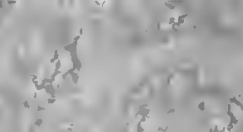

(1)

Xestis

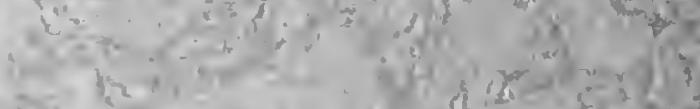

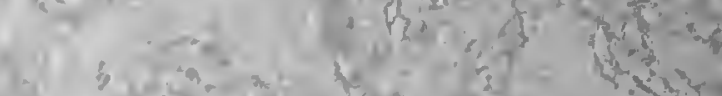

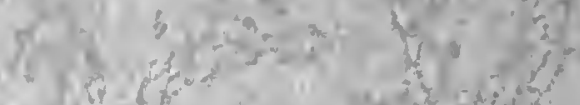

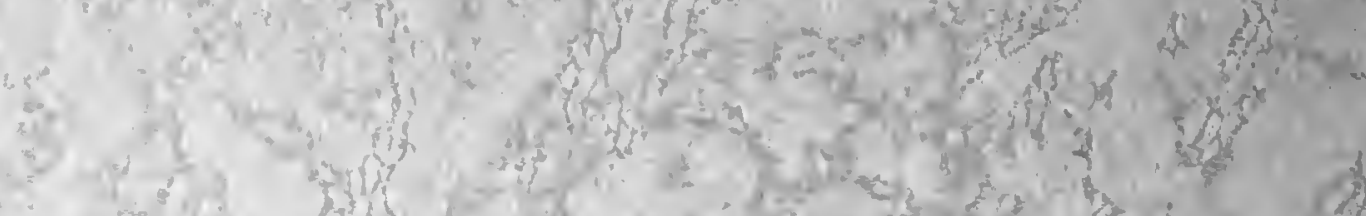

$112+3$ a

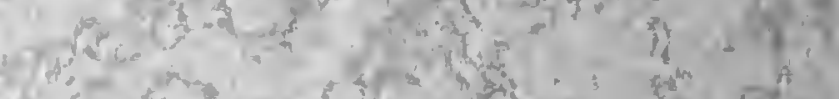

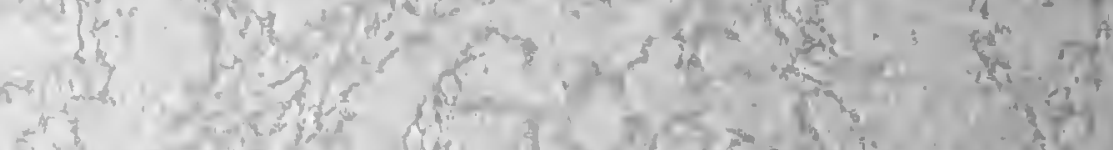

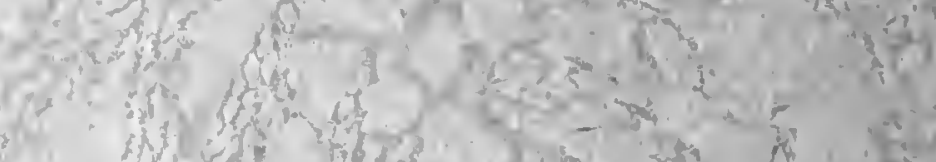

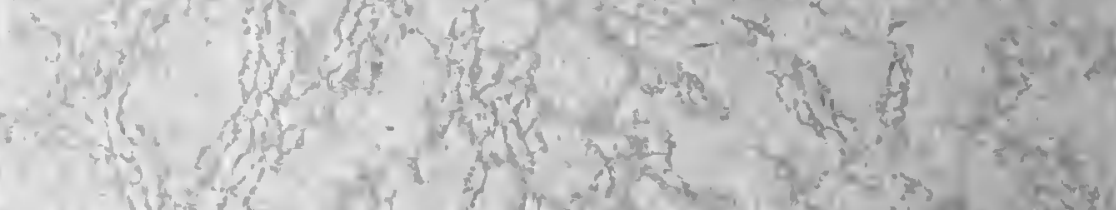

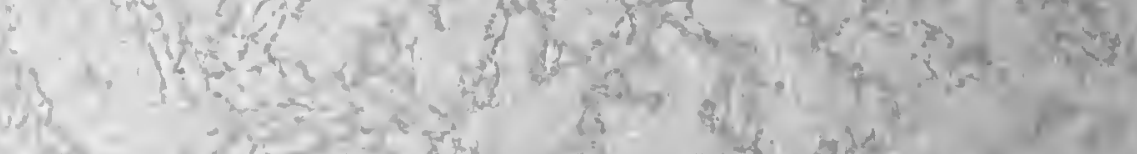

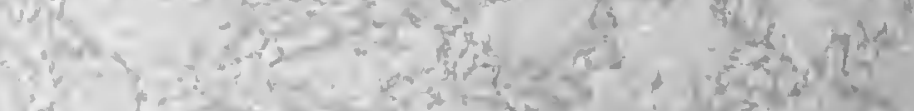

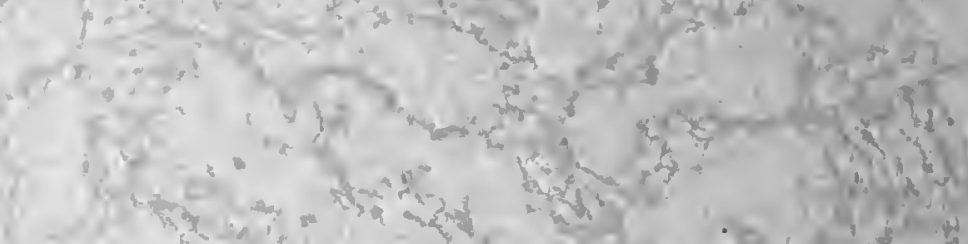
Wife -

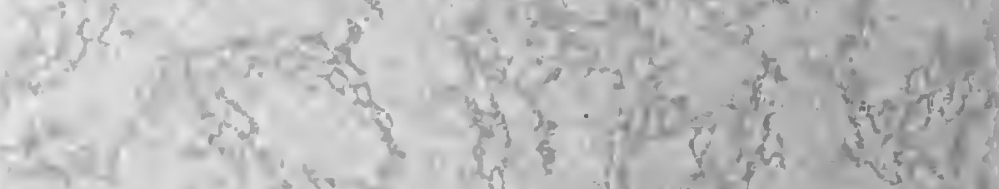

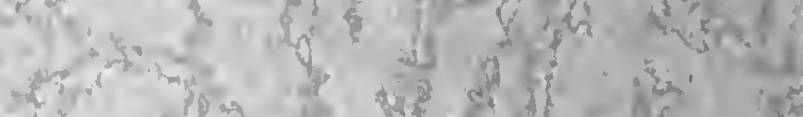

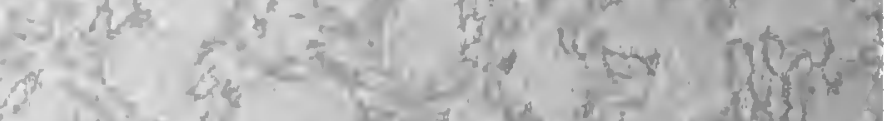
4.

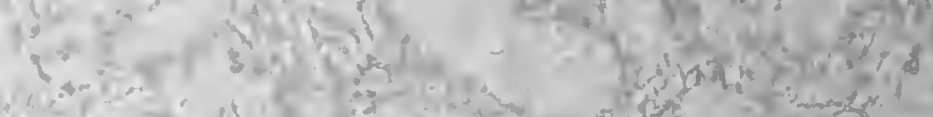

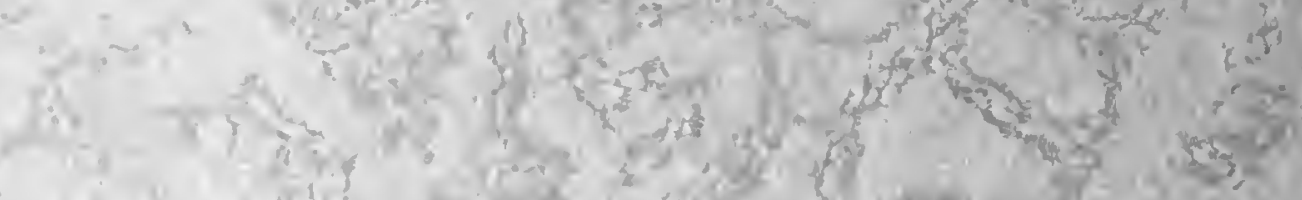

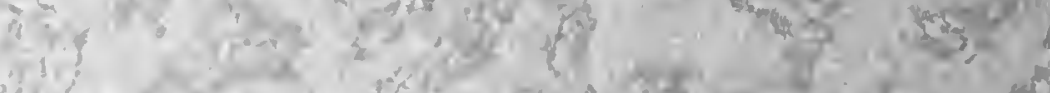

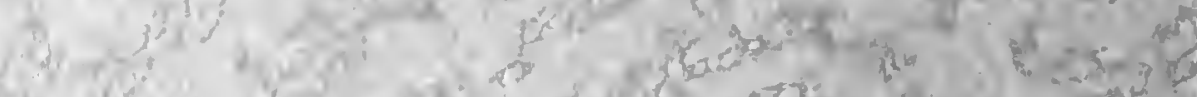

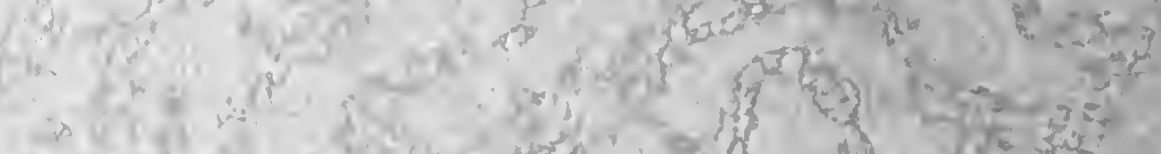

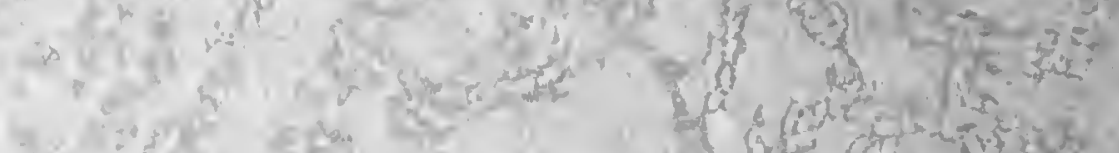

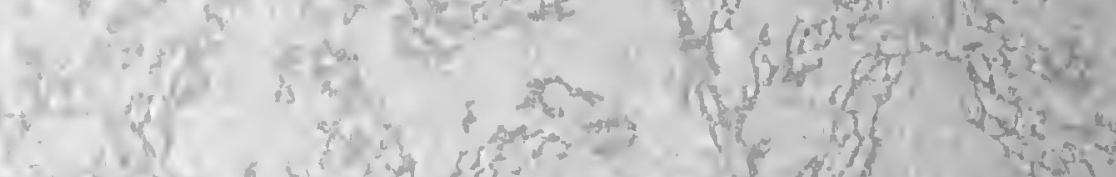

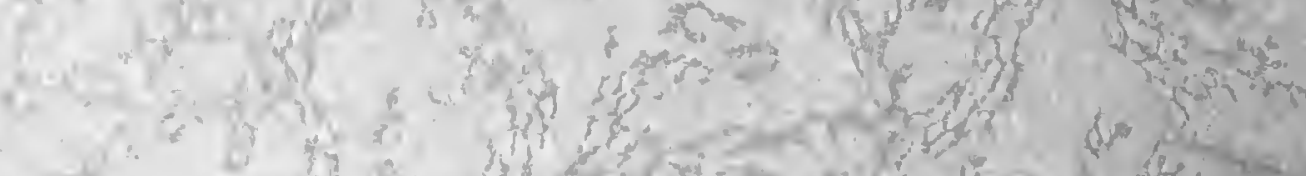

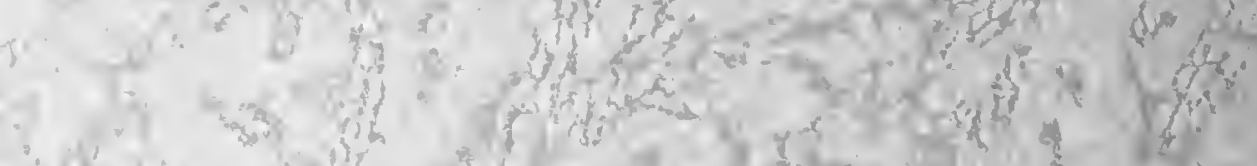
(5. 